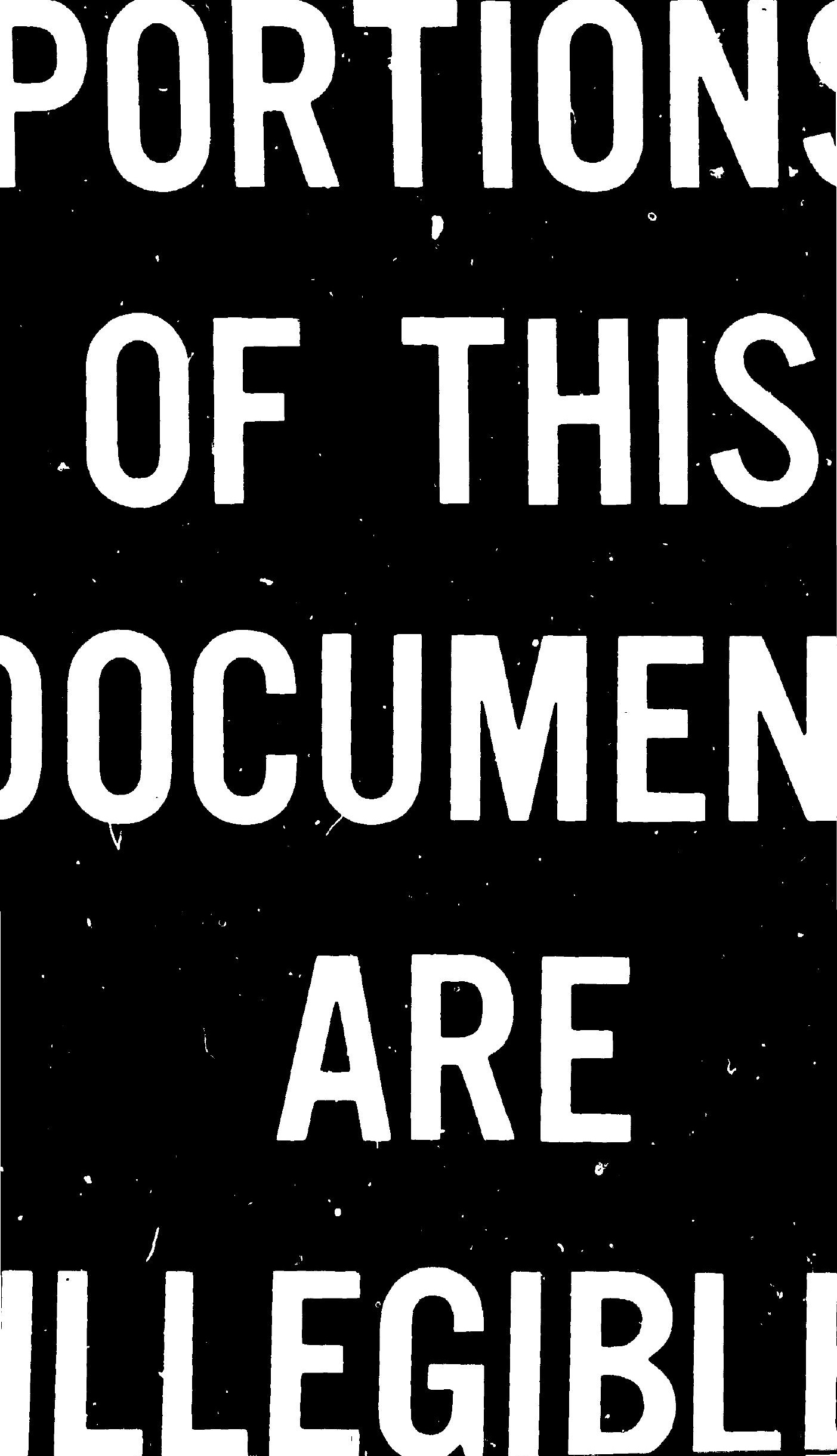


ORNI.-5147/RI

Dist. Category UC-7!

Contract No. W-7405-eng-26

CHEMICAL TECHROLOGY DIVISION

SAFETY ANALYSIS REPORT FOR PACKAGING (SARP) OF THE

OAK RIDCE NATIONAZ LABORATORY-

TRU CURIUM SHIPPING CONTAINER

\author{
W. D. Box
}

B. B. Klima*

R. D. Seagren

L. B. Smappent

G. A. Aramayo**

-Retired. Present address: Roane State Community College, Harriman, Tennessec.

* UCC-ND Engineering.

Date Published: June 1980

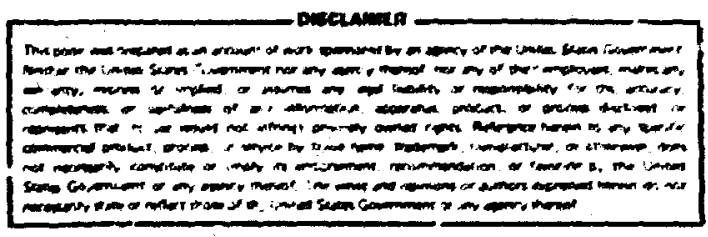

O.AK RIDGE NATIONAL LABCRATORY

Oak Ridge. Tennexcee 37850

operated by

UNION CARBIDE CORPORATION

for the

DEPARTNENT GF ENERGY 
1. INTRODUCTION

I.I Description of TRU Curium Shipping Container......................... 2

1.2 Contents of Package ............................................. 5

2. STR UCTURAL EVALUATION

2.1 Mechanical Properties of Materials................................. 5

2.2 General Standards for All Packages .................................. s

2.2.1 Reactions between materials of construction and package contents ........ 5

2.2.2 Closure .................................................... ?

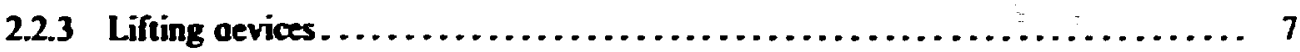

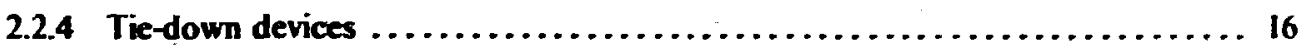

2.3 Standards for Type B and Large-Quantity Packaging .................... 25

2.3.I Load resistance ......................................... 26

2.3.2 External pressure $\ldots \ldots \ldots \ldots \ldots \ldots \ldots \ldots \ldots \ldots \ldots \ldots \ldots \ldots \ldots \ldots \ldots \ldots \ldots \ldots \ldots \ldots \ldots \ldots, 27$

3. COMPLIANCE WITH STANDARDS FOR NORMAL CONDITIONS

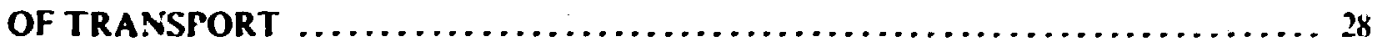

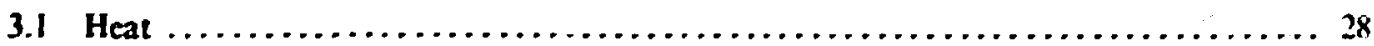

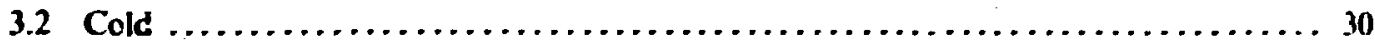

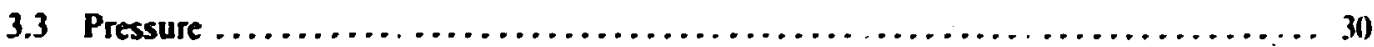

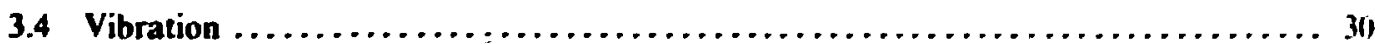

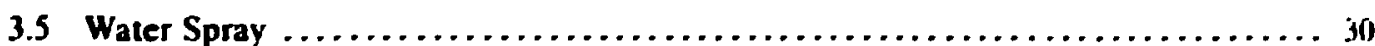

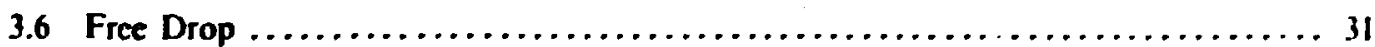

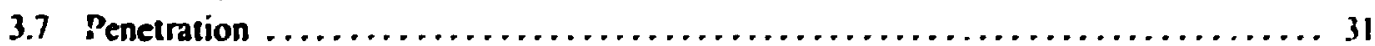

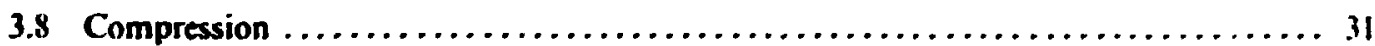

4. COMPLIANCE WITH STANDARDS FOR HYPOTHETICAI.

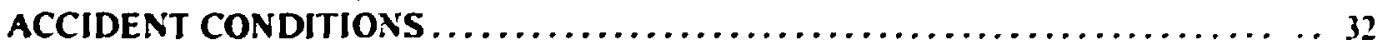

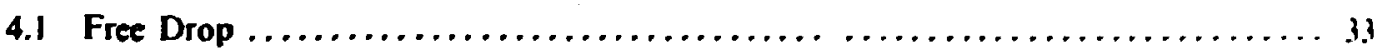

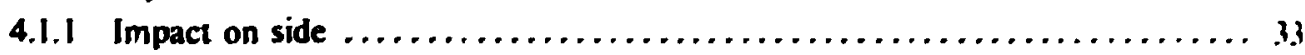

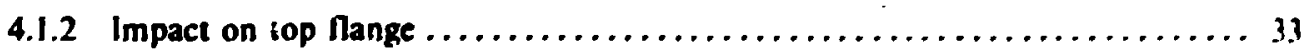

4.1.3 Impact on top corner...................................... 37

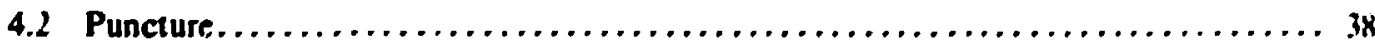

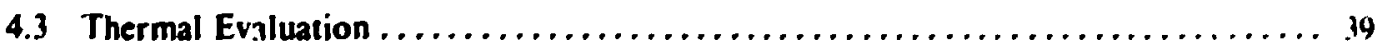

4.3.I Thermal properties of materials,$\ldots \ldots \ldots \ldots \ldots \ldots \ldots \ldots \ldots \ldots$, s9

4.3.2 Thermal accident analysis ................................ i9

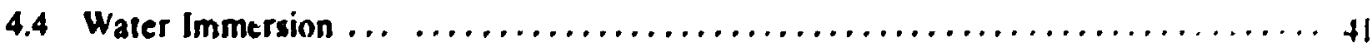




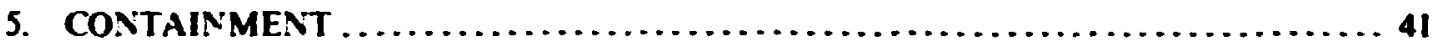

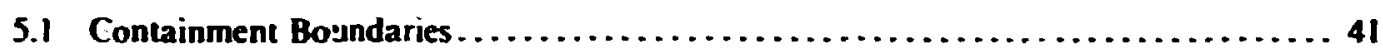

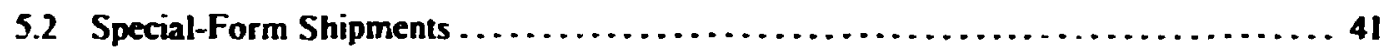

5.3 Containment Requirements for Normal Conditions of Transmort ............. 46

5.4 Containment Requirements During the Hypothetical Accident ................. 46

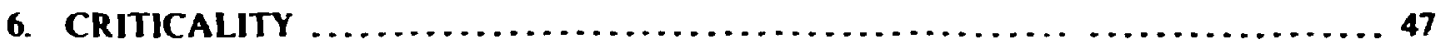

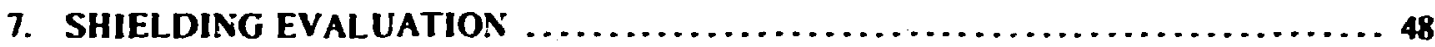

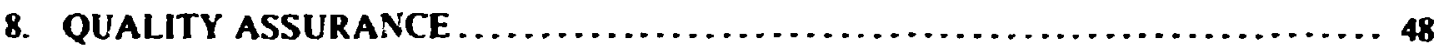

8.1 Fabrication, Inspection. and Acceptance Tests ...................... 48

8.2 Operating Procedures and Routine Inspection $\ldots \ldots \ldots \ldots \ldots \ldots \ldots \ldots \ldots \ldots \ldots \ldots \ldots$

8.3 Periodic Maintezance and Inspection ............................ 48

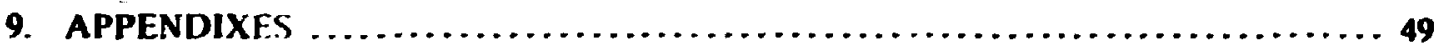

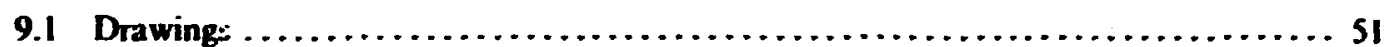

9.2 Approval Documents.......................................... 55

9.3 Computer Programs to Calculale Corner Drop Deceleration Forces ............ 71

9.4 Operating and Inspection Procedures .......................... 81

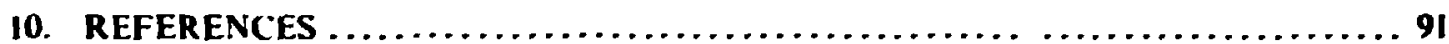




\title{
SAFETY ANALYSIS REPORT FOR PACKAGING (SARP) \\ OF THE OAK RIDGE NATIONAL LABORATORY \\ TRU CURIUM SHIPPING CONTAINER
}

\author{
W. D. Box, B. B. Klima, R. D. Seagren.
}

L. B. Shappert, and G. A. Aramayo

\begin{abstract}
An analytical evaluation of the Oak Rudge National Laboratory Transuranium (TRU) Curium Shipping Container vas made io demonstrate its compliance with the regulations governing offsite shipment of packages conkaining radioactive material. The evaluation encompassed five primary catcguries: structural integrity, thermal resistance, radiation shielding, nuckear criticality safety, and quality assurance. The results of the evaluation show that the container complies with the applicable regulations.
\end{abstract}

\section{INTRODUCTION}

When a package is to be used in uffsite shipment of radioactive or fissste material. it is subject to regulations governing its structural integrity, heat dissipation capabilities. shielding ability, nuclear criticality safety, and quality assurance. The safety st:ndards for the packaging of such material are set forth in the Code of Federal Regulations, Titk 10. Part 7I.' and DOE Manual Chapter 0529. ${ }^{2}$ To secure approval for shipment, it must be shown, either by testing or by experimental or computational methods, that the package corsplies with the regulations. The Oak Ridge National Laboratory (ORNL) TRU Curium Shipping Container was evaluated to deturmine whether it complies with the applicable regulations. The methods used and the results of the evaluation are reported here.

The TRU Curium Shipping Container is illustrated in Fig. I.I. Three o! the shipping containers that have been fabricated are in service at ORNL (ORNL Shipping Cask Nos. 4S2-209, -210, and -213). The Department of Transportation (DOT) assigned Special Permit Number 5461 to this container. A certificate of compliance (Sect. 9.2) thas been issued, aud approval of this Safety Analysis Report for Packaging (SARP) by the Department oi Energy (DOE) will complete the requirements of the certificate. The IAEA Certificate of C.mpetent Authority is also in Sect. 9.2. The cask is intended to be used to trarsport isotopes of americium, curium, berkelium, californium, einsteinium, fermium, and plutonium in the form of metal, oxide, chloride, or other salt.

The cask consists of a 30-in.-tall. 29-in.-high cylinder with a 6-in.diam internal cavity that is 8-in. deep (Fig. 1.I). The shielding consists of approximately I in. of lead and 9-3.t-in. of Blackburn limonite concrete. The cask has a bolied-in-place top plug that is protected by a bolted-down cover plate. The cover-plate nuts are secured by a seal lockwire. The TRL Curium Shipping Container weighs $2640 \mathrm{lb}$. In the normal mude of shipment, the carrier is mounted on a special akid that permits forklift handling. The combirsed weight of the container and the skid is $2800 \mathrm{lb}$. 


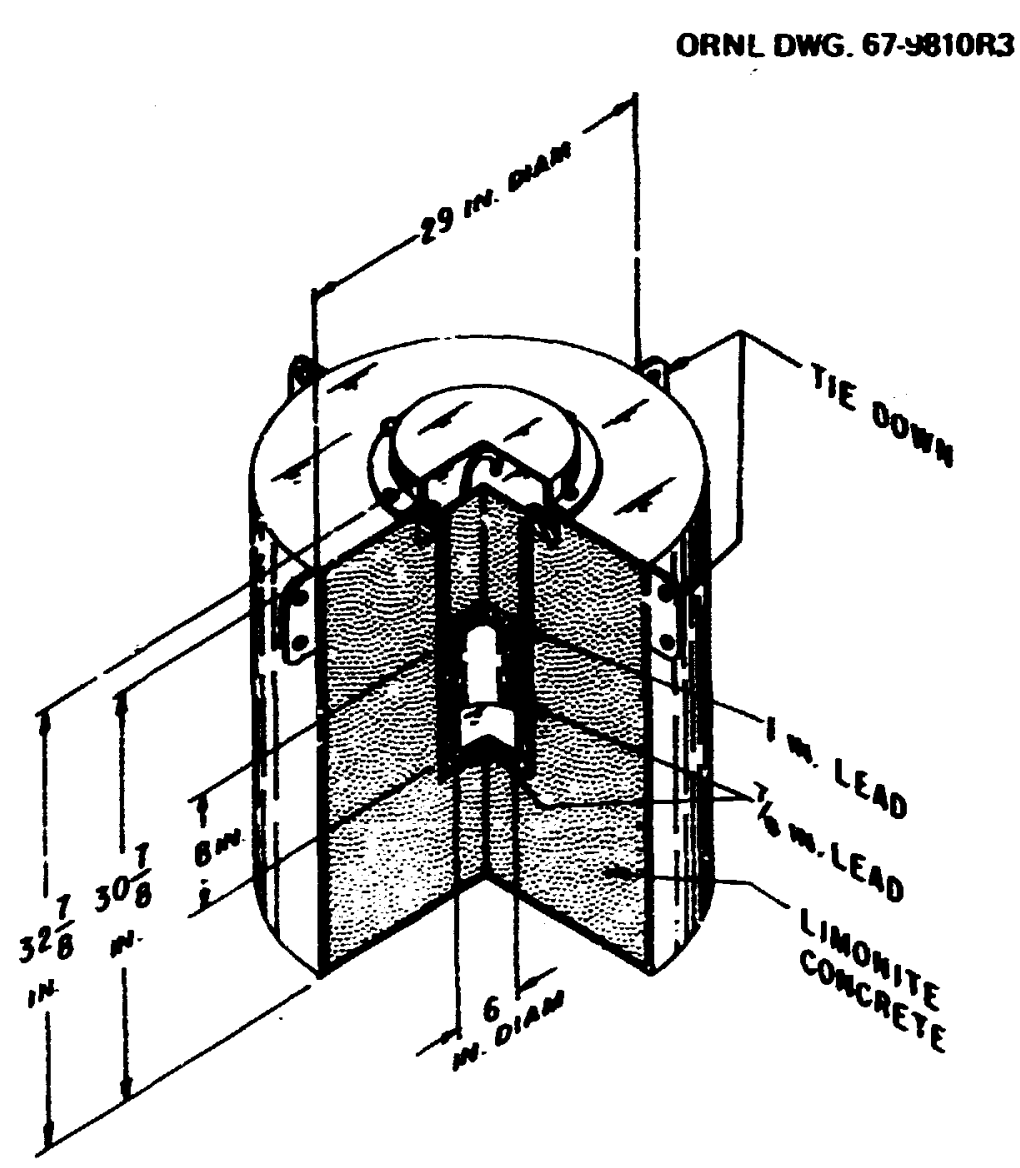

Fig. 1.I TRU Curium Shipping Container.

Computational procedures were used to evaluate the TRU Curium Shipping Container and to determine it $3 t$ it meets the requiremen!s for offsite iranspontation of radinactive materials. The rexults of this analysis. which are presented here. show that the aask complies with the regulations. In addition to the evaluation. this SARP contains operating and inspection procedures.

\subsection{Description of TRU Curium Shipping Container}

A detaiked eross section of the TRU Curium Snipping Container is shown in Fig. 1.2. The outer shell sides aid bottom are 3:8-in.-thick 3041. stainless steel. The outside diameter of the shell is 29 in., and the height is 30-7/8 in. The top of the outer shell is 1/4-in.-thick 304L. stainkese steel. The inner cavity shell. which is fabricated from 1/4-in.thick .041. stainless steel plate, is $8-1.4 \mathrm{in.}$ ID by 19-1 4 in. deep and is recessed from the top by a 1-3:8-in.-deep offset. The inper eavity in which the radioactive or fissile material package is placed fer shipment has a diameter of 6 in. and height of 8 in. and is surrounded by 7.8-in.-phick lead contained in a pocket of 1 4-in.ethick stainless steel. The lead was cast in place through iwo l-in.-diam pour holes in the hottom of the inner sinell. These holes werr welded shut after filling was complete. Twelve I-shaped reinforcement rods were welded in the inside of the outer shell. In adcition to the I.-reinforcement, two cylinjers of to hy 6-in.. 10-gage wire reesh 


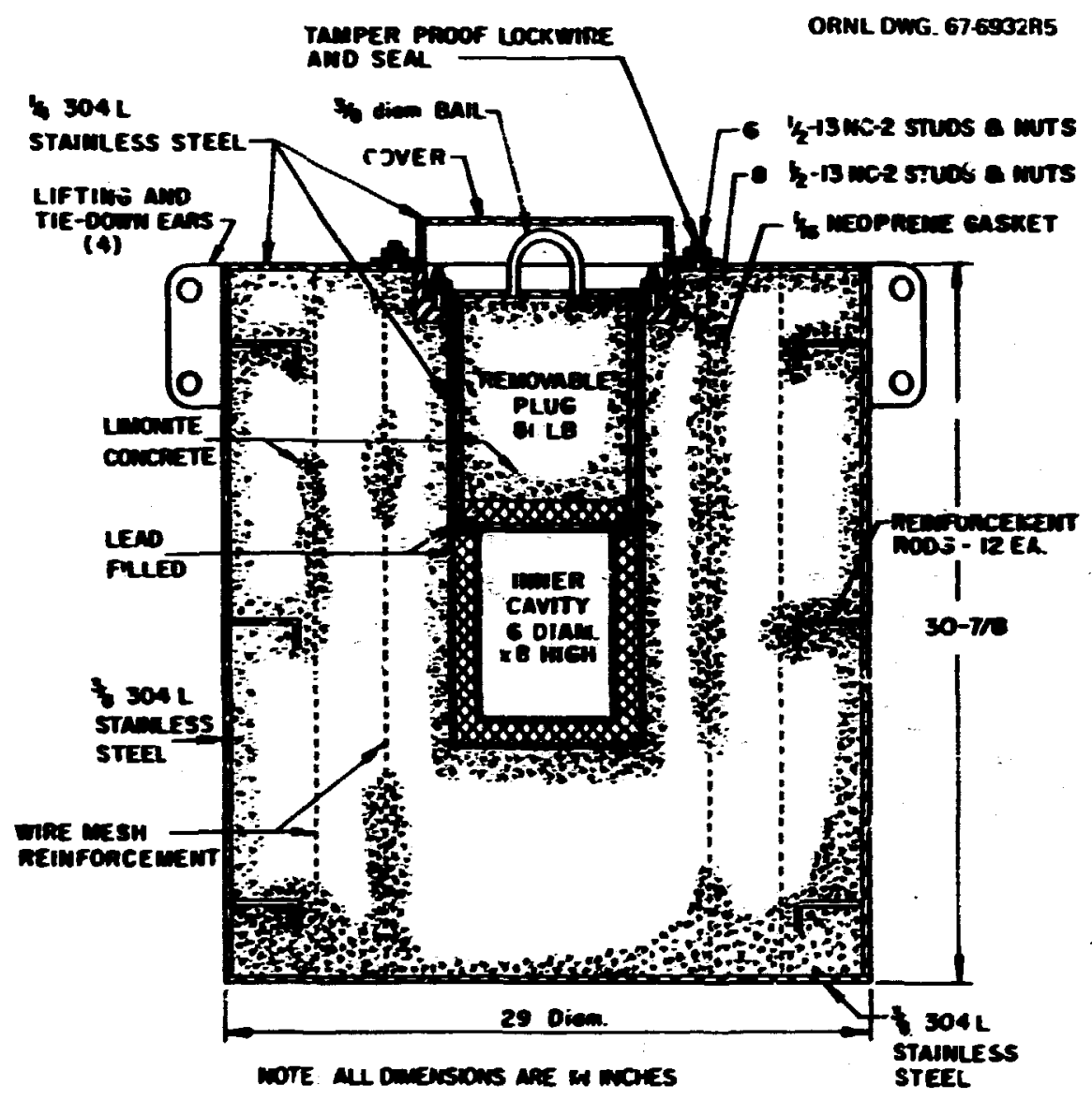

Fig. I.2 Cross section of TRU Curium Shipping Container (all dimensions are in inches).

reinforcement were used in the body of the concrete. The annulus betweet. the outer and tive inner shell was filled with limonite concrete that was adied through two 4-in.-diam pour holes located in the bottom of the outer shell. These holex were welded shut atter filling was complete.

The inner cavity is closed with a plug of conerete and lead cast in a shell built from 1 4-in.thick $304 \mathrm{~L}$ stainless steel plate. The steel shell was first filled with lead in a depth of I in. and then filled with limonite concrete. After the limonite concrete had cured, the top plate was welded on the plug.

The gask t that makes a seal between the top flange of thw plug and the body is made of I 16-in.-thick Neoprene. The Nange and gasket are held tn the body by eight 1/2-in. $x$ /3 NC-2 nuts on studs. The plug is lifted by a 3/8-in.-diam 304L stainless ster. bail.

The top flange and bail of the plug are protected by a 1:4-in.-rhick 304L stainless steel plate cover that is held to the top of the container by six 1/2-in. X 13 NC-2 nuts on studs. When the plug is secure and the cover is in place, the six nuts are safeguarded from accidental removal by a seal lockwire.

Ther: are four 1/2-in.-thick $\times$ 2-1/2-in.-wide $\times$ 6-in.-long lifting and tie-down ears wrlded to the top of the side of the container body. Each ear has two l-in.-diam holes.

Figure 1.3 stows the carrier mounted on its skid. 


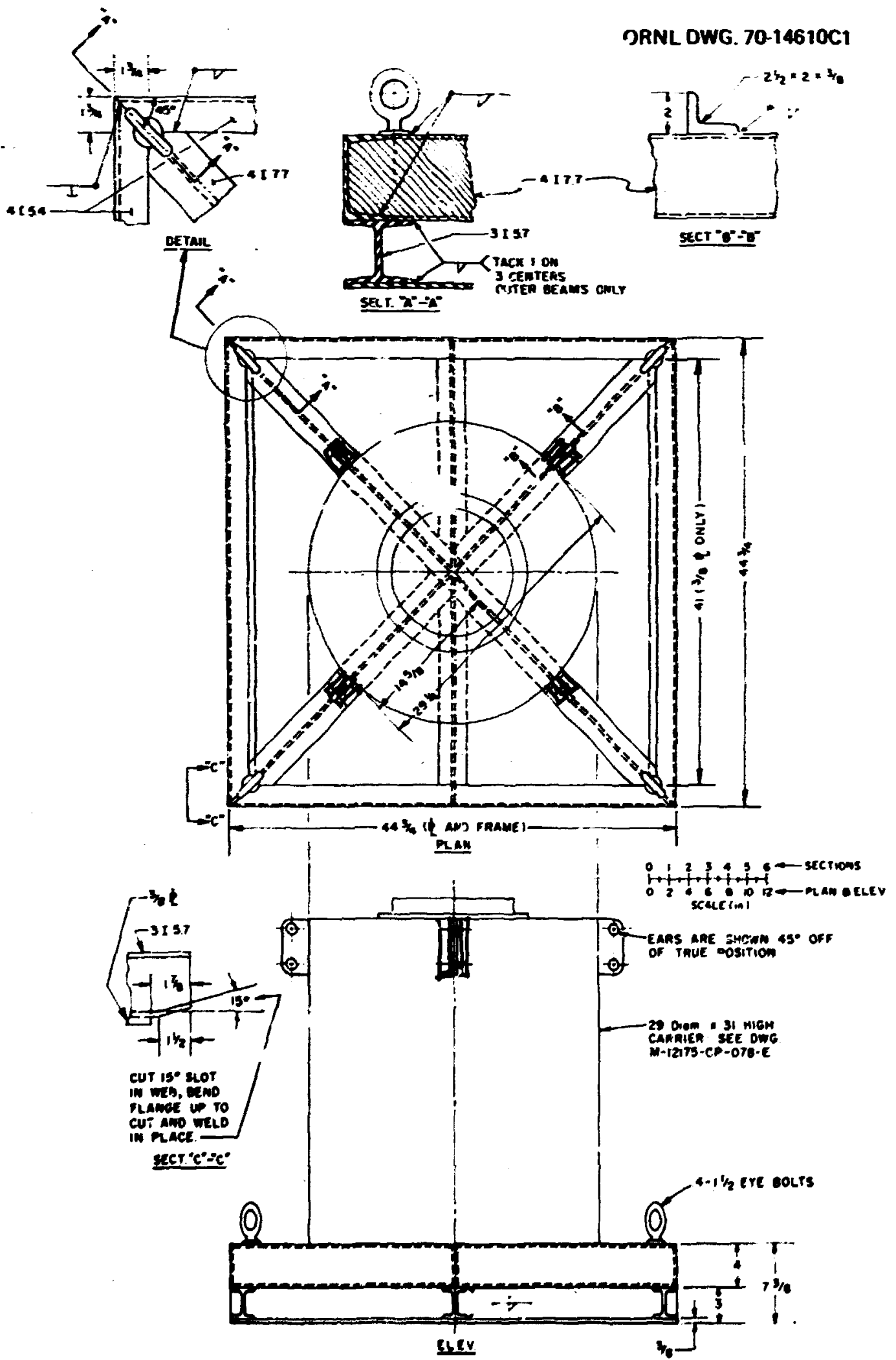

Fig. I.3 Skid for TRU Curium Shipping Container. 


\subsection{Contents of the Package}

The TRU Curium Shipping Container will be used to transport any isotope of plutonium, americium, curium, berkelium, californium, and fermium in the form of metal, oxide, chloride, or other salt. Any of these isotopes can be alpha or heta emitters, may fission spontaneousty,

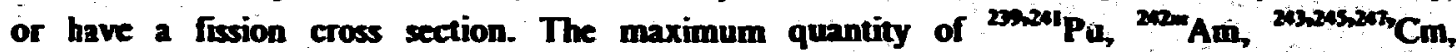
and/or ${ }^{39} \mathrm{Cr}$ shipped will be $10 \mathrm{~g}$. The maximum yuantity of ${ }^{251} \mathrm{Cr}$ shipped will not exceed $3 \mathrm{~g}$ The remaining isolopes will be limited ty heat $(500 \mathrm{Btu} / \mathrm{hr})$ or source strength such that the extemal dose rate wịl not exceét the levels specified in the DOT regulations. The cuntainer, with its contents, is rated Fissile Class 1 .

The contents will be singly or dowbly encapsulated, as described in Sect 5 , in a welded container or in special form containers which may occasionally be phoed within arother container for handling purposes. The package may be shipped by any commercial surface transportution sysiem.

\section{STRUCTURAL EVALUATION}

Three TRU Curium Shipping Containers have been fabricated for use at ORNL. Two were constructed in 1967; the third was constructed in 1970. The package complies with the structura! requirements of the regulations (see Sects. 2-4). The calculations, test results, and engineering logic presented in the following sections demonstrate compliance with these performance criteria. The effects of both normal transport and specified accident conditions on the structural integrity of the package are considered.

\subsection{Mechanical Properties of Materials}

The mechanical properties of 304L stainless steel and limonite concrete are summarized in Table 2.1.

\subsection{General Standards for Ali Packages}

The general standards for all packages include an evaluatiun of the folluwing: (I) the chemical and galvanic reactions between the materials of construction and the intended package contents; (2) the method used for closure; (3) the cask-lifting devices; (4) the lid-lifting devices; and $(5)$ the tie-down devices used in securing the package to the trailer.

\subsubsection{Reactions between materials of constructicn and package contents}

The container is constructed. as shown in the as-built drawing (see Fig. 1.1 and Stect, 9.1). of type 304L stainless steel, limenite concrete, and lead. No evidence of any significant chemical, galvanic, or other reaction between these materials has been noted: additionally, past experience has not revealed any indication of reactions between these materials of construction and the intended package contents. Even if the contents were shipped in the chloride form. they would be welded into a primary container capable of withstanding the action of chloride and thus prevent no reaction. problem to the cask materials. 
Tabie 2.1. Hechanical properties of 304L stininless steel and limonite concrete

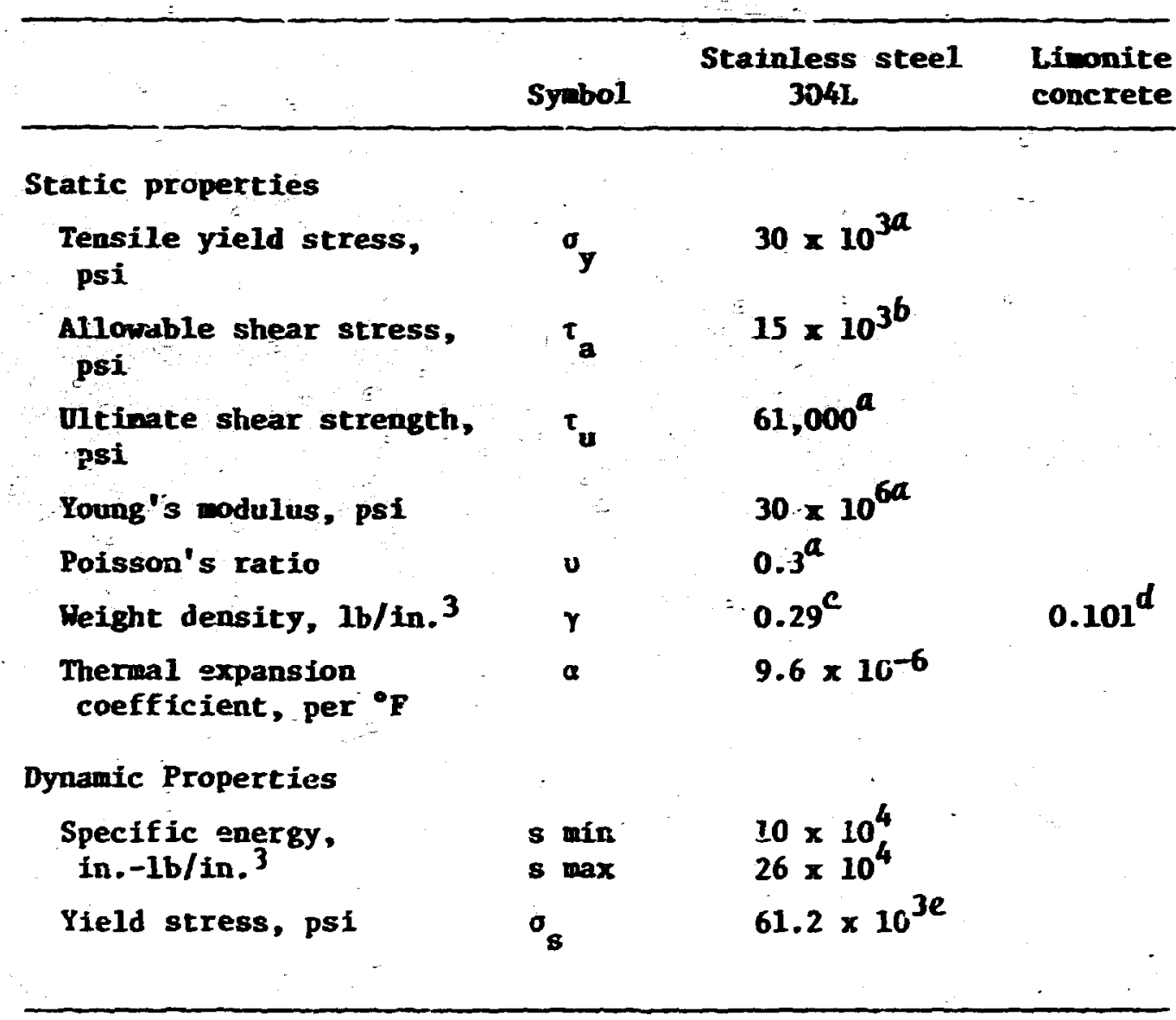

anternational Nickel Company, Inc., Mechanical and Physical Propertie: of Austenitic Chromium-Kickel Stainiess Steel at Arbient Temperatures, 1963.

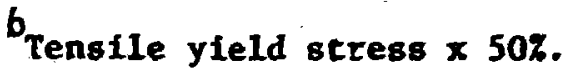

C. B. Shappert, Cask Designers Gulde, ORI/NSIC-68 (February 1970).

d. B. K1ima and L. B. Stappert, The TRU Ten-Ton Californium Shtpping Contafuer, ORriL/MI-3505 (Nuvember 1971).

Rased on minis ratio of yield/ultimate values for bolts as indicated in Table 5.1 end on minfmum tensile strength of 95,000 psi, p.55 in D. D. Caunon's Structural Analyeis of Shipping Casks, vol. 1.2, Energy Absorption Characteristics of Stainless Steel Bolts Under Impact Loading, ORNL-1.31i, vol. 12 (May 1972). 


\subsection{Clasure}

The inner cavity is scaled with the Neoprene gasketed plug and eight 1/2-in. nuts on studs. The plug is protected by a cover secured by six 1/2-in. nuis on studs. These nuts and stids are manufactured with mating holes so that a seal wire must be jroken before the uuts can be removed from the studs. The package can thus be equipped with a positive closure that will prevent inadvertent opening.

\subsubsection{Lifting devices}

If there is a system of lifing devices that is a structural part of the package, the regulations stipulate that this system must be capable of supporting three times the weight of the loaded packege without generating stress in any material of the package in excess of its yield strength. In addition, each lifting device which is a structural part of the packaging shall be so designed that failure of the device under excessive load would not inpair the containment or shielding properties of the packaging.

Plug-ligting evaluarion. The boil on the plug is not strong enough to lift the package; therefore, a cover is provided that prevents this part from being used for that purpose. Use is denied by a lockwire and seal. Analysis of the phig-lifting device, based on three times the weight of the plug, is given below. The plug-lifting mechanism is a bail constructed from a 3/R-in.-diam steel rod shaped like an inverted " $U$ " and welded upside down al each end in the top of the plug.

The stress ( $\left.S_{3}\right)$ in the lifting bail is determined as follows:

$$
\begin{aligned}
S & =\frac{3 W}{A}=\frac{3(81)}{0.1107} \\
& =219+16 . \text { in. }^{-2},
\end{aligned}
$$

where

$$
\mathrm{S}=\text { stress as if it were a straight beam, } 1 \mathrm{~b} / \mathrm{in.}^{2},
$$

$W=$ weight of plug. $81 \mathrm{lb}$,

$A=$ cross-sectional area of $3 / 8$-in.diam rod, 0.2208 in. $^{2}$

The value of $\mathbf{S}$ is corrected to account for the curvature in the bail using factors $k_{0}$ and $k_{1}$ from R. J. Roark's formulas for curved beams.'

The stress ( $S_{0}$ ) on the outside fibers is

$$
\begin{aligned}
S_{0} & =k_{0} S=0.91(2194) \\
& =1997 \text { psi }(<30,000 \text { pai }) .
\end{aligned}
$$


where

$k_{0}=0.91$ at an $R / c$ vahue of 8.0,

R $=$ rzdius of curvature measured to centroir of section.

$c \doteq$ radius of rod.

ithe stess $\left(\dot{S}_{i}\right)$ on the inside fibes is

$s_{\mathrm{i}}=1 \mathrm{~s} s=1.10(2194)$

政

Whe

$\mathrm{H}=1.10$ at an R/c value of 8.0 .

"Iherefore the metal of the lifing beil is adequate to ift the plug

Welt between phug ard phug-lifting bait. The nominal thickness of the required weld may be calculated as follows:

$$
t=\frac{3 W}{L T}=\frac{243}{(2.35)(15,000)}
$$$$
=0.01 \mathrm{in} .(<0.375 \mathrm{in}) \text {, }
$$

where

$$
\begin{aligned}
& t=\text { nominal weld thickness, in., } \\
& W=\text { the plug weight, } 81 \mathrm{lb}, \\
& L=\text { weld lengtin, } 2.35 \mathrm{in} . \\
& \tau=\text { allowable shear atress. } 15,000 \text { psi. }
\end{aligned}
$$

The 3/8-in. weld is thus - dequate. Hence, the bail and its weld to the plug are capable of meeting the requirement of supportiug three times their weight without generating stresses in exceus of the yield stress.

Cask-liffing evaluation. Maximum stresses in the combination lifting and tie-down cars are calculated for the most sever: lifting condition. This condition would exist if the cask-akid combination were lifted from only one of the four tie-down devices, as shown in Fig. 2.1. Normally, two of the four are used for lifting purpous. which results in the cask-skid combination being lifted at an angle of about $47^{\circ}$ with the vertical. Fur caiculational purposes, it is also assumed that the center of mase is at the zeometric center of the cask. 
ORNL DWE. 79-11326

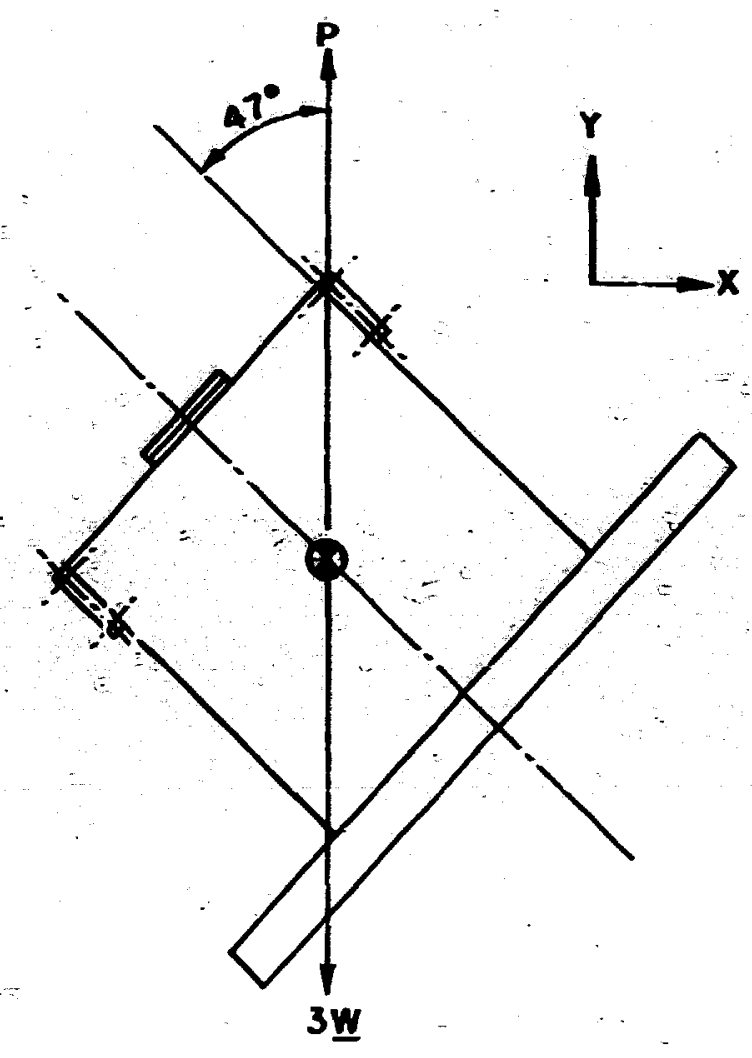

Fig. 2.I Cask attitude during lifting from onie tie-down pcint.

Tr.e lifting tie-down device is shown in Figs. 2.2-2.5. A generalized load may be applied via rables or shacinie to either solid shaft that connects the two tie-down ears. These shafts are of th : same diameter as the holes in the ears so that the load is distributed uniformly in the loaded portion of the perimeter of the hole. The sum of the distributed uniform load shown in Fig. 2.6 is equl to one-half the load applied at the half point of the connecting l-in.-diam hafi. The mathematical mociel of the tie-down. shown in Fig: 2.7, is idealized as a straight team of length equal to the diameter of the hole and loaded by a uniform load. It is assumed that the boundaries of the beam are constrained.

Summation of the forcer in the y-direction in Fig 2.1 gives

$$
\because F_{y}=0 \text { 1. positive direction; }
$$

therefore.

$$
P=3 \mathbb{W}
$$

so that the force F', shown in Fig. 2.7, is equal to

$$
P^{\prime}=\frac{P}{2}=\frac{3 W}{2}
$$




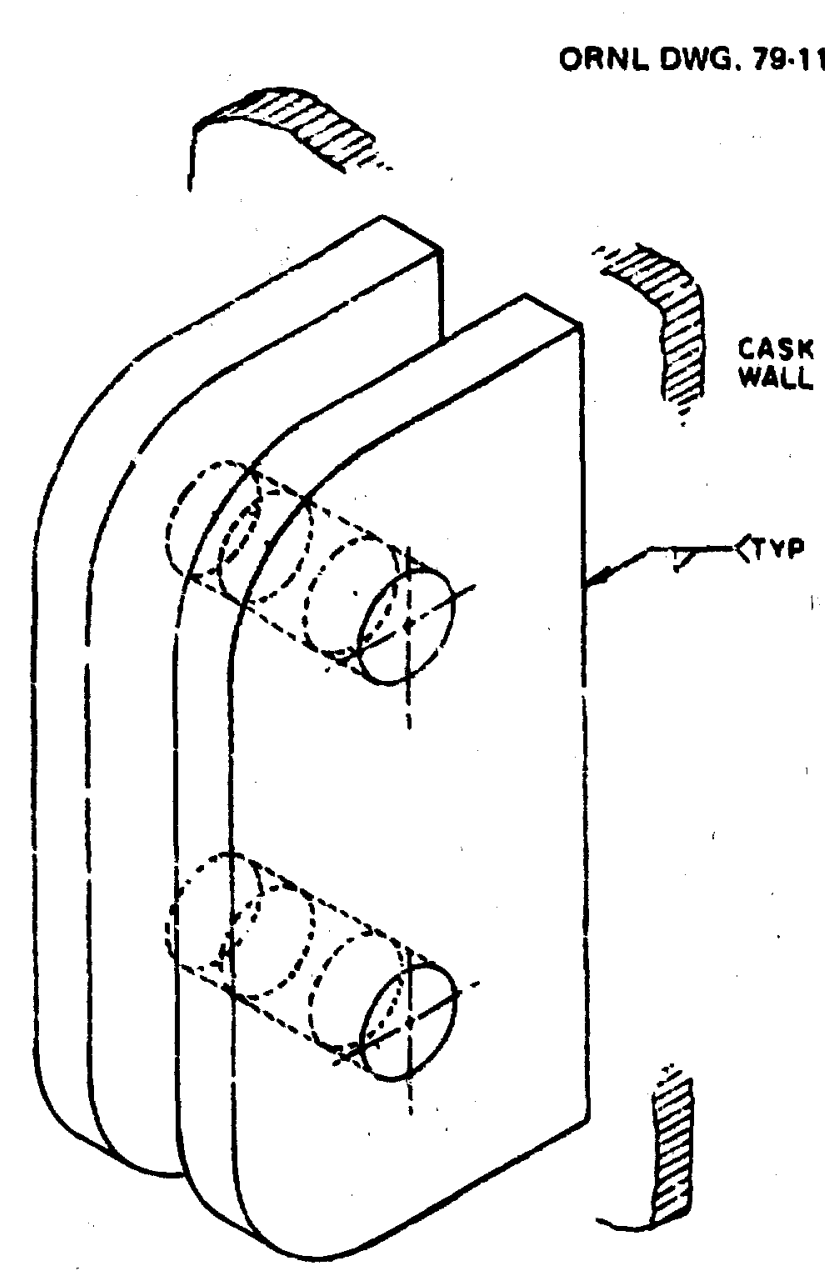

Fis. 2.2 Lititing and tie-rown device.

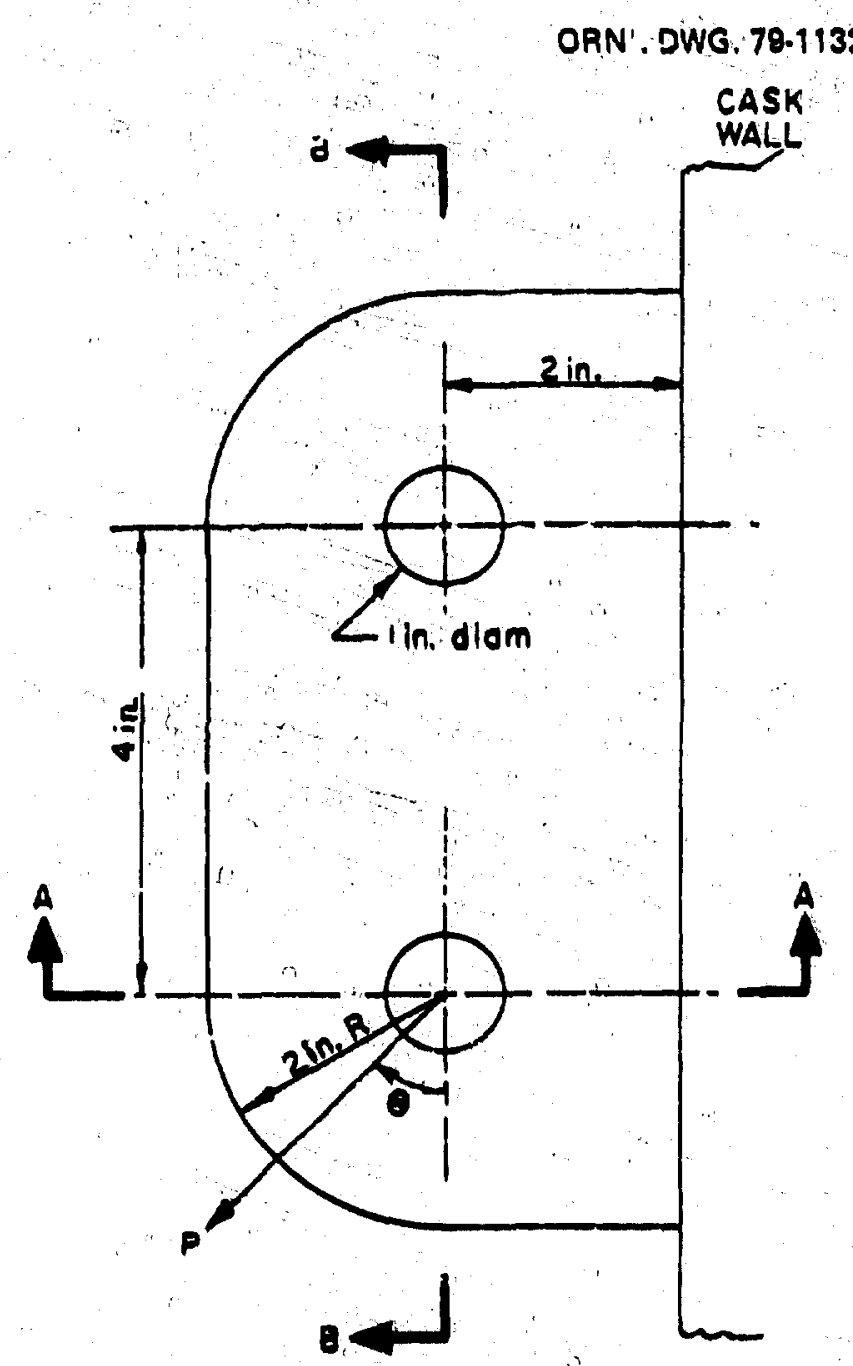

Fig. 2.3 Tie-duwn device. 

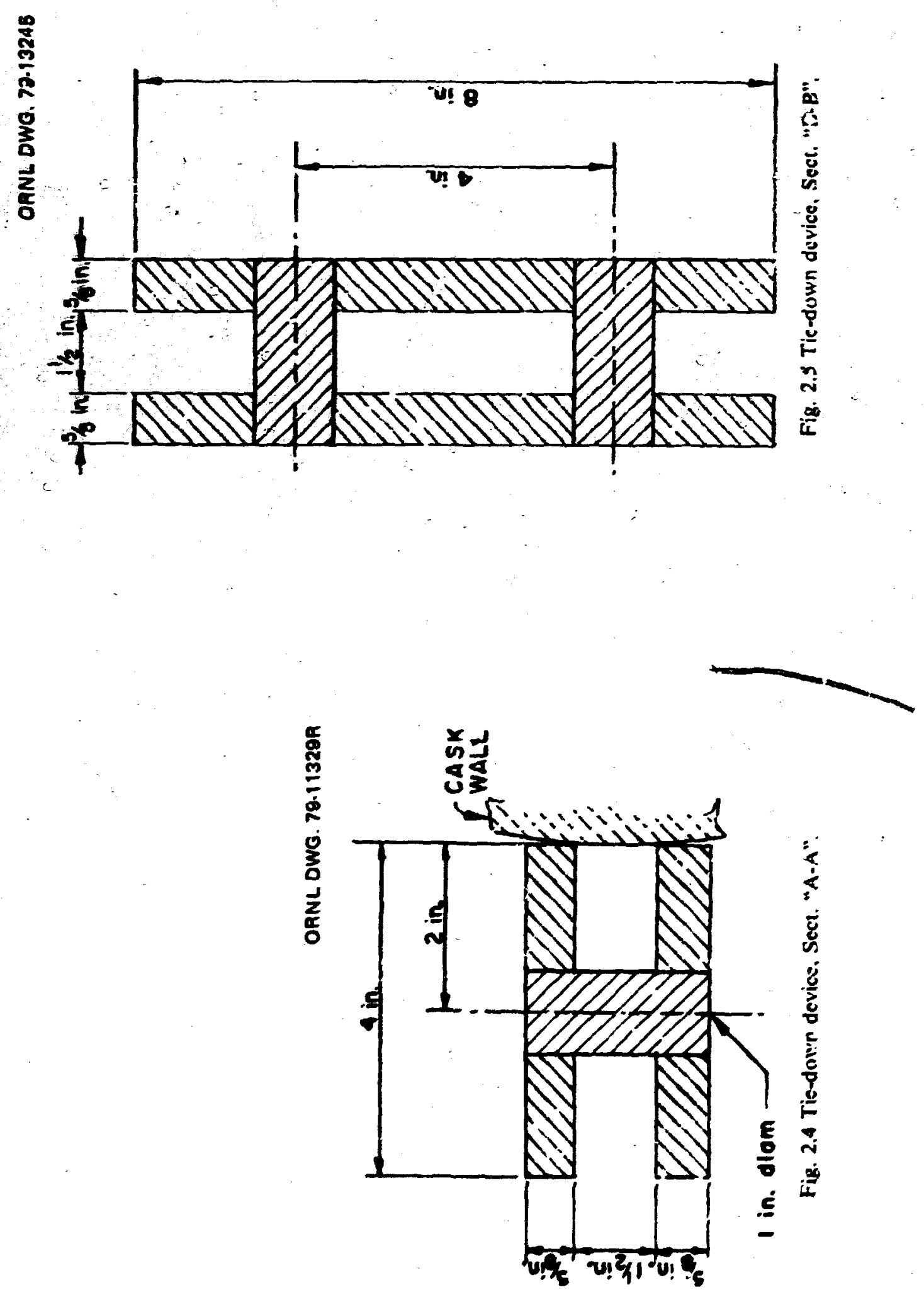


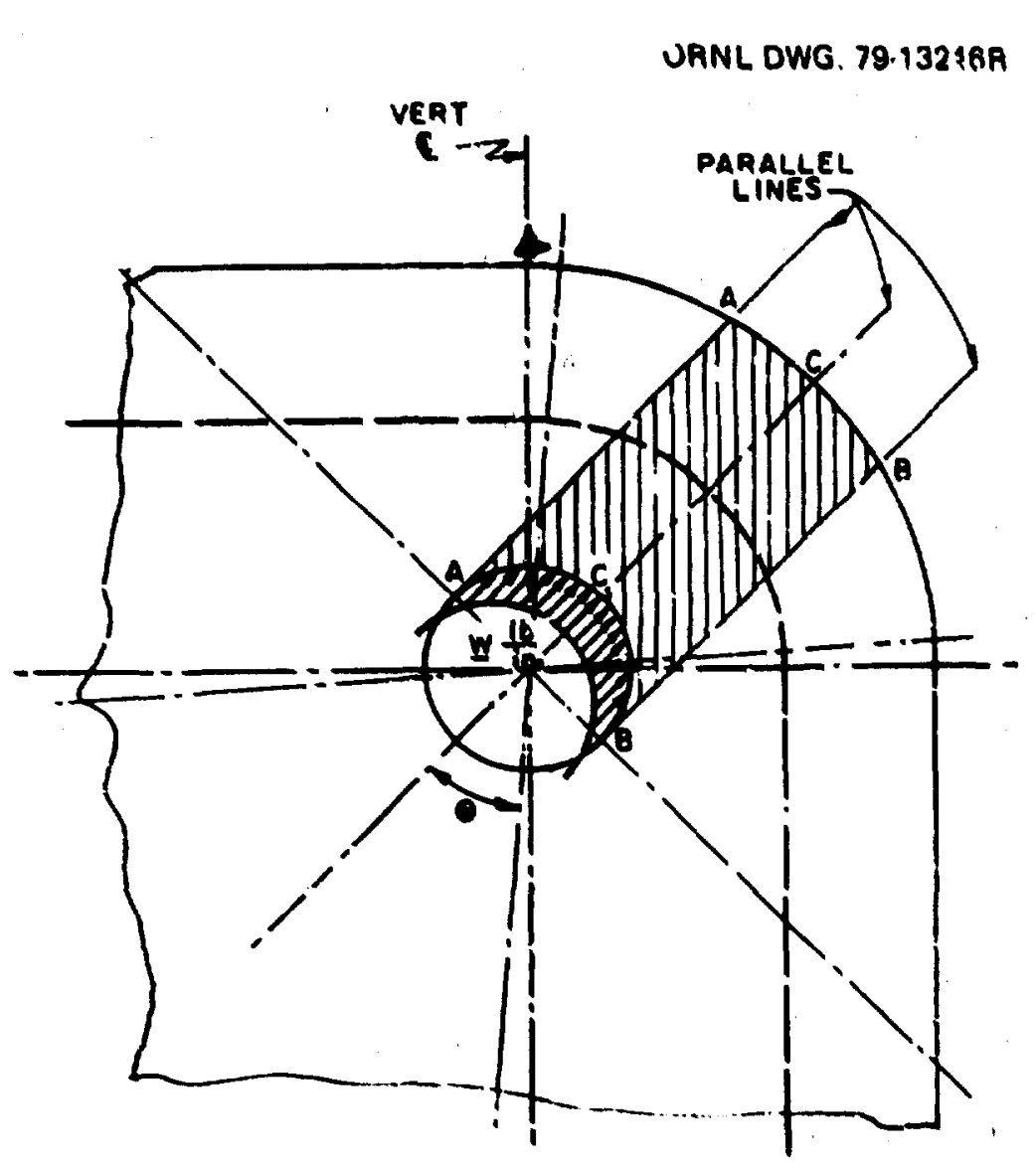

Fig. 2.6 Tie-down land model.
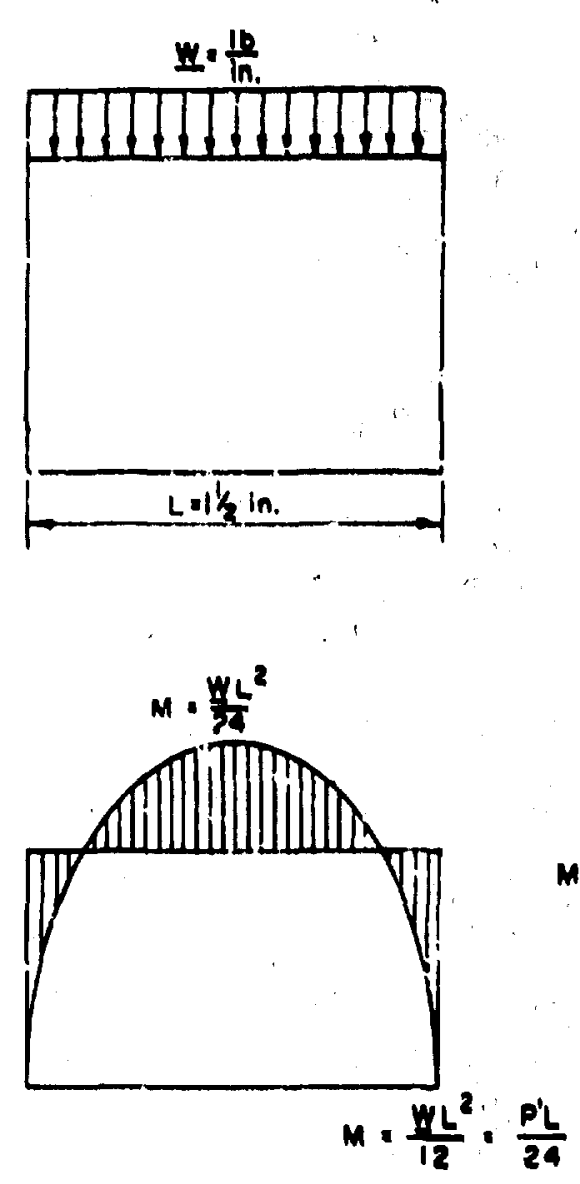

Fig. 2.7 Mathematical model of tic-down Inud.

MOMENT DIABRAM

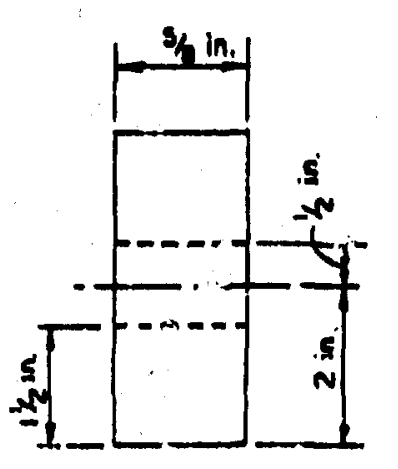

$\therefore \frac{1}{\pi}(4 / 3)\left(2 \beta=0.42 \mathrm{in}^{4} \quad \pi\right.$ $A \cdot(2)(8) \cdot 1.25 \mathrm{ln}$ $x \cdot \frac{p^{\prime}}{2 T}$
ORNL DWG. 79.13247R

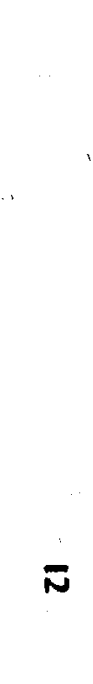


The maximum bending inoment in the ring sezment occurs at the edgex: the mapnituts is cqual in

$$
\begin{aligned}
M & =\frac{P^{\prime} L}{24}=\frac{? \mathrm{~W}(15)}{2(24)} \\
& =263 \mathrm{in}-! \mathrm{b} .
\end{aligned}
$$

The bending stresses for the straight team are:

$$
\begin{aligned}
\sigma_{b} & = \pm \frac{M_{c}}{I}=\frac{(26 j)(0.5)}{0.42} \\
& =312.5 \text { poi. }
\end{aligned}
$$

The bending stresses in the corresponding curved beam shown in Fig 25 ars on $12^{\prime}$ to

$$
\sigma_{c}=k \sigma_{b}=4(312.5) \text { psi. }
$$

The factor $k$ takrs into consideration the shifting of the neutral axis as well as the parabulic distribution of stresses in the cross section of the curved beam. For the beam under consideration.

$$
\begin{aligned}
& k=0.67 \text { for the tension sidz, and } \\
& k=1.8 \times \text { fin the compression sio.. }
\end{aligned}
$$

It follows that ine stress in the outsice fiber is 733 psi and in the inside fiber it is 1969 psi.

The maximum shear strim occurs at the clamped end of the beam. From straight-beam theory, the shear strain in the vicinity of the neutral axis is equal to

$$
r=\frac{V}{h} a
$$

where

$$
a=\text { cross section of shear factor. }
$$

For a rectangular cross section.

$$
\begin{aligned}
T & =\left(\frac{P}{2}\right) \frac{1}{A}\left(\frac{3}{2}\right)=\frac{9(2800)}{8(1.69)} \\
& =1864 \text { poi. }
\end{aligned}
$$


where A-is the gross cross section at the location of maximum shear. The stresses at the welds of tive te-down to cask inte face ase calculated on the basis of the free-body diagram shown in Fie. 28. From this diagram. it follows that

$$
\begin{aligned}
P^{\prime \prime} & =\frac{3 W}{2} \sin 47^{\circ}=\frac{3(28 W v)}{2} \sin 47^{\circ} \\
& =3072 \mathrm{Bb} . \\
V & =\frac{3 W}{2} \cos 47^{\circ}=\frac{3(2800)}{2} \cos 47^{\circ} \\
& =2864 \mathrm{BD} . \\
M & =P^{\prime \prime}\left[2.0+\left(0.5 \cos 47^{\circ}\right)\right]-V\left[2.0+\left(0.5 \sin 47^{\circ}\right)\right] \\
& =3072(2.34)-2864(2.37)=401 \text { in. } .16 .
\end{aligned}
$$

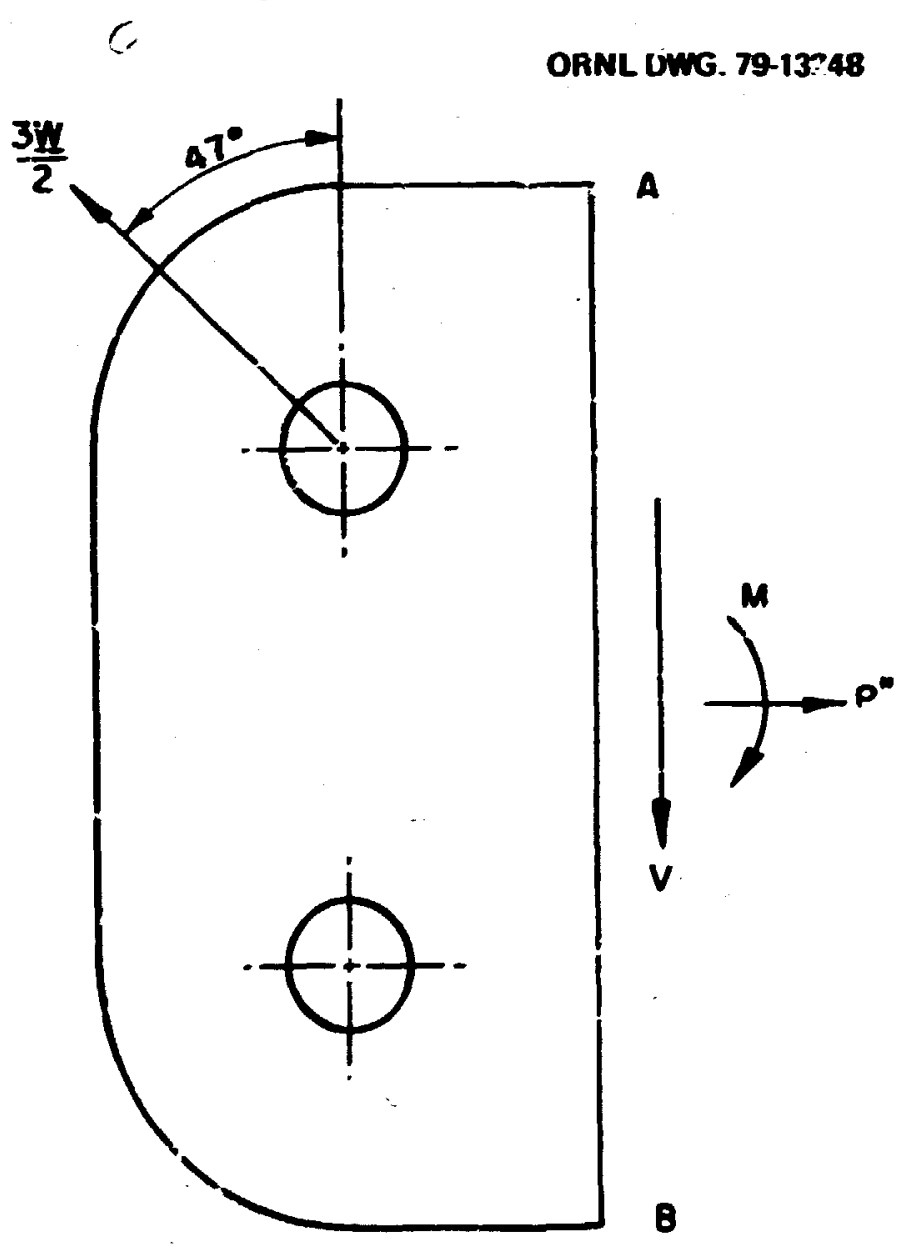

Fig. 2.8 Loads at wells between tie-down and cask body. 
Maximum stresses at the meld. assuming the ear betaves lite a cantikever beam. are given by the expreasion

$$
\sigma=\frac{P}{A}+\frac{M E}{I}
$$

Where $A$ is the net area of the weld at the point of minimum area and

$$
\begin{aligned}
\boldsymbol{A} & =2[(0.707)(\boldsymbol{H})(0.5)] \\
& =5.66 \mathrm{in}^{2} .
\end{aligned}
$$

The parameter $I$ is the met second moment of the wed patterm, calculated at the minimum section zrea of the weld. The gross $I$ is colculated in Fig 2.9 and is equal to 72.05 in."; the net value of $I$ is equinal ir

$$
I=\{0.707)(2.05)=50.94 \mathrm{int} \text {. }
$$

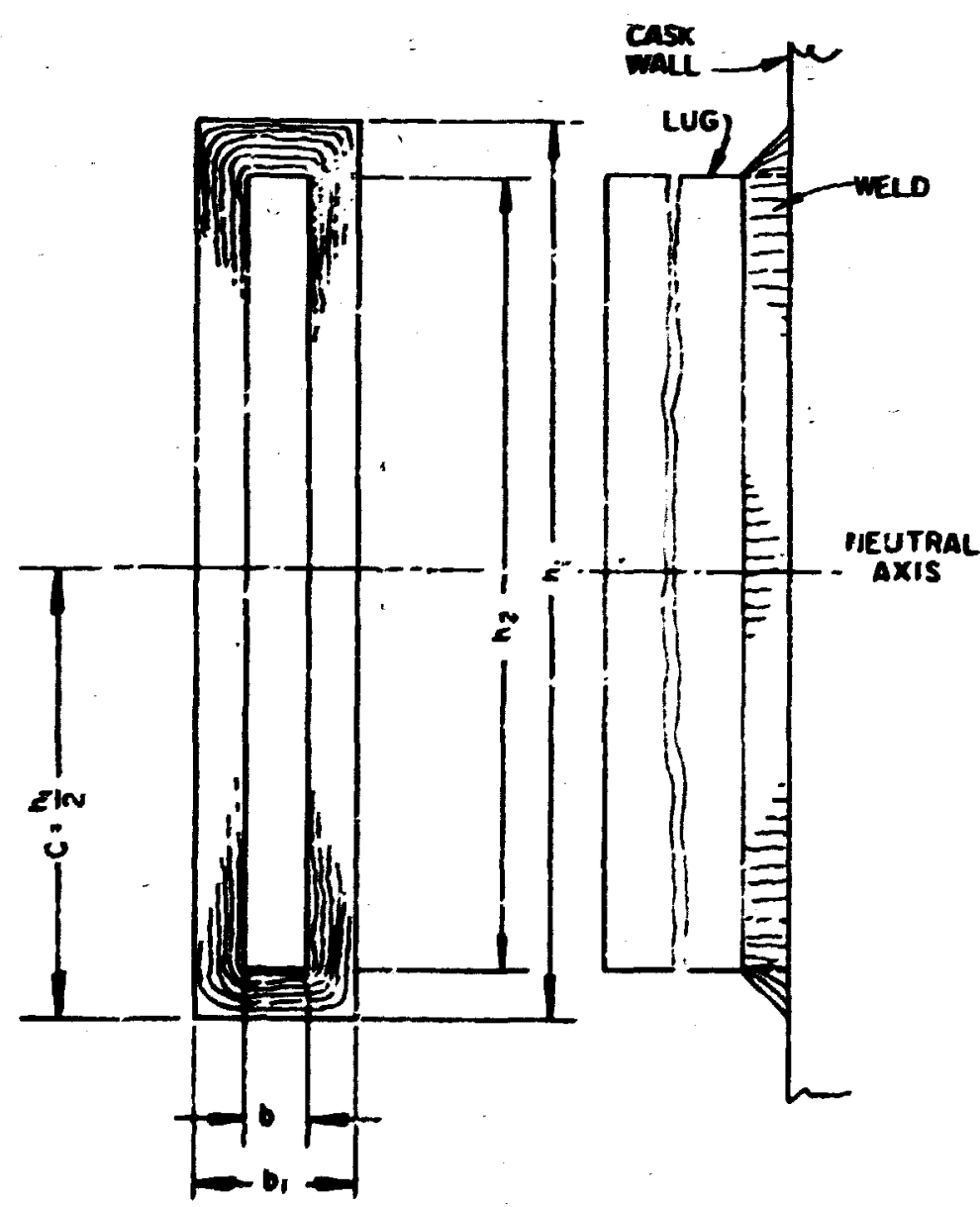

OANL DWG. 79-13249

$$
\begin{aligned}
& n_{2}=t_{0} \text { in. } \quad n_{2}=8 \mathrm{~m} . \\
& n_{1}=A_{2} \mathrm{in} . \quad
\end{aligned}
$$

$I=\frac{1}{12}\left(b_{1} m_{1}^{3}-b_{2} n \frac{3}{2}\right)$

$I=72.05$

Fig. 2.9 Mument of inertia diagram for weld patiern. 


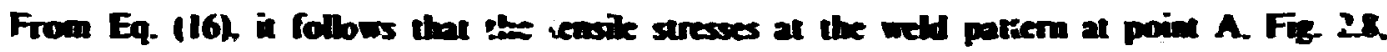
are

$$
\begin{aligned}
- & =\frac{3072}{5.56}+\frac{(001)(4.5)}{50.94} \\
& =578 \mathrm{pac}
\end{aligned}
$$

The peak shear strews at ibe weld patiern is equal to

$$
\begin{aligned}
T & =\propto \frac{V}{A}=\frac{3}{2}\left(\frac{2864}{566}\right) \\
& =759 \mathrm{pai}
\end{aligned}
$$

Therefore, it has been sionen that the available welds that attach the tie-down devize to the cast shell are adequate to support the proposed leed equal to threx times the combined weight of the cast and stid. In las abo been shom that one rie-dumn device by itself is adequate to support the 3y houl.

The shear stresses 2: the pins are calculated as follows:

$$
T=\frac{V}{A}=\frac{3 W}{2 A}=\frac{3(2800)}{2(0.7854)}
$$

where $A$ is the gross shear area of the pin. 0.7854 in. $^{2}$, and

$$
\tau=5348
$$

This value is also smaller than the allowable shear stress.

\subsubsection{Tie-down devices}

The regulations require that if there is a system of tie-down devices which is a strurtural part of the package, this system must be capabte of withatanding a static force applied to the center of gravity of the package with (1) a vertical component of two times the weight (2W) of the package and its contents, (2) a horizontal component along the diretion of iravet of ten times the weight (JOY) of the packaje and its contents, and (3) a horizonul comp ment in the transverse direction of five times the weight (SW) of the package and its contents. This applied load shall not zenerate stresces in any material of the package in excess of the yield atength of that material. In addition, any tic-down device that is a structural part of the package mus be dasigned so that failure of the device under excessive load will not impair the ability of the package to meet other requirements of the regulations.

The cask is tied down to its skid by four eables that run between the lower irunnion bar (see Fig. 2.2) and the skid. It is attached to the vehicle by four cables that run between the upper trunnion bur and the tie-down points on the bed of the vehicle. The analysis of the tie-down poini on the cask is given below. 
To demonstrate the adequany of the tie-downs, it wil be demonstrated that: (I) the ie down of the Curium carrier to the stid is adequate, and (2) the tie down of the castr-stid combination to the truet is also adequate.

Evalhation of requirements staned in Sect. 2.2.4. For the general case of any angle $\theta$ of the tieniom angle (measured from the vertical. Fig 210). the forwand cables go in compressions and therefore do mo sustain any boed. The stationary potential energy of the sysuem is used to solve for the redundant forces. This is a general analysis for either ast to stid or a combination of eask to stid to vehicte. The only variation is in the numerica! values axizned to the variables.

When the cables that undergo shat are resooved the system becumes overspezified. Th's problem is easily solved by superimposing the beds hat lie in the hotizon'al plane to the vertical beal case. The resolus are also given for a general angle $\theta$ with the vertical axis.

Let + force be tension in eables

$$
\begin{aligned}
& \Sigma F_{x}=0 \rightarrow \\
& R_{x}^{i}+R_{x}^{2}-R_{x}^{3}-R_{x}^{k}=10 \underline{W}
\end{aligned}
$$

where superscripts denote cable number and subscripts denote component orientation (see Figs. 2.10 and 2.11$)$.

$$
\begin{aligned}
& \Sigma F_{Y}=0-7 \\
& -R_{Y}^{1}+R_{Y}^{2}+R_{Y}^{3}-R_{Y}^{4}=5 W_{-} \\
& \sum F_{Z}=01 \\
& R^{2}+R^{2}+R^{3}+R^{4}=2 W
\end{aligned}
$$

For a typical cable. $n$, the components of force along the axis system are given by the expressions

$$
R_{x}^{n}=R_{x y}^{n} \cos 45^{\circ}
$$

and

$$
R_{y}^{k}=R_{x y}^{\ln } \sin 45^{\circ}
$$

where $R_{x y}^{n}$ is the resultant force of the eables in the xy plane. In this expression. the angle of $45^{\circ}$ is chosen because it represents the angle that is fixed by the physical dimensions of the cask-akid combination.

The relationship that exists between the total resultant load in the typical cable. $n$. the resultant force in the $x y$ plane $\left(R_{x y}^{n}\right)$. and the ande $\theta$ that exists between this total resultant force $\left(R^{2}\right)$ and the vertical axis is given by the expreasion:

$$
\mathbf{R}_{\mathrm{xv}}^{\mathrm{n}}=\mathbf{R}^{\mathrm{n}} \operatorname{in} \theta
$$




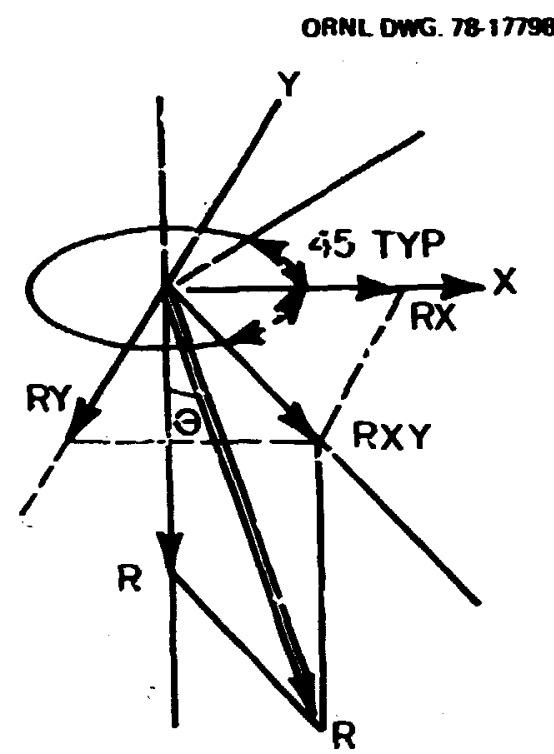

Fig. 2.10 Schematic of cask tie dorvn.

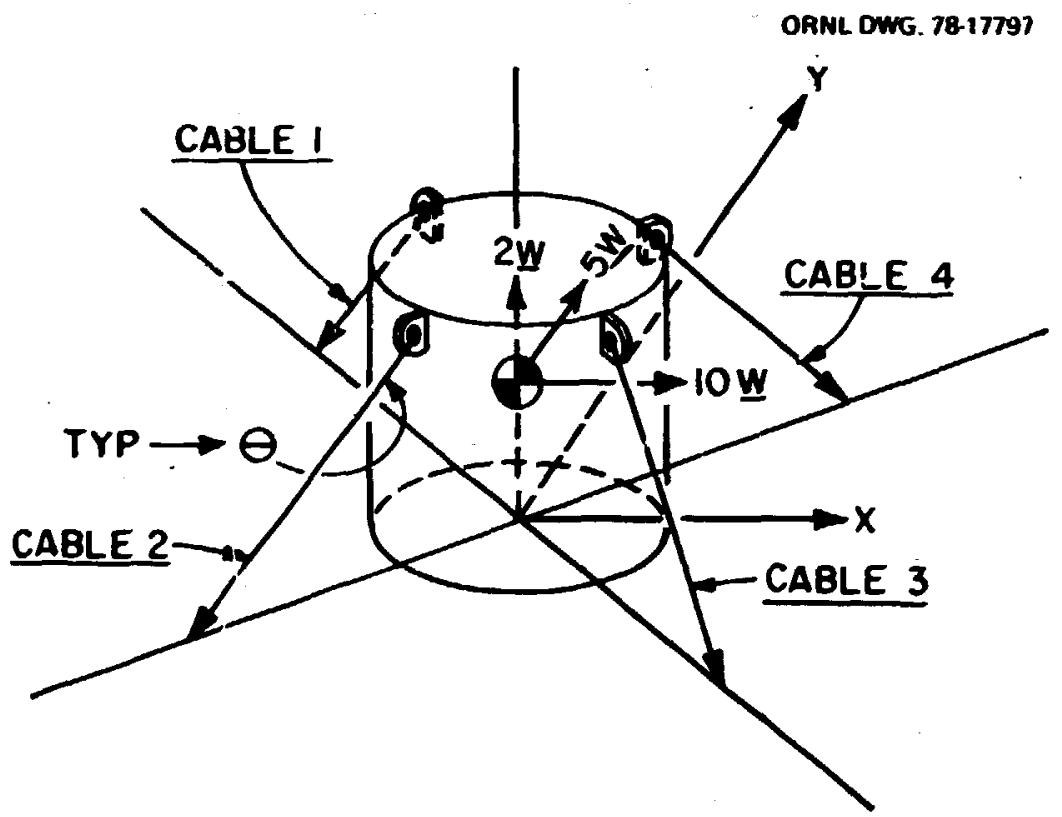

Fig. 2.11 Mathematical model of cask tie downs to vehicle.

therefore, substitution of Eq. (28) into Eq. (27) yiclds:

$$
R_{x}^{n}=R_{y}^{n}=R^{n} \cos 45^{\circ} \sin \theta
$$

where

$n=1,2,3$, or 4 for cables 1, 2, 3, or 4 . 
and

$$
\mathbf{R}_{\mathbf{z}}^{\mathrm{n}}=\mathbf{R}^{\mathrm{n}} \cos \theta
$$

is the vertical component of load in the cable dus to a tocal reactive load equal to $R^{n}$.

Substitution of Eqs. (29) and (30) in Eq. (24) yields:

$$
\begin{aligned}
& R^{1}+R^{2}-R^{3}-R^{4}=\frac{10 \underline{W}}{\cos 45 \sin \theta} \\
& -R^{1}+R^{2}+R^{3}-R^{4}=\frac{S W}{\cos 45 \sin \theta} \\
& R^{1}+R^{2}+R^{3}+R^{4}=\frac{2 W}{\cos \theta}
\end{aligned}
$$

If $R$ is the redundant force, Eq. (3I) reduces :0:

$$
\begin{aligned}
& \mathbf{R}^{2}-\mathbf{R}^{3}-\mathbf{R}^{4}=\frac{10 \underline{W}}{\cos 45 \sin \theta}-\mathbf{R}^{1}=\mathbf{F}^{1} \\
& \mathbf{R}^{2}+\mathbf{R}^{3}-\mathbf{R}^{4}=-\frac{5 \underline{W}}{\cos 45 \sin \theta}+\mathbf{R}^{1}=\mathbf{F}^{2} \\
& \mathbf{R}^{2}+\mathbf{R}^{3}+\mathbf{R}^{4}=\frac{2 W}{\cos \theta}-\mathbf{R}^{1}=\mathbf{F}^{3}
\end{aligned}
$$

0. , in matrix form.

$$
\left[\begin{array}{l}
1-1-1 \\
1+1-1 \\
1+1+1
\end{array}\right]\left[\begin{array}{l}
R^{2} \\
R^{3} \\
R^{4}
\end{array}\right]=\left[\begin{array}{l}
F^{1} \\
F^{2} \\
F^{3}
\end{array}\right]
$$

or

$$
\left[\begin{array}{l}
\mathbf{R}^{2} \\
\mathbf{R}^{3} \\
\mathbf{R}^{4}
\end{array}\right]=\left[\begin{array}{l}
1-1-1 \\
1+1-1 \\
1+1+1
\end{array}\right]^{-1}\left[\begin{array}{l}
F^{1} \\
F^{2} \\
F^{3}
\end{array}\right]=\left[\begin{array}{lll}
1 / 2 & 0 & i / 2 \\
-1 / 2 & 1 / 2 & 0 \\
0 & -1 / 2 & 1 / 2
\end{array}\right]\left[\begin{array}{l}
F^{1} \\
F^{2} \\
F^{3}
\end{array}\right]
$$

hence,

$$
\begin{aligned}
& R^{2}=\frac{F^{\prime}}{2}+\frac{F^{2}}{2}=\frac{10 W}{2 \cos 45 \sin \theta}+\frac{2 W}{2 \cos \theta}-R^{\prime} \\
& R^{3}=-\frac{F^{\prime}}{2}+\frac{F^{2}}{2}=-\frac{10 W}{2 \cos 4, \frac{W}{\sin \theta}}+\frac{5 W}{2 \cos 45 \sin \theta}+R^{\prime} \\
& R^{4}=-\frac{F^{2}}{2}+\frac{F^{3}}{2}=-\frac{5 \underline{W}}{2 \cos 45 \sin \theta}+\frac{W}{\cos \theta}-R^{\prime}
\end{aligned}
$$


The unit load methud is used to solve for the unknowns of the system.

The elonmiticns in cables 2, 3. and 4 are computed as follows: elongations $=e=($ force $)[L / E A]=(F) K)$, since all the cables have the same length and stiffness characteristics: substitution into Eq- (35) (where $F$ is substituted by $R^{2}, R^{3}$. and $R^{4}$ ) yields:

$$
\begin{aligned}
& e_{1}=(K) R^{1} \\
& e_{2}=(K) R^{2} \\
& e_{3}=(K) R^{3} \\
& e_{4}=(K) R^{4}
\end{aligned}
$$

The loads in cables 2. 3, and 4 due to a unit load applied at cable I and all other external loads are removed:

$$
\begin{aligned}
& r_{1}=1 \\
& r_{1}=-1 \\
& r_{3}=1 \\
& r_{1}=-1
\end{aligned}
$$

The reduction in kngth of the first cable $\left[e_{t}=\left(R^{\prime} X(K)\right]\right.$ is equal to $\Sigma e_{r}$, from Eqs. (35)-(37).

$$
\begin{aligned}
-R^{\prime} K= & {\left[\frac{10 W}{2 \cos 45^{\circ} \sin \theta}+\frac{2 W}{\cos \theta}-R^{\prime}\right](-1)+K\left[-\frac{10 W}{2 \cos 45^{\circ} \sin \theta}+\right.} \\
& \left.\frac{5 \underline{W}}{2 \cos 45^{\circ} \sin \theta}+R^{\prime}\right](1)+K\left[-\frac{5 \underline{W}}{\cos 45^{\circ} \cos \theta}+\frac{2 W}{\cos \theta}-R^{\prime}\right](-1)
\end{aligned}
$$

Solving for R':

$$
R^{\prime}=\frac{10 W}{4 \cos 45^{\circ} \sin \theta}-\frac{5 W}{4 \cos 45^{\circ} \sin \theta}+\frac{2 W}{4 \cos \theta}=\frac{5 \underline{W}}{4 \cos 45^{\circ} \sin \theta}+\frac{W}{\cos \theta}
$$

where

$\theta=i^{\infty}$, and substitution of Eq. (39) into Eq. (35) gives:

$$
\begin{aligned}
& K^{\prime}=\frac{S W}{4 \cos 45^{\circ} \sin 30^{\circ}}+\frac{W}{\cos 30^{\circ}}=4.12 W \\
& R^{2}=\frac{5 W}{\cos 45^{\circ} \sin 30^{\circ}}+\frac{W}{\cos 30^{\circ}}-4.12 W-11.18 W \\
& R^{3}=\frac{10 W}{2 \cos 45^{\circ} \sin 30^{\circ}}+\frac{5 W}{2 \cos 45 \sin 30^{\circ}}+4.12 W=-2.95 \underline{W} \\
& R^{4}=\frac{5 W}{2 \cos 45^{\circ} \sin 30^{\circ}}+\frac{W}{\cos 30^{\circ}}-4.12 W=-10.04 W
\end{aligned}
$$


The signs in cables 3 and 4 are reversed, indicating that the assumption made (t force $\cong$ tensicn in all cables) is not valid.

Since it has been shown that two of the cables go in compression (a condition not usually cealistic in cables), the system will be reduced by the removal of these cables and the loads will be solved in the remaining cables.

If $R^{3}$ and $R^{4}$ are each equal to zero, the expressions in Eq. (23) reducr to

$$
R_{x}^{1}+R_{x}^{2}=10 \underline{W}
$$

and Eqs. (24) and (25) reduce to

$$
\begin{aligned}
& -R_{y}^{3}+R_{y}^{2}=5 W \\
& R_{z}^{1}+R_{z}^{2}=2 \underline{W}
\end{aligned}
$$

The system is nverspecified. Equation (42) is decoupled from Eq. (4I) and can be solved independently. Operating in Eq. (4i), it foilows that after substituting expression (29) into (4I). these equations become:

$$
\begin{aligned}
& R_{x y}^{I} \cos 45^{\circ}+R_{x y}^{2} \cos 45^{\circ}=10 \underline{W} \\
& -R_{x y}^{1} \sin 45^{\circ}+R_{x y}^{2} \sin 45^{\circ}=5 \underline{W}
\end{aligned}
$$

or

$$
\left[\begin{array}{r}
\cos 45^{\circ} \cos 45^{\circ} \\
-\sin 45^{\circ} \sin 45^{\circ}
\end{array}\right]\left[\begin{array}{l}
R_{x y}^{I} \\
R_{x y}^{2}
\end{array}\right]=\left[\begin{array}{r}
10 W \\
5 \underline{W}
\end{array}\right]
$$

and

$$
\begin{aligned}
{\left[\begin{array}{l}
R_{x y}^{i} \\
R_{x y}^{2 \cdot}
\end{array}\right] } & =\left[\begin{array}{r}
\cos 45^{\circ} \cos 45^{\circ} \\
-\sin 45^{\circ} \sin 45^{\circ}
\end{array}\right]^{-1}\left[\begin{array}{r}
10 W \\
S \underline{W}
\end{array}\right] \\
& =\frac{1}{2}\left[\begin{array}{c}
\frac{1}{\cos 45^{\circ}}-\frac{1}{\sin 45^{\circ}} \\
-\frac{1}{\cos 45^{\circ}} \frac{1}{\sin 45^{\circ}}
\end{array}\right]\left[\begin{array}{l}
10 \underline{W} \\
5 W
\end{array}\right] \\
R_{x y}^{\prime} & =\frac{10 \underline{W}}{7 \cos 45^{\circ}}-\frac{5 \underline{W}}{2 \sin 45^{\circ}}=\frac{5 \underline{W}}{2 \cos 45^{\circ}} \\
R_{x y}^{2} & =\frac{10 \underline{W}}{2 \sin 45^{\circ}}+\frac{5 \underline{W}}{2 \sin 45^{\circ}}=\frac{15 \underline{W}}{2 \cos 45^{\circ}}
\end{aligned}
$$

This results in $R_{x y}^{\prime}$ and $R_{x y}^{2}$ in the $x y$ plane for cables $I$ and 2 respectively. These reactions. given in terms of the axial load on the cable. become:

$$
R=\frac{R_{x y}}{\sin \theta}
$$


so that

$$
\mathbf{R}^{1}=\frac{5 W}{2 \cos 45^{\circ} \sin \theta}
$$

Similarly;

$$
\mathbf{R}^{2}=\frac{15 \mathrm{~W}}{2 \cos 45 \sin \theta}
$$

The vertical load on the cables, from $F_{2}=0$, is resolved as foliows:

$$
\mathbf{R}_{\mathbf{2}}^{\mathbf{1}}+\mathbf{R}_{\mathbf{2}}^{\mathbf{2}}=\mathbf{2} \mathbf{W}
$$

if it is assumed that the total vertical load is equally resisted by each cable, Eq. (5I) becc mes

$$
\mathbf{R}_{\mathbf{z}}^{\mathbf{1}}=\mathbf{R}_{\mathbf{2}}^{2}=\mathbf{W}
$$

and, from Eq. (30). the components of $R^{\prime}$ and $R^{2}$ due to the verticil load only are:

$$
\mathbf{R}^{\prime}=\mathbf{R}^{2}=\frac{\underline{W}}{\cos \theta} \text {. }
$$

The total load on the cables is

$$
\begin{aligned}
& \mathbf{R}^{1}=\frac{5 \underline{W}}{2 \cos 45^{\circ} \sin \theta}+\frac{W}{\cos \theta} \\
& \mathbf{R}^{2}=\frac{15 W}{2 \cos 45^{\circ} \sin \theta}+\frac{W}{\cos \theta} \\
& \mathbf{R}^{3}=\mathbf{R}^{4}=0 .
\end{aligned}
$$

Fur the cases when the loads on the tie-down Jevice are associated with the cask-skid combination to the truck bed, $\mathbf{W}=2800 \mathrm{lb}$. Thus, the loads in cables $\mathbf{l}$ and 2 are:

for $\theta=30^{\circ}$

$$
\begin{aligned}
& R^{\prime}=.7,960 \mathrm{lb}, \\
& R^{2}=62,630 \mathrm{lb} ;
\end{aligned}
$$

$\operatorname{for} \theta=45^{\circ}$

$$
R^{\prime}=17,200 \ddot{~} \ddot{b},
$$$$
\text { - } \mathrm{R}^{2}=45,960 \mathrm{lh} \text {; }
$$

for $9=60^{\circ}$

$$
\begin{aligned}
& R^{\prime}=17,030 \mathrm{lb}, \\
& R^{2}=39,893 \mathrm{lb} .
\end{aligned}
$$


The bending stresses in the eye (Fig- 2.12) are calculated using the same model discussed previously in the lifting analysis. For the cask-to-skid case when $\theta=30^{\circ}$, these stresses are:

$$
M=\frac{\left(R^{2}\right) L}{24}=\frac{R^{2}}{24}
$$

$$
\begin{aligned}
\sigma_{\text {outside }} & =\frac{(0.67)\left(R^{-}\right)}{24} \frac{(0.75)}{(0.18)}=\frac{(0.67)(62630)(0.15)}{24(0.18)} \\
& =7285 \text { psi }
\end{aligned}
$$

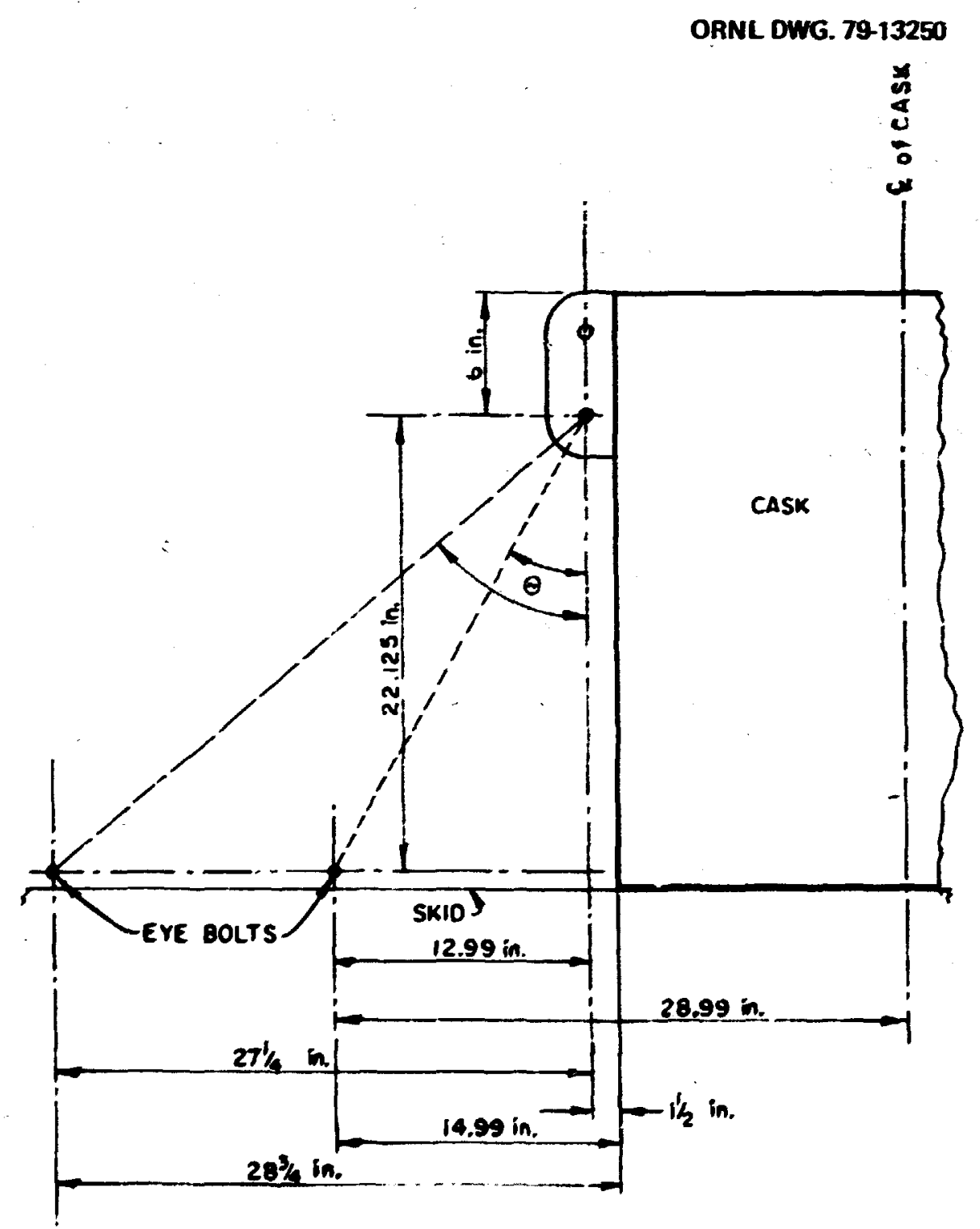

Fig. 2.12 Geometry of cask-10-síid tie dnwn. 


$$
\begin{aligned}
\sigma_{\text {inside }} & =\frac{(1.80)\left(R^{2}\right)(0.75)}{(24)(0.181)}=\frac{1.80}{0.67}(7,285) \\
& =19.572 \mathrm{psi} .
\end{aligned}
$$

Bending stresses associated with the combination cask-skid to truck-bed cases are minimal. since these cables are attached to the upper ear of the lifting device and the cables do not significartly load the curved portion of the eye in this upper-ear case.

The shear stresses for the cask-to-skid case are also compoued using the formulation used in the cask lifuing device analysis where the shear stresser are given by the expression

$$
\begin{aligned}
\tau & =\frac{V}{A} \sigma=\left(\frac{R^{2}}{2}\right) \frac{1}{2 A}\left(\frac{3}{2}\right)=\frac{3\left(R^{2}\right)}{8 A} \\
& =\frac{(3)(62,630)}{(8)(1.91)\left(\frac{5}{8}\right)} \\
& =19,674 \mathrm{poi} .
\end{aligned}
$$

For the other cases when the combination is tied to the truck bed. the shear strain is equal to

$$
\mathbf{T}=\frac{\mathbf{V}}{\mathbf{A}}
$$

where $A$ is the total shear area equal to the sum of the areas at the tangent planes that are parallel to the direction of the force anplied:

$$
\begin{aligned}
\text { for } \theta & =30^{\circ} \\
\tau & =\frac{62,630}{\left(\frac{5}{8}\right)(4.7+3.1)}=12,847 \mathrm{pos} \\
\text { for } \theta & =45^{\circ} \\
\tau & =\frac{39.893}{\left(\frac{5}{8}\right)(3.3+2.3)}=11,398 \mathrm{psi} .
\end{aligned}
$$

The streses in the welds at the tie-down device and cask interface due to tit-down loads are also calculated using the model described in the lifting device analysis. It will be sufficient to show that the stresces at these welds due to the Iargest tiedown case (when $\theta=30^{\circ}$ ) satisfy i he criteria. With reference to Fig. 2.R. the following parameters are calculated:

$$
P^{\prime}=\frac{R^{2}}{2} \sin 30^{\circ}=\frac{62,620}{2} \sin 30^{\circ}
$$

$=15,658 \mathrm{lb}$. 


$$
\begin{aligned}
V & =\frac{R^{2}}{2} \cos 30^{\circ}=\frac{62,630}{2} \cos 30^{\circ} \\
& =27120 \mathrm{Ib} . \\
M & =P^{\prime \prime}\left(2.0+0.5 \cos 30^{\circ}\right)=-v\left(20+0.5 \sin 30^{\circ}\right) \\
& =15,658(2.43)-27,120(2.25) \\
& =-22,971 \text { in. } 7 .
\end{aligned}
$$

The maximum teasik strass at the minimum sertion area of the wield is:

$$
\begin{aligned}
0 & =\frac{P}{A}+\frac{H c}{I}=\frac{15,658}{5.66}+\frac{(22,971)(4.5)}{50.94} \\
& =4,796 \mathrm{poi} .
\end{aligned}
$$

The peak shear stress at the weld pattern is equal to:

$$
\begin{aligned}
T & =\alpha \frac{V}{A}=\frac{3}{2}\left(\frac{27,120}{5.66}\right) \\
& =i .187 \mathrm{par} .
\end{aligned}
$$

The analysis shows that the tie-down device is adequate to meet the specified criteria when subjected to the loads associated with the tie-down for the cask to skid and combination cask-skid to carrier bed. The analysis shows that the shear stress at the tie bolt is about 20 percent in excess of the allowable strear quantity; this calculated stress is a peak value when calculated using straight beam theory, it can sajely be shown that the average shear stress in the shear plane is leas than this value, therefore. there is a certain amount of conservatism in the calculation scheme shown.

The evaluation of the shear stresces at the pins associated with the tie-down loads follows. The maximum forsecable load in the pins is equal to $62.630 \mathrm{lb}$ which occurs when the cask-skid combination is tied down to the carrier bed; the shear stress in the pins is

$$
\begin{aligned}
T & =\frac{P}{2 A}=\frac{62,630}{2(0.7854)} \\
& =39.870 \mathrm{pic}
\end{aligned}
$$

If it is specified that the material of the pins is steel with designation AISI type 4140. which has a minimum yield aress of $100 \mathrm{ksi}$ (and a minimum shear stress allowable of 50 ksi). the computed value is within the allowable stress.

The pins should be threaded at the ends and bolted permanentiy to the ears.

\subsection{Standards for Type B and Large-Quantity Packaging}

The arvetural andards for large-quantity packaging of the segulations include load resiutance of the packaging and the external pressure tha: the package must withstand. 
Compliance of the TRU Curium Shipping Container with these requirements is discussed in the following subsecuons.

\subsubsection{Load resisfance}

When regarded as a simple heam supported at its ends along any major axis. the container must be capable of withstanding a static load. normal to and uniforml: distributed along its length. that is equal to five tines its fully loaded weight without generating stress in any material of the cask in excess of the yield strength of that material.

Load evaluation. The TRU Curium Shipping Container. loaded as required as a simple cylindricai beam, is shown in Fig. 213. The reactant force acting on the end of ${ }^{2}$ simple beam $\left(R_{1}\right)$ is found as follows:

$$
\begin{aligned}
\mathbf{R}_{\mathrm{I}} & =\frac{\underline{\underline{W}}}{2} \\
& =7000 \mathrm{lb},
\end{aligned}
$$

where

$$
C=\text { factor } 5 \text {. }
$$

$\underline{W}=$ weight of the container, $2800 \mathrm{lb}$.

The unit loading. $W$, is found as follows:

$$
\begin{aligned}
\underline{W}_{u} & =\frac{C W}{I} \\
& =453 \mathrm{in}-1 \mathrm{lb} .
\end{aligned}
$$

where

$$
L=\text { length of the beam, } 30.875 \mathrm{in} .
$$

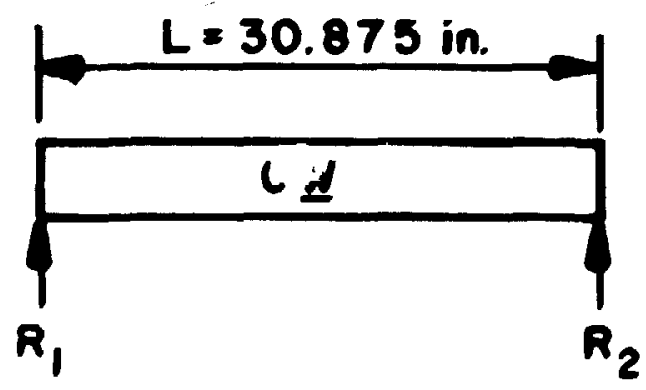

rig. 2.13 L.oading diagram of the TRU Curium Shipping Container regarded as a simple heam. 
From these loadings, the maximum bending moment $\left(M_{m}\right)$. which is in the center of the beam, is calculated as follows:

$$
\begin{aligned}
M_{\max } & =\left(\frac{R_{1} L}{2}\right)-\left(\frac{Y_{1} L^{2}}{8}\right) \\
& =54,084 \text { in. } 1 \mathrm{~b} .
\end{aligned}
$$

The moment of ivertia ( $($ ) is calculated as follows:

$$
J=\left(\frac{\pi}{4}\right)\left(r_{0}^{4}-r_{1}^{4}\right)=3455 \text { in. }
$$

where

$$
\begin{aligned}
& r_{0}=\text { radius of outside of drum, } 14.5 \mathrm{in} . \\
& r_{1}=\text { radius of inside of drum, } 14.125 \mathrm{in} .
\end{aligned}
$$

The maximum bending stress $\left(S_{\circ}\right)$, which is also at the center of the beam. may be calculated as follows:

$$
\begin{aligned}
S_{b} & =\frac{M_{\max } T_{0}}{I} \\
& =227 \text { psi }(<30,000 \text { pai }) .
\end{aligned}
$$

Since the maximum bending stress is weli beluw the yield stress. the TRU Curium Shipping Container exceeds the load resistance requirement. The concrete. which was not considered in this calculation. will also help the drum to resist bending.

\subsubsection{Exiernal pressure}

The regulations require that the dcsign of the shipping package be adequate to ensure that the containment vescel will suffer no loss of contents if subjected to an external pressure of 25 psig.

Evaluation of requirements stated in 2.3.2 The inner containment vissel will not suffer loss of contents if and when the shipping container is subjected to an external pressure of 25 psig.

The critical unit load for thin-wall cylinders' may be calculated as follows:

$$
\begin{aligned}
p^{\prime} & =\frac{\left(\frac{l}{r}\right) s_{y}}{\frac{1+4 S_{y}}{E\left(\frac{r}{t}\right)^{2}}}=\frac{\left(\frac{0.065}{0.625}\right)(25,000)}{1+(4 \times 25,000)} \\
& =1956 \mathrm{lb} / \mathrm{in}^{2}\left(>25 \mathrm{lb} / \mathrm{in.}^{2}\right) .
\end{aligned}
$$


where

$$
\begin{aligned}
& p^{:}=\text {critical unit load, lb in: } \\
& \text { I = wall shickness. in., } \\
& r=\text { mean ratius, in. } \\
& S_{y}=\text { vield strength, lb in. }{ }^{2} \text {. } \\
& F=\text { Young's modulus, } 16 \text {; in. } .
\end{aligned}
$$

The inner container calculations were compared to the values listed in the "Table of Maximum Uniform External Pressure for Steet Pipe" (ref. 5) and were found to have external pressure resistance many times greater than the required $25 \mathrm{lb}$ in..

\section{COMPLIANCE WITH STANDARDS FOR NORMAL CONDITIONS OF TRANSPORT}

The regulations stipulate that a single package must be abke to withstand the normal conditions of transport without substantially reducing the effectiveness of the pactage and withoul releasing radioactive material from the containment vesel. The contents of the container are limited such that the package will contain no gases or vapors that could reduce the effectiveness of the packaging. No circulating coolant other than atmospheric air is used. and no mechanical cooling device is required or provided The TRU Curium Shipping Container and its inner containers are designed so that the contents will not be vented to the atmosphere under normal cenditions of transport. These normal conditions include the effects of heat, cold, pressure, free drop, and penetration.

\section{I Heat}

The cast. must be designed and constructed so that if it were subjected to direct sunlight at an ambient temperature of $130 \% \mathrm{~F}$ in still air. its effectiveness would not be reduced. In addition, the temperature of the accessible external surfaces of the cusk nuust not excad $122^{\circ} \mathrm{F}$ in the shade when fully loaded, assuming still air at ambient temperatures. If the cask is transported in a vehicle assigned for the sole use of the consignor, the maximum accessible external surface temperatures shall not exceed $180^{\circ} \mathrm{F}$.

To evaluate the adequacy of the curium snipping cask under normal operating conditions. heat transiter tests were conducted both in the shade and in the sun.

The first test performed at ORNL simulated full-shade conjitions. The second test simulated exposure to the sun. In the first test, the cask was placed in the crane bay of a building where the ambient temperature was controlled at $700 \mathrm{~F}$. A heat source of $150 \mathrm{~W}$ was placed inside of the inner container. The cask was closed in its normal way and the resultant temperatures were monitorec for 4 days by use of chromel-alumel thermocouples. One thermocouple was attached to the outside of the cask, one was incated at the inside bottom corner of the inner container, and a third was placed in the ambient air, approximately 6 in. from the external surface of the cask.

The temperature in the inner container reached equilibrium approximately $32 \mathrm{hr}$ after the start of the test. The surface vimperature equilibrsted about $8 \mathrm{hr}$ after the inner cavity. Table 3.1 lists these recorded tempra'ures and the corresponding extrapolated temperatures. 
The test to measure the effects of ( reet sun was colducted during the first week of December ami the thermocouples again measured the same locations as in the "shade" tast. The weather was clear and cool with bright. sunny days.

The cask and its skid were placed outside on a bitumen surface in full sunlight and the heater in the inner container was adjusted to $150 \mathrm{~W}$. The temperature in the cavity reached a maximum in about $42 \mathrm{hr}$ and remained there for the remainder of the test. The surfaxe temperature also took about 42 hr to equilibrate and it remained constant thereafter. Table 3.2 fists the temperatures attained at the three locations and the tem,y.ratures calculated for $13 \mathbf{w}^{\mathrm{j}} \mathrm{F}$ arrieient conditions.

The neoprene gasket area reached a temperature of approximately 105' F 1192: F extrapolated). Since the maximum operating temperature of the mioprene gasket material is $300^{\circ} \mathrm{F}$, the package will operate properly under normal temperature conditions required by the regulations.

Table 3.1. Cask temperatures with a $150 \mathrm{~W}$ source, deterwined in the shade

(inside crane bay)

\begin{tabular}{lcc}
$\begin{array}{l}\text { Measurement } \\
\text { location }\end{array}$ & $\begin{array}{c}\text { Measured } \\
\text { temp } \\
\left({ }^{\circ} \mathrm{F}\right)\end{array}$ & $\begin{array}{c}\text { Extrapolated } \\
\text { temp } \\
\left({ }^{\circ} \mathrm{F}\right)\end{array}$ \\
\hline Ambient & 70 & 100 \\
Dutside surface & 91 & 121 \\
Inside cavity & 185 & 215 \\
\hline
\end{tabular}

Table 3.2. Cask temperatures with a $150 \mathrm{~W}$ source, determined in the sun

(on bitumen surface)

\begin{tabular}{lcc}
\hline $\begin{array}{l}\text { Measurement } \\
\text { losation }\end{array}$ & $\begin{array}{c}\text { Measured } \\
\text { temp } \\
\left({ }^{\circ} \mathrm{F}\right)\end{array}$ & $\begin{array}{c}\text { Extrapolated } \\
\text { temp } \\
\left({ }^{\circ} \mathrm{F}\right)\end{array}$ \\
\hline Ambient & 43 & 130 \\
Outside surface & 70 & 152 \\
Inside cavity & 145 & 232 \\
\hline
\end{tabular}




\subsection{Cold}

The shipping package must be abte to withstand an ambient temperature of $-10 \mathrm{~F}$ in still air and shade.

If $T_{1}=40 \mathrm{~F}$ (420RR) and no intermal heat hed is assomed, ibe final or maximum pressure $\left(P_{3}\right)$ in any cavity sealed at a pressure of 14.7 psia and a temperature of $70^{\circ} \mathrm{F}(530 \mathrm{R})$ is

$$
\begin{aligned}
P_{2} & =\frac{\left(P_{1} T_{2}\right)}{T_{1}} \\
& =11.65 \mathrm{pmin}
\end{aligned}
$$

The resulting pressure differential is less than the 25-psia differential pressure investighed in Sect. 2.3.2 A remperature of $-40 \mathrm{~F}$ is kithin the operatiag temperature rage of the seals and the stainkess sted cladding, structural components. and fasteners. Britte fracture of ibese components are above their ductike-to-britlle trassition temperatures.

The above considerations indicate that the stipubted cold conditions will not reduce the effectiveness of the packaging, and that the container conforms to the requiremerts for the cold condition of normal transport.

\subsection{Pressure}

The regulations for normal conditions of transport specify that the package must be able to withstand an atmospheric pressure of 0.5 times the standard atmospheric pressure: the resulting pressure is $7.35 \mathrm{psia}$.

Pressure evaluotion. The radionctive material is shipped in containers deseribed in Sect. 5. in addition, the inner cavity is sealed with a gasketed closure and the cover is also pasketed. All seats are capable of withstanding a differential pressure of $0.5 \mathrm{~atm}$. Checklists (Sect. 9.4) are used to determine that the gasket is in place and that the bolts are adequately tightened. The integrity of the package will, therefore, not be reduced should the ambient pressure be reduced to $0.5 \mathrm{~atm}$.

\subsection{Vibration}

The containes is of welded construction, and vibrations received in transit are not expected to affect the integrity of the seloment. All lasteners are equipped with lock washers and are not expected to loosen during such vibrations.

In addition, the casks built several years ago have operated in the transporation environment, suffering no ill effects as a re st of sibrations encountered.

\subsection{Water Spray}

The containment capabilities of the TRU Curium Shipping Container are not compromised by water spray since all external surfaces are of stainless steel. The closure xeal is impervinus to water. 


\subsection{Free Drop}

The regubtions for normal conditions of transport require that a package weighing less than 10.000 ib shall be capabte of withstanding a free drop through a distance of 4 ft onto a Athe cosentialify unyieding borizonal surface. striking the surfuce in a position at which maximum damage is expected to resul.

Freedrop enduntion. A free drop of the TRU Curium Shippiag Container through a distance of $4 \mathrm{f}$ is expected to produce a denting of the outside steel shell and some fracturing of the concrete. The fractured concrete is expected to be contained, and there should be no reduction in effectiveness of the pactage or loss of contents beczuse of the 4-fi free drop. Amalysis of the bypothetion accident involving a $30-f$ free drop indicates that damage from a

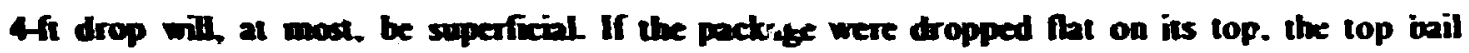
cover would be crubled. However, no other damage would result, and the effectiveness of the pactage would not be reduced.

\subsection{Penetration}

The regubtions for normal conditions of transport stipulate that the package must be capable of withstanding the impact of the hemispherical end of a vertical steel cylinder that weighr $13 \mathrm{lb}$. has a I-1/4 in. diam, and is dropped from a height of 40 in. onto the exposed surfaxe of the package that is expected to be the most vulnerabte to puncture.

ests have been conducted on simibr snipping casks and the results indicate that the eflectiveness of the stainless steel jacket will not be reduced.

\subsection{Compression}

The package must be able to withstand the greater of iwo compressive loads equal to either five times the weight of the package or $2 \mathrm{lb}$. in.' multiplied by the maximum inorizontal cross ssection of the package. The load shall be applied uniformly against the top and bottom of the package for $24 \mathrm{hr}$ in the position in which the package would normally be transported.

Compression evaluation of carrier shell. The stress $\left(\mathbf{S}_{3}\right)$ created in the steel shell by imposing on the head a weight of five :imes the weight of the package is determined as follows:

$$
\begin{aligned}
S_{t} & =\frac{5 W}{\pi d t}=\frac{S(2640)}{\pi(29)(0.375)} \\
& =386 \text { pii. }(<30.000 \mathrm{pdi}),
\end{aligned}
$$

where

$$
\begin{aligned}
& W=\text { weight of fully loaded container. } 2640 \mathrm{lb} . \\
& d=\text { diameter of container, } 29 \mathrm{in} . \\
& t=\text { thickness of container sheil. } 0.375 \mathrm{in} .
\end{aligned}
$$


The stress $\left(\mathrm{S}_{\alpha}\right)$ crated in the stee: shell by a pressure on the top of the packing of 2 psi is determined as follows:

$$
\begin{aligned}
S_{<} & =\frac{2 \pi d^{2}}{4 \pi d t}=\frac{2(\pi)(29)^{2}}{4 \pi(29)(0.375)} \\
& =39 \mathrm{psi}(<30,090 \mathrm{psi}) .
\end{aligned}
$$

The stress that was develuped in the sheil by imposing a weight of five times the weight of the packige of $386 \mathrm{lb}$ was the greater of the two compressive loads required This stress did not exceed the strength of the shell of the rontainer, therefore. the TRU Curium Shipping Container meets the requirements. No allowance was made for the additional strength that results from the cask being filled with concrete.

Comprission evaluation of inner cavity cover. The stress $\left(S_{s}\right)$ created in the inner cavity hy a weight imposed on the head of five times the weight of the pach age is determined as foilows:

$$
\begin{aligned}
S_{s} & =\frac{S W}{\pi \mathrm{dt}}=\frac{S(2640)}{x(12)(0.250)} \\
& =i 400 \text { psi }(<30,000 \mathrm{psi}),
\end{aligned}
$$

where

$\underline{N}=$ weight of fully loaded container, $2640 \mathrm{lb}$,

d =- diameter of inner cavity cover, 12 in..

$t=$ thickness of inner cavity cover, 0.250 in.

The stress $\left(\mathrm{S}_{d}\right)$ created in the inner-cavity cover walls by a pressure on the inner cavity cover of 2 psi is determined as follows:

$$
\begin{aligned}
S_{d .} & =\frac{2 \pi d^{2}}{4 \pi d t}=\frac{2(\pi)(12)^{2}}{4(\pi)(12)(0.250)} \\
& =24 \text { psi }(<30.000 \text { psi }) .
\end{aligned}
$$

The stress of 1400 psi developed in the inner-cavity cover walls by the weight imposed of five times the weight of the package was the greater. and it did not exceed the strength of the shell of the cover. Therefore. both the carrier shell and the cover for the inner cavity can withstand the conditions of the compression lest.

\section{COMPLIANCE WITH STANDARDS FOR HYPOTHETISAI. ACCIDENT CONDITIONS}

The standards for the hypothetical accident conditions stipulate that a container used for the shipment of fissile or large quantities of radioactive material shall the designed and constructed in such a manner and its contents limited so that, if it is subjected to the specified 
free-drop. puncture. thermal. and water-immersiots conditions. the following requirements would he met:

I. The reduction in shielding would not be sulficient to increase the external raciation dose rate to more than $1000 \mathrm{mR} h$ a: a distance of 3 ft from the sitside suface of the package.

2. No radivetive material would be released from the package except for gases containing total radioactivity not to exceed $0.1 \%$ of the total radioactivity of the contents of the packag:.

3. The contents would remain subcritical.

\section{I Frex Drop}

The first in the sequence of hypothetical accident conditions to which the cask must be subjected is a free drop tnrough a distance ui 30 ft onto a flat. essentially unyielding horizontal surface, striking the surface in a position at which the maxinum damage is expected to occur.

Damage to the ORNL Curium Shipping Cask was etaluated by assuming the cask struck the unyielding surface in one of three different orientations. These included impact on the side. the top end. and the top corner.

\subsubsection{Impect on side}

A series of tests was performed at the Brookhaven National Laburatory (BNL) in which three concrete-shielded waste-vault containers were dropped 30 fi onto a I0-in.-thick slab of armor plate." The container. having outside dimensions of $4 \times 8 \times 4$ ft and designed with a concrete shielding thickness of 17 in.. survived the impact with only hairline cracks observable. Its shielding efficiency was reportedly unimpaired.

The BNL containers were of bare concrete made from normal type stone. Review of these test results indicates that concrete in rapid compressior. (such as in an impact) will crumble and shear on fault planes: however. in the case of the TRL Curium Container. the fragments formed will be held in place by the reinforcing wire and the outer steel shell. which will become distorted only in the impact ared.

These tests. together with observations made of high-speed impact onto reinforced concrete bridge abutments. suggest that the concrete in the immediate area of the impact will fragment: however. the concrete only slightly removed from the impact area will be undamaged. Because the concrete fragments will remain approximately in their original area as a result of the reinforcing wire and the stainless steel shell. the shielding is not expected to be significantly reduced. In addition. cracking. probably all hairline, would not be in a straight line and would not allow streaming if radiation.

\subsubsection{Impaci on ion Mange}

It can be demonstrated that the shell of the cavity "lop-hat" covẹr lails by compression in lieu of buckling. 
The buckling load is calculated' as follows:

$$
\left.F_{\mathrm{BX}}=\frac{\left[\mathrm{Et}^{2}\right.}{\left(1-\mathrm{V}^{2}\right)}\right]^{1 / 2}\left(\frac{1}{\mathrm{R}}\right)
$$

$$
=190,800 \mathrm{in} . \mathrm{tb} \text {. }
$$

where

$E=\operatorname{modulus}$ of elasticity. $29 \times 10^{\circ}$.

$:=$ thickness of cover shell. 0.25 in..

$V=$ Poisson's ratio. 0.300.

$R=$ inside shell radius. 5.75 in

=The compression load is calculated as follows:

$$
F_{C P}=\sigma t=15,000 \text { in }-1 b \text {, }
$$

where

$$
\begin{aligned}
& \sigma=\text { dynamic yield steel, } 60,000 \text { psi." } \\
& t=\text { thickness of cover shell. } 0.25 \text {. }
\end{aligned}
$$

Because the cavity top-hat cover will fail under compression with a load of only 15.000 Ib in., or less than $10 \%$ of the load required for failure in buckling. it can be assunk,d that the cover will fail under cempression when an axial load is applied. The energy required to crush the side walls of the top-hat cover is found as described below.

The energy absorbed in deforming the cover side walls a distance. $d \Delta$. is calculated as follows:

$$
d u=F d \Delta
$$

where

$$
\begin{aligned}
d u & =\text { incremental energy absorbed, } \\
F & =\text { force. lb. } \\
d \Delta & =\text { incremental deformation. }
\end{aligned}
$$

The length of the deformed side is calculated as follows:

$$
\Delta=\boldsymbol{e l}
$$

where

$$
\begin{aligned}
& \Delta=\text { deformation, in.. } \\
& C=\text { fraction deformed, in. in., } \\
& L=\text { length of side, in. }
\end{aligned}
$$


Differentiatine to. (82). it is deternined that

$$
d \Delta=L d \epsilon
$$

Force is found as follows:

$$
F=\sigma_{\mathbf{r}} A_{i}
$$

wirete

$\pi_{\mathrm{e}}=$ stress, psi,

$A_{i}=$ cross-sectional area ci metal in sides of cover, in.'.

becalise

$$
\sigma_{e}=f(\epsilon)
$$

where

$$
f(\epsilon)=\text { function of } \epsilon
$$

Substituting Eo. (85) into Eq. (84) gives:

$$
F=\left\{(\epsilon) A_{i}\right.
$$

Further. substituting Eqs. (86) and (83) into Eq. (81) yields:

$$
\mathrm{du}=\mathrm{f}(\epsilon) \mathrm{A}_{\mathrm{i}} L \mathrm{~d} \epsilon
$$

Integrating Eq. (87),

$$
1
$$

$$
U=A_{i} L \int f(\epsilon) d \epsilon
$$

It has been determined that

$$
f(t)=\sigma_{e}=4.33 \times 10^{5} t+60,000 \text { (see ref. 9): }
$$

therefore, substituting Eq. (88):

$$
U=A_{i} L \int_{0}^{e}\left(4.33 \times 10^{5} \epsilon+60,000\right) d \epsilon
$$

Integrating Lq. (90) and solving within the limits of zero of $t$. We find that

$$
\begin{aligned}
U & =\left[\frac{4.33 \times 10^{5}}{2 \epsilon^{2}+6.000 \epsilon}\right] A_{i} L=(54.125+30.000)(18.46) \\
& =1.553 \times 10^{6} \text { in. } 16 .,
\end{aligned}
$$


where

$\epsilon=0 . \therefore$

$A_{i}=$ arra a ${ }^{-}$metal in shell wall. 9.23 in.' $^{2}$

$L=$ length of sides of shell wall. $20 \mathrm{in}$.

The maximum energy (Um) available is the energy of the falling cask. which is calculated as follows:

$$
\begin{aligned}
U_{\text {mb }} & =\underline{W}_{T} h=2640(360) \\
& =0.9504 \times 10^{6} \text { in. }{ }^{\circ} \text {. available: }
\end{aligned}
$$

utere

$$
\begin{aligned}
\underline{W}_{r} & =\text { weight of cask, } 2640 \mathrm{lb} . \\
h & =\text { drop height. } 360 \mathrm{in} .
\end{aligned}
$$

The energy, $\boldsymbol{l}_{\mathrm{m}}$. that is atailable when a cask is dropped is not as great as the energy $z$ quired to crush the side walls of the top hat $\left[U, F_{f}(? ?)\right]$. An intermediate value of $\epsilon$ is therefore determined using the available energy fourd in 19. (92). It wis found that

$$
t=0.368
$$

The stress in the cover sides attain.t is tire aciual final alue by solving Eq. (8.5) was

$$
a=2.195 \times 10^{5} \mathrm{psi} \text {. }
$$

The force was determined by solving

$$
\begin{aligned}
\equiv & =\sigma A_{i}=\left(2.195 \times 10^{5}\right)(9.23) \\
& =2.026 \times 10^{6} \mathrm{ib} .
\end{aligned}
$$

The maximum acceleration $\left(x_{m}\right)$ was found as follows:

$$
\begin{aligned}
g_{m} & =\frac{F}{W_{-T}}=\frac{2026}{2640} \times 110^{6} \\
& =767 \times \mathrm{g}
\end{aligned}
$$

The furce on the cight $\mathrm{J} / 2$-in. studs holding the shielding plug is determined from

$$
\begin{aligned}
F_{P} & =W_{\text {sgen }}=103 \times 767 \\
& =79,000 \mathrm{ll} .
\end{aligned}
$$

where

$-F_{p}=$ force on studs,

$\underline{w}_{s}=$ weight of shielding plug and contents. $81+22 \mathrm{lb}$. 
The siress on eacil bolt is determint as follows:

$$
\begin{aligned}
\sigma & =\frac{F_{p}}{N A}=\frac{79,000}{8(0.142)} \\
& =09,500 \mathrm{psi} .
\end{aligned}
$$

where

$\mathbf{N}=$ number of bolts. 8 .

$A=$ area of bolt. $0.142 \mathrm{in}^{2}$.

The stress of 69,500 psi is such that the bolts. under the extreme accident condition of dropping the cask on its top, will yield but not break. (Figure 4.1 indicates that stress would have to exceed 90,000 psi before bolt fracture would occur). ${ }^{20}$

The bolts will not rupture or break to release the shielding plug: in any rase. the plug could not fall out becaus the cask is resting on it. Containment of the cavity will have be $n$ broken; however, thiswill happen in the fire when the plug gasket is destroyed. The contents of the inner cavity must therefore be contained in a $2 R$-type container or be encapsulated as described in Sect. 5.

\subsubsection{Impact on top corner}

The ability of the bolts to hold the shielding plug in the cavity when the cask is dropped on its top comer depends on their capability to u.....iund the stresses genernted in an impact as a result of cask deceleration. These deceleration forces will act on the plug and the zontents of the inner cavity. Upon impact on an edge. the steel shell and concrete immediately inehind it

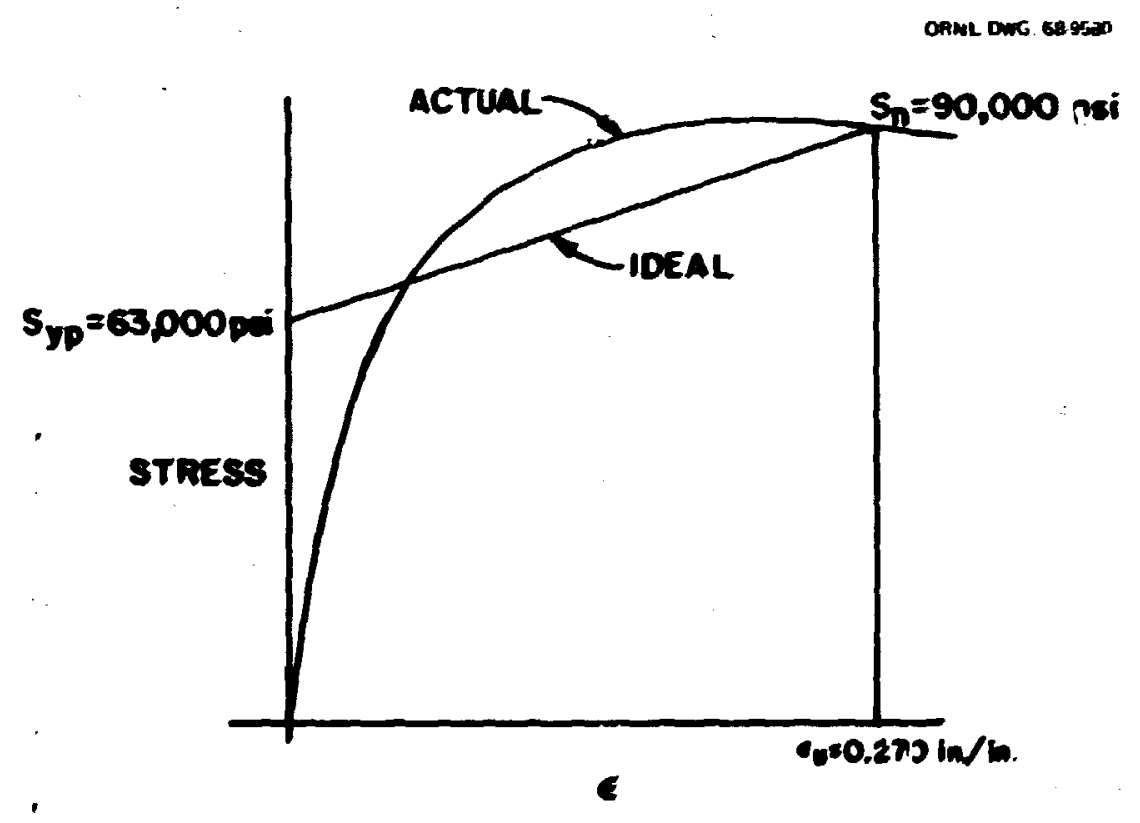

Fig. 4.1 Stresu-strain curve for annealed 4140 -series steel. 
will stan to crush. A computer program was developed (see Sect. 9.3) to analyze the forces and acceleration involved in an edge drop. This program calculates the cask deceleration as a function of the specific energy (in. th in. ') of concrete.

As a result of the analysis. it was found that a specific conerg: of 28.000 in.- Ib in.". which is considered to be very high for concrete encased in steet. produces a deceleration of $450 \mathrm{~g}$ Applying this $g$-tevel to the weight of the cask lid $>$ ad contents. the force $(f$, ) on the cight I 2 -in. studs holding the shiclding plug is determined as foll,wr:

$$
\begin{aligned}
F_{p} & =\underline{w}=103(450) \\
& =46,350 \mathrm{lb} .
\end{aligned}
$$

where

$\underline{w}_{s}=$ weight of plug plus contents of inner cavity. $103 \mathrm{lb}$.

The stress (o) on each bolt is determined from:

$$
\begin{aligned}
\sigma & =\frac{F_{z}}{N A}=\frac{46,350}{8(0.142)} \\
& =40,800 \mathrm{psi}(<90,000 \mathrm{psi})
\end{aligned}
$$

where

$x$ = number of bolts. 8 .

$A=$ tensile stress area of bolt. 0.142 in. $^{2}$.

Because the stress in the bolts is below the yield stress, the bolts are adequate and the plug will remain sealed on the top corner drop.

The computet prograr. described in Seer. 9.3 was used to experimentally calculate the deformation resuling from a $30-\mathrm{ft}$ comer drup. Results indicatz that the shielding remaining after he defermation is more than adequate to safely shield the cask.

\subsection{Punctire}

The second in the sequence of hypothetical accident conditions requires that the cask must be subircted to a free drop through a distance of $\mathbf{4 0} \mathrm{in}$. striking the top and of a vertical mild-steel bar mounted on an ussentially unyielding. horizontal surface. At the moment of impact, the cask must be in a position at which maximum damage is anticipated. The mild-steel bar shall have a diameter of 6 in., with the top horizontal and its edge rounded to a radius of $I 4$ in. and the bar shall be of such length that it will cause maximum damage to the cask. but not less, than 8 in. long. The long axis of this bar shall be normal to the surface of the cask upon impact.

To analy.x the puncture accident, a rather conservative model can be used which assumes that all the energy absorbed by the cask is absorbed by the outer stainless strel and none is absorbed by the concrete shrelding. A testing program. conducted at ORNL. evaluated the resistance to puncture of cast $2 \times 4 \times 8$ in. limonite concrete bricks. There approximate twelfth-scale. I6-1b concrete bricks covered with 30 -mil stainken steel shee? were dropped from 
40 in. Onto a 12 -in diam punch The 30-mil stainlass steel sheet covering the brick did not puncture. but there was extersive frarture of the trick and some fracture of the limonite ageregate. Full-size aggregate was used in all tests. To estimate the effect of the puncture test on the full-size cask. these tests were scaled up based on the linear dimension of the punch ta factor of 12). The scaled-up weight of the test is then $16 \mathrm{lb} \times 12^{3}$. or $27.348 \mathrm{lb}$. and the scaled-up shell or cover plate thickness is 0.030 in. $x 12$ or 0.36 in.

Because the TRC Curium Shipping Container weighs 2640 lb. which is considerably kess than $10 \mathrm{x}$ of the scaled-up weight. the 38 -in. side and bottom plates are more than adequate. and the 14 -in. top plate is abo adequate to resist puncture in the prescribed test of the 40-in. drop onto a 6-in.diam piston. On the basis of a different set of test data." I 4-in. 304L. stainlas steal was determised to be adequite for a cask weighing $2640 \mathrm{lb}$.

\subsection{Thcrmal Evaluation}

The thind in the sequence of hypothetical accident conditions specified by the regulations to which the cask must be subjected is a 30 -min exposure te a source of radiant heat (fire) having a temperature of $1475^{\circ} \mathrm{F}$ and an emissivity coefficient of 0.9 or equivalent. For calculational purposes. it shall be assumed that the package has an absorption coefficient of 0.8. The package shall not be cooled artificiaily until after the 30 -min test period and the temperatu.e at the center of the package has begun to fall. or until $3 \mathrm{hr}$ following the test period.

\subsection{Thermal properites of materials}

The thermai properties of materials used to compute the temperaturs distribution under steady-state and transient conditions are listed in Table 4.1 (see Sect. 3.1.I).

\subsubsection{Thermal accident analysis}

A thermal analysis of the TRU Curium Shipping Container (using the HEATING5 code)." assumed that the container was exposed to the hypothetical accident conditions described above. The temperature distribution in the cask was initialized. assuming an internal heat source of 500 btu hr. an ambient tempera:ure of $100_{7}$ F. a solar heat load of 44 Btu hr imposed on the projected container surface area, and dissipation of heat from the sides and top of the cask by convection and radiation. The container was then exposed to the $1475^{\circ} \mathrm{F}$ radiation heat source for $30 \mathrm{~min}$, after which the original ambient conditions were reimposed.

The inner cavity temperature was initially $179^{\circ} \mathrm{F}$; this temperature increased and peaked at $412^{\circ} \mathrm{F}$ approximately $3 \mathrm{hr}$ after the end of the fire. At this temperature. any residual moisture $(<0.1 \%)$ would increase the internal pressure of the inner container by less than I atm. The lead shielding remained below this temperature. The maximum concrete temperature oceurred at the outer surface, reaching $919^{\circ} \mathrm{F}$ at the end of $30 \mathrm{~min}$.

As a result of these temperatures, the TRU Curium Shipping Container gaskets are expected to be destroyed." and some water may be driven out of the concretc. Only the outer 2 in 2-1 2 in. of concrete is expected to be affected by temperatures above $212 \% \mathrm{~F}$ : consequently. the effectiveness of the shielding will not be impaired to any significant extent. 
Table 4.1. Thermal properties of materlals used to compute temperature distribution

\begin{tabular}{|c|c|c|c|c|}
\hline Material & $\begin{array}{l}\text { Temperature } \\
\left({ }^{\circ} \mathrm{F}\right)\end{array}$ & $\begin{array}{l}\text { Thermal conduct lvity } \\
\left.\text { [Btu } h r^{-1} \mathrm{ft}^{-1}\left({ }^{\circ} \mathrm{F}\right)^{-1}\right]\end{array}$ & $\begin{array}{l}\text { Density } \\
(1 \mathrm{~b} \text { in. } \\
-3)\end{array}$ & $\begin{array}{c}\text { Heat } \\
\text { capac1ty } \\
{\left[B t u b^{-1}\left({ }^{\circ} \mathrm{F}\right)^{-1}\right]}\end{array}$ \\
\hline Fuel & & 6.62 & 0.0978 & 0.214 \\
\hline Seal & & 0.143 & 0.0347 & 0.469 \\
\hline $\begin{array}{l}\text { Stainless steel, } \\
\text { 304L }\end{array}$ & $\begin{array}{r}32.0 \\
212.0 \\
932.0 \\
1292.0 \\
1472.0\end{array}$ & $\begin{array}{r}7.736 \\
9.428 \\
12.571 \\
14.989 \\
15.000\end{array}$ & 0.282 & 0.130 \\
\hline Air & $\begin{array}{r}32.0 \\
212.0 \\
392.0 \\
572.0 \\
752.0\end{array}$ & $\begin{array}{l}0.017 \\
0.018 \\
0.022 \\
0.026 \\
0.029\end{array}$ & $4.11 \times 10^{-5}$ & 0.240 \\
\hline Concrete & & 0.600 & 0.090 & 0.21 \\
\hline
\end{tabular}


Ony limited experimental dita are avaibabte on the temperature distribution in conrete exposed to a fire." Table 4.2 confurms that concrete. when exposed to a fire of 30 -min duration. is not affected to any great depth.

The source inside the TRU Curium Shipping Container will always be conained in either

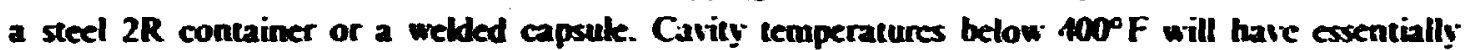
no effect on the integrity of these inner containers. Table 4.2. Heasured temperatures in concrete
exposed to a $1300^{\circ} \mathrm{F}$ fire ${ }^{a}$

\begin{tabular}{ccc}
$\begin{array}{c}\text { Distance from } \\
\text { face (in.) }\end{array}$ & $\begin{array}{c}\text { Temperature } \\
\text { after 15 min } \\
\left({ }^{\circ} \mathbf{F}\right)\end{array}$ & $\begin{array}{r}\text { Temperature } \\
\text { after } 30 \text { min } \\
\left({ }^{\circ} \text { F) }\right.\end{array}$ \\
\hline 0.5 & 716 & 950 \\
1 & 356 & 608 \\
2 & 158 & 230 \\
\hline a Datil based on ref. 14.
\end{tabular}

\subsection{Water Immersion}

The fourth in the sequence of hypothetial accident conditions to which the cask must be subjected is immersion in water in such a manner that all portions of the package are under at least $3 \mathrm{ft}$ of water for not less than $8 \mathrm{hr}$.

It is assumed that all rubber gaskets will be destroyed in the fire. Howeve since the solid radioactive material is contained in seakd capsules whose integrity has mained intact throughout the accident sequence. no material will be lost. In addition. " mo moderation afforded by the water is not detrimental. Therefore the cask will mext the water immersion requirements.

\section{CONTAINMENT}

Containment inr radinactive material transported in the TRU Curium Shipping Container is provided by welded special-form capsules. These capsules are occaninnally enclosed in a $2 R^{15}$ container for ease of handling.

\section{I Containment Boundaries}

The containment boundaries for the shipping options available with the curium cask are the cask cavity sealed by its gaskets (see Fig. 1.2) and an inner container that meets special form requirements. Any material carried in a $2 R$ container will be enclosed in a welded capsule. Ib, all cases, there will be at least nue welded seal hetween the source and the cask cavity.

\subsection{Special-Form Shipments}

The welded encapsulation provides primary containrient for all special-form shipments (see Figa. 5.1 through 5.4 for examples of special-form encapsulations). If the niaterial is doubly 


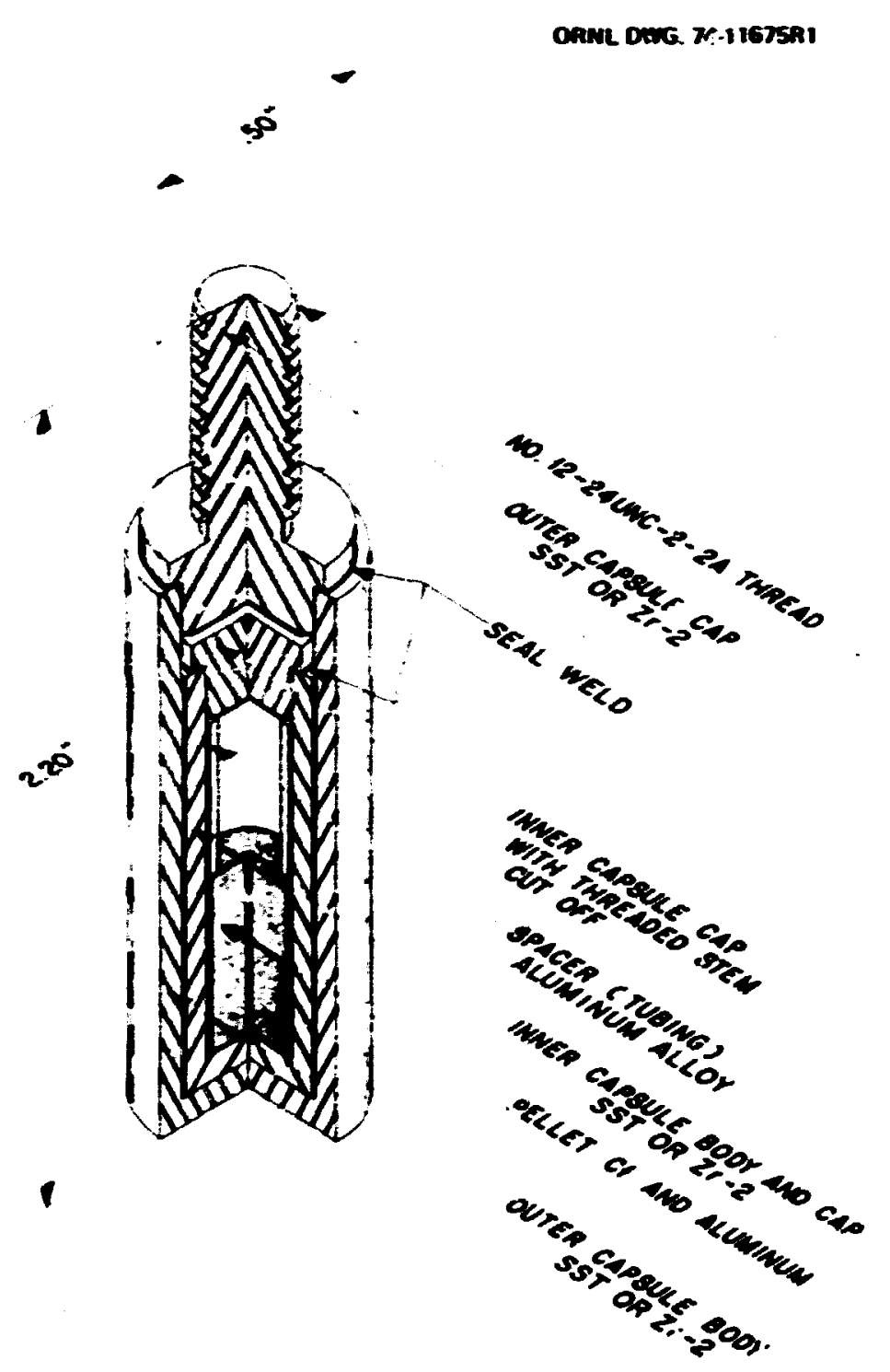

Fig. 5.1 Assembly for TRU shipment of "Cf (for details see Drawing M-12175-CP-335-D), a iypieal specialform inner container. 


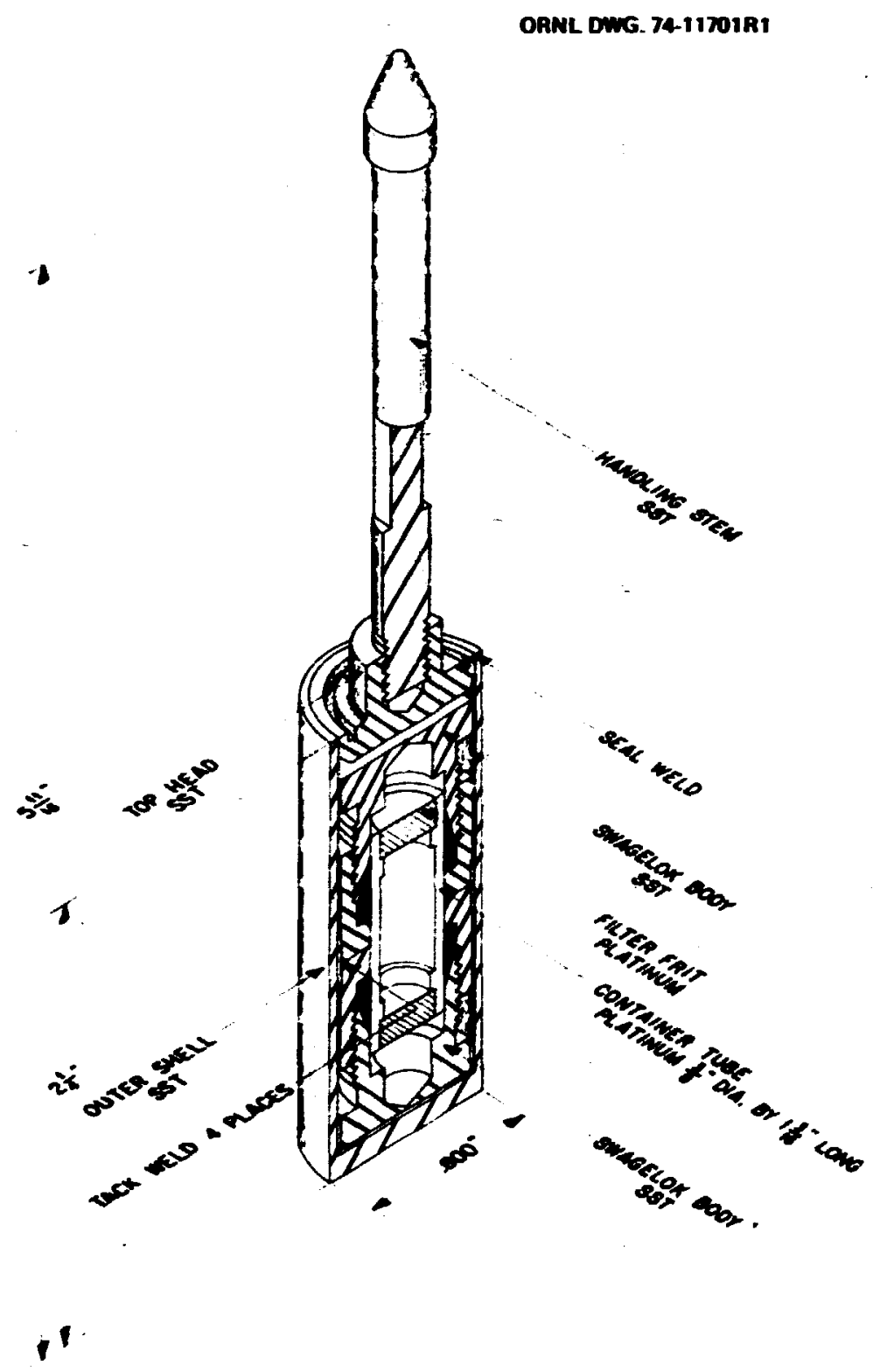

Fig. 5.2 Standard neutron source container (for details see Drawing M-12175-CP-636-D), a typical special-form inner container. 


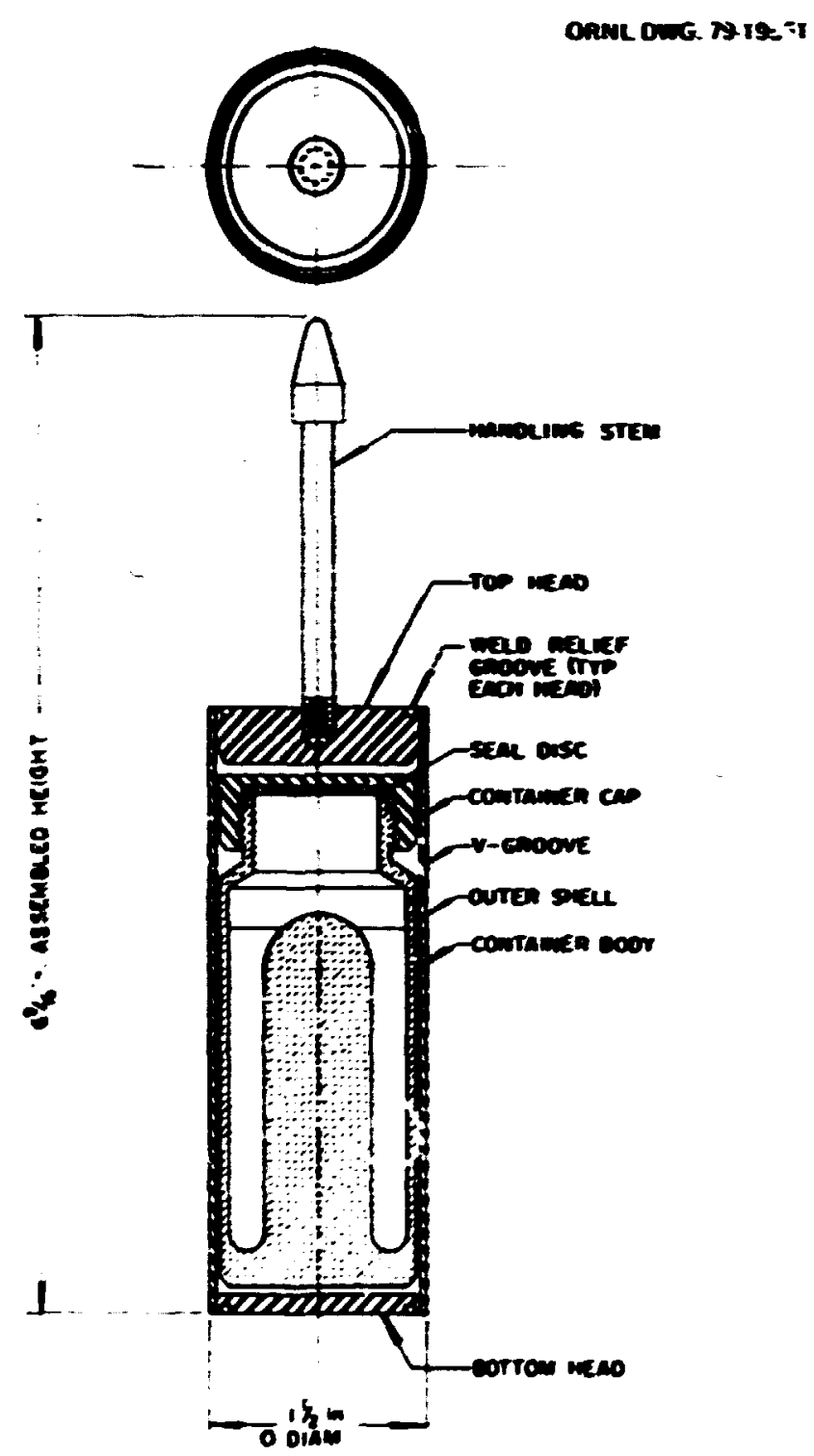

5.3 Curium shipping capsule used th the TRU processing plant. 


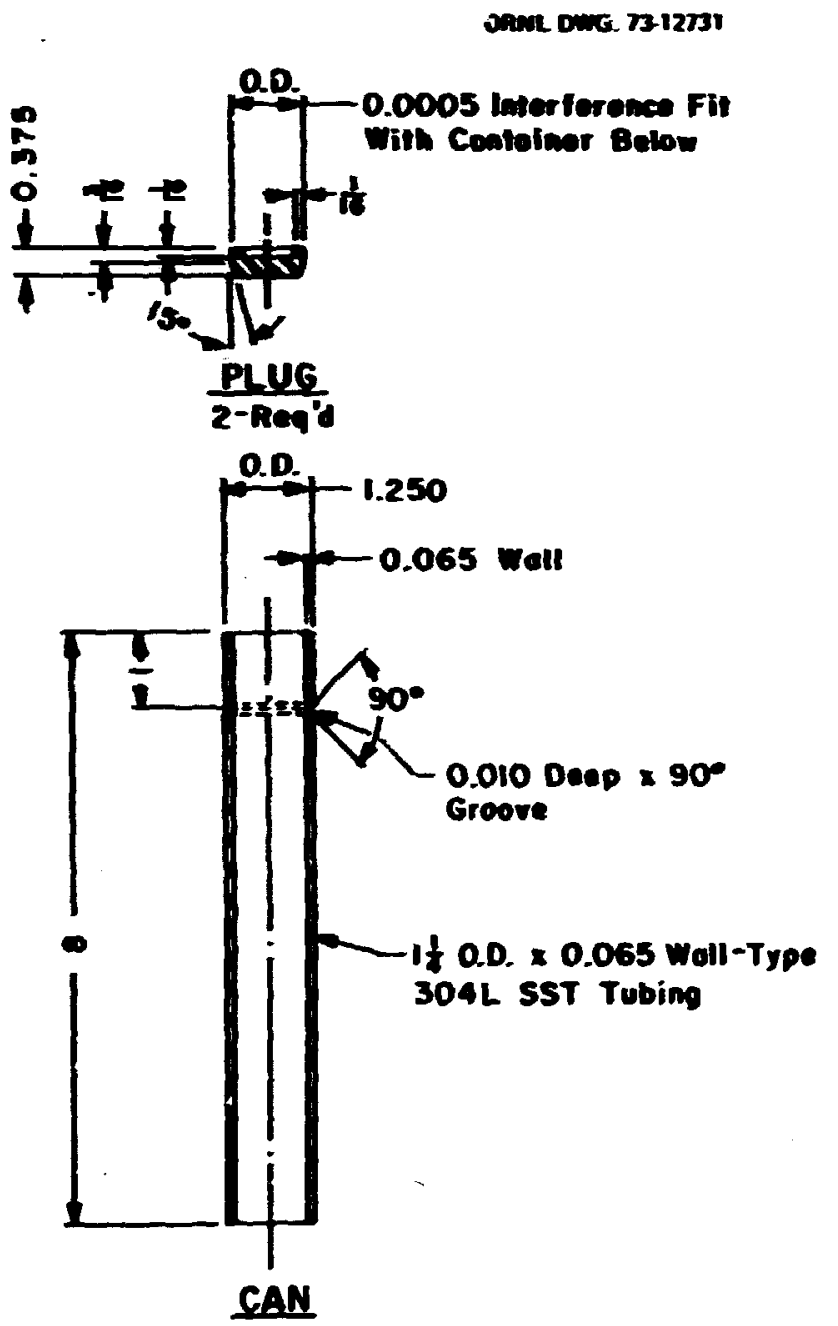

Matorial: 304L SST

5.4 Singly encapsulated container for shipping powder. 
encapsulated, the outer welded capsule provides secondary containment. Visual inspection of these lines of containment are performed on a routine basis. and the welds are radiographed. The cask seals form an additional line of containment. The cask is equipped with gasketed closures that are keaktight during normal transport. An accident might result in a rupture of the seals, but the contents in their primary containers would remain in the cavity.

The ORNL Operations Division is authorized by Laboratory management to certify that a material conforms to the special form requirements of Appendix D of 10 CFR Part 7I. ${ }^{\text {th }}$ The tests prescribed have been performed on a number of capsule designs. When a capsule is stmilar in design to a capsule previously tested (i.e., in relation to size. mass. wall thicknesses. materials, weld, etc.). the design is certified as passing the special-form requirements based on previous test results. If this similarity does not exist, it is required that a prototype be tested as prescribed.

\subsection{Containment Requirements for Normal Conditions of Transport}

The test sequence for containers of special-form materials is more severe than for those with normal conoitions of iransport. The pressure increases that are encountered will be less than those experienced in the thermal test for special-form materials. No loss of primary coolant (air) is expected.

The $2 R$ containers, housing a welded capsule, are designed for pressures and temperatures in excess of those encountered in normal transport. No release of radioactive material, loss of coolant (air). or contamination of coolant should occur.

\subsection{Containment Requirements During the Hypothetical Accident}

The test series for special-form containers demonstrates that special-form encapsulation will not fail or leak the contents as the result of the free falls. The thermal test temperatures of special-form containers exceed those experienced by the inner cavity contents during the hypnthetical accideni (see Sect. 4.32); hence, no release will occur during the thermal exposure. The water immersion test for spectal-form containers is identical to that specified in the hypothetical accident conditions.

The $2 \mathrm{R}$ containers, housing a welded capsule, are designed for pressures and temneratures in excess of those encountered in the hypothetisal accident. 


\section{CRITICALITY}

The analysis for the singl: container given below is adequate for an infinite array of similar containers because the concrete shielding assires essentially no inter iction.

A study ${ }^{17}$ has been made of the criticality of curium and other transuranium elements under conditions of optimum moderation and water reflection. The results are presented in Table 6.1.

The quantity of fissile isotopes to be carried by this cask will be limited to $10 \mathrm{~g}$ with the exception of ${ }^{23} \mathrm{Cf}$ which will be limited to $2 \mathrm{~g}$. Approval of the use of this cask for that quantity of fissice material has been granted by an ORNL Nuclear Safety Review (see Sect. 9.5).

Since the quantities of fissionable isotopes carried is below all minimun critical masses for these isotopes under optimum moderation and reflection, and since the cask effectively isulates the contents from neutron interaction with packages of sinnilar design, unlimited numbers could be stacked together without creating a criticality problem. Thus the package is adequate for Fissile Class I shipments.

Table 6.1. Minimum critical masses of fissile transportation nuclides

\begin{tabular}{|c|c|c|c|}
\hline \multirow[b]{2}{*}{ Nuclide } & \multicolumn{2}{|c|}{$\begin{array}{l}\text { Mass } \\
(\mathrm{g})\end{array}$} & \multirow[b]{2}{*}{$\begin{array}{c}\text { Concentration } \\
\text { (g/liter) }\end{array}$} \\
\hline & Critical & $\begin{array}{c}\text { Subcritical } \\
\text { limit }\end{array}$ & \\
\hline $242 \mathrm{~m}_{\mathrm{Am}}$ & 23 & 10 & 5 \\
\hline $243 \mathrm{~cm}$ & 213 & 150 & 40 \\
\hline${ }^{245} \mathrm{~cm}$ & 42 & 25 & 15 \\
\hline${ }^{247} \mathrm{~cm}$ & 159 & 120 & 60 \\
\hline${ }^{249} \mathrm{Cf}$ & 32 & 20 & 20 \\
\hline${ }^{251} \mathrm{Cf}$ & 10 & 3 & 6 \\
\hline
\end{tabular}

a Approximate concentraitr 7 at which minimum critical mass occurs. 


\section{SHIEIDING EVAILATION}

\section{T.I Discussion and Results}

The TRU Cutium Shipping Container is designed so that its cavity is surrounded by I 4-in.-thick stainless steel and a $3 \times$-in.-ihick outer shell. The shiclding hetween the two is fillod with 9-3 4-in. Blackburn limovite concrete and approximately $I$ in. of lead. The shiclding effectiveness has been checked with transuranium sources and found to be adequate. $A$ 4X.X-g source of ${ }^{\text {Hs }} \mathrm{Cm}$ nroduced a reading of 1 -mrem hr gammas and 3-m-em hr neutrons at a distance of 6 ft from the sude of the truck. In this case the driver's conpartment registered approximately I mrem hr. The cask contents $u$ ill be limited so that the soutci will not excecd the allowable radiation dose limits of the DOT regulations." The shielding effectiveness will not be reduced by the hypothetical 30-'t drop accident. hecause concrete fractures in an intergranular manner providing a labyrinthine pathway for radiation. allowing no possibility of radiation streaming.

\section{R. QLAI.ITY ASSLRATCE}

\section{I Fabrication. Inspection, and Acceptance Tests}

This container was fabricated in the ORNI. shops in actordance with normal stop labrication precedures and prior to the adaption of a formal quality assurance program by the IOEE and ORNI. Material was specified on the original drauings as -304I. SST." Material uas withdrayn Irom Bill of Materials Stores stock. The casks were inspected by OR Ni. Snop Inspection Department personnel lor conformance (1) the drauings. quality of uorkmunship. and compliance with welding requirements when fabricated. In the opinion of the inspecting personnel. the weldments were made in accordance with the drawings and specifications. This is further supported by the fact that these casks have operated for as many as I3 years without lailures or loss of effectuveness. The rouline operating inspection procedures specity perindic weld inspections to verify ueld integrity.

$\Lambda$ formal quality assurance program has now been prepared." and furure shipping containers will be constructed in accordance with provisions set forth in this program.

\subsection{Operating Procedures and Routine irspection}

The Transuranium Processing Plant, Chemical Technology Division. has established operating and routine inspection prncedures and standard checklists to ensure that all shipments are safe and that they comply with DOE regulations as well as all ORNI. procedures and regulations. A copy of iypical procedures and checklısts are presented in Sect. 9.4

\section{- 8.3 Periodic Maintenance and Inspection}

Inspections are required prior to each shipment, or biennially (see Sect, 9.4). Míaintenance will be required only when routine inspections indicate damage. 


\section{I Drawing}

TP.U Curium Shippinz Container Assembly and Details - M-12175-CP-078-E-3 

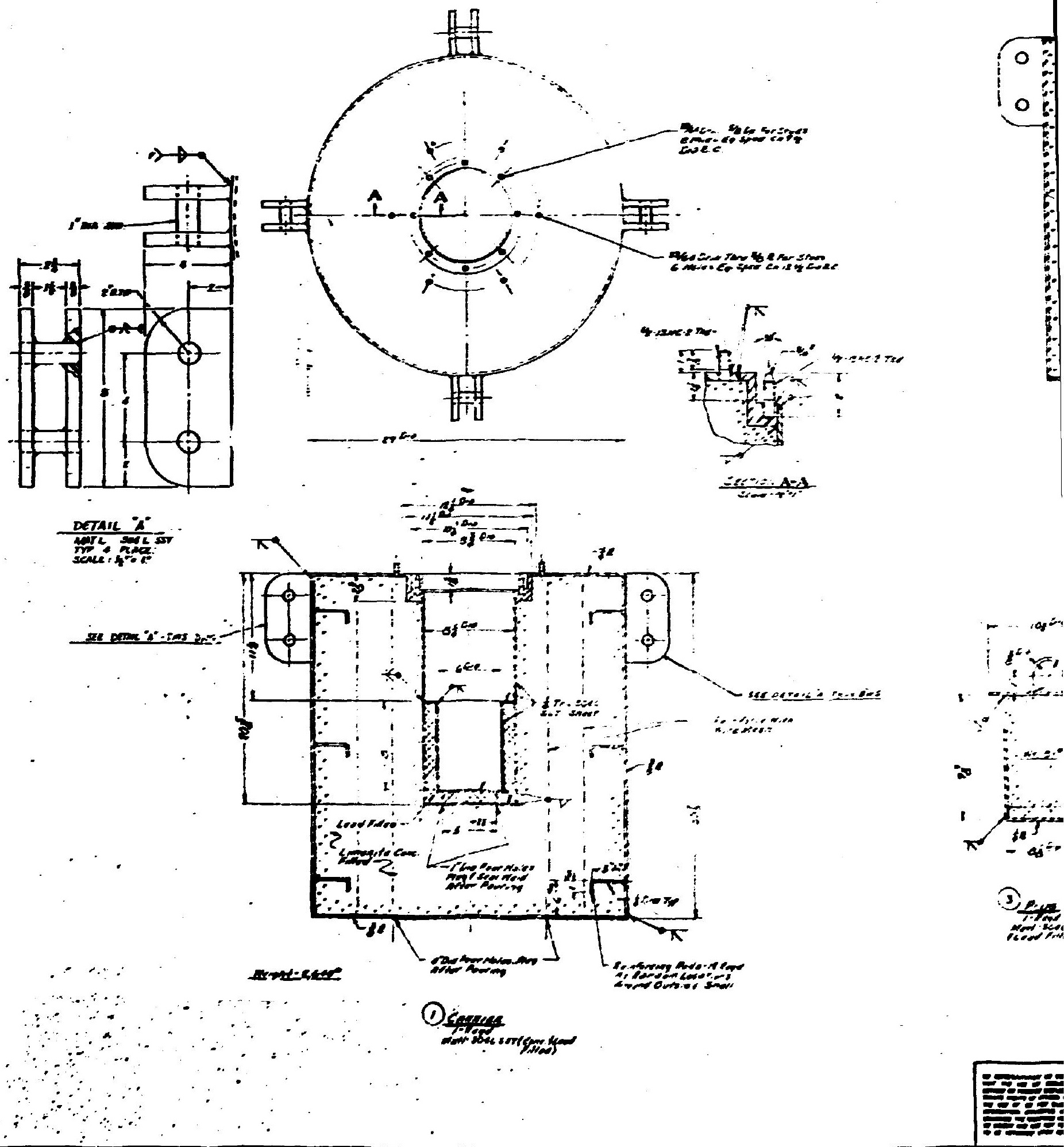
9.2 Approval Documents 


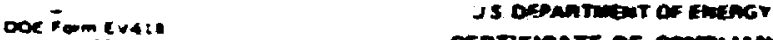

$$
\begin{aligned}
& \text { centificate of communce } \\
& \text { is creis }
\end{aligned}
$$

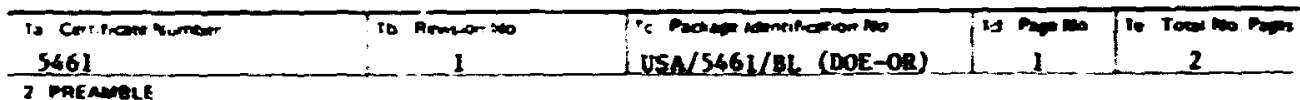

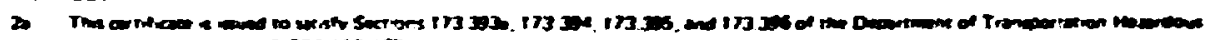

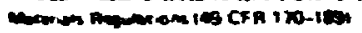

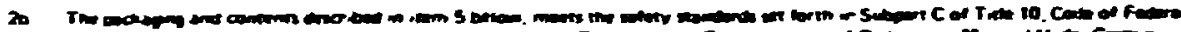

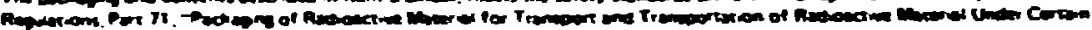
conatens

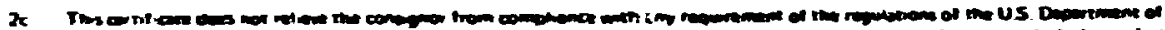

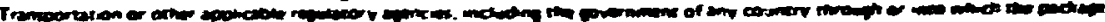
The remoerse

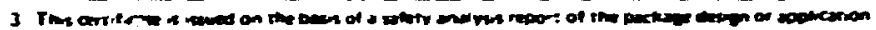

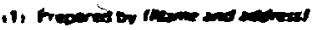

Dak Ridge bational Labotatory

Post Office Bax $x$

Oak Ridge, Tennessee $\mathbf{3 7 8 3 0}$

Safety Analysis Report for Packasing

Dec. 1979

(sure) of the oak afde kational Labotatory

Irw carfo Shipplas containex

Report Ho.: Opl-514]/21

a comontions

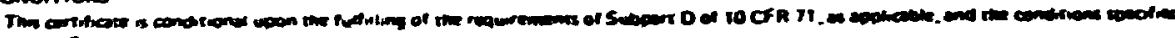
mim 5 onitom

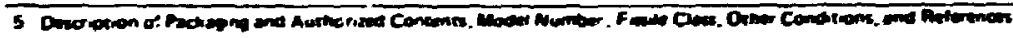

a. Packatin:

(1) Model: owi Ta curiw shipping Container

(2) Description:

Packaging for solid radiaactive materials. The coacainer is a right circular cylinder $29 \mathrm{In}$. In dianeter and $307 / 8 \mathrm{in}$. high vith a $304 \mathrm{~L}$ stainless steel outer shell, which is $3 / 8 \mathrm{in}$. chick for the botcos and stdes and $1 / 4$ in. for the cop. The shell for inner cavicy is $81 / 4 \mathrm{fn}$. dianeter $\times 191 / 4 \mathrm{In}$. deep, is fabricated froe $1 / 4$ in. thick 3041 staloless steel plate, and is recessed $13 / 8 \mathrm{in}$. from c.': top. The cavity shell is a cylinder 8 1/4 In. diacter $x 191 / 4 \mathrm{in}$. high and is fabricated from $1 / 4 \mathrm{fn}$. chick 304? stalnlese steel. The inner cavicy for the radioactive materials is 6 In. diveter $x$ in. high and fabricated fro $1 / 4$ in. thick $304 \mathrm{~L}$ stainless steel. Seven-eighes in. chick lead fills the space between the sldes and botcon of the cavity shell and the inner cavity. The annulus betreen che outer shell and Inoer shell is filled with limonice conctere.

The Inner cavity is closed with a concrete-and-lead plus which is anclosed in 1/4 in. 304L atainlese seel place. A 1/16 in. thick neoprene gashet serves as a seal between the top flange of the plus and the cack body. Eicht

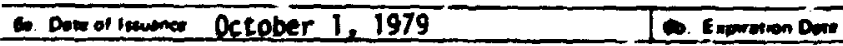
FOA THE US OFPARTEET OF ENEAGY

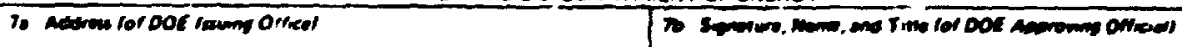

U. S. Depertent of Enerey

Post office Dox E

Dak Redee, In 37830 
Page 2 - Certificate of Compliance USA/5461/RL

(2) Description (continued)

1/2 1n. $x 13$ wC-2 nuts on studs bold the plug flange to the cask body. A 3/8 in. disweter 304L stainless steel ball is used to lift the plug.

A 1/4 In. thick 304l stainless steel plate, which covers the top flange and ball, wo beld to the top of the cask by six 1;2 in. $x$ 13 m-2 nuts on studs.

The cask is equipped with four 1/2 in. thick lifting and tie-down ears with two $1 \mathrm{fm}$. dimeter boles pez ear. The cask is aiso monted on a okdd for handling with a forklift.

The gross weight of the cask and sitd is $2800 \mathrm{lb}$.

(3) Drawing:

The packaging for the Trd Curive Shipping container is constructed in accordance with Oak Ridge tational Laboratory Draring Wo. H-12175CP-078-E-3.

b. Contents:

(1) Type anf Form of Material:

Any leotope of plutoalu, anericiu, curiu, berkelib, califoralu, and ferniu in the form of metal, uxide, chloride or other sait.

(2) Waxing quantity of aterial per package:

(1) A cotal of $10 \mathrm{~g}$ of ${ }^{239} \mathrm{Pu},{ }^{24} \mathrm{Pu},{ }^{242 \mathrm{As}},{ }^{243} \mathrm{Cu},{ }^{245} \mathrm{Cm},{ }^{247} \mathrm{C}$, and/or ${ }^{249} \mathrm{Cf}$.

(11) 38 of ${ }^{251} \mathrm{Cf}$.

(111) The balance of the tranouranic and other aon-fiastle radioactive anterials will be linted to a heat $10 a d$ of $500 \mathrm{Btu} / \mathrm{hr}$. and to the external radiation levele specified in US DOT Repulations 49 CTR Part 173.393.

(Iv) Conteate are efther singly or doubly encapsuinted is a welded contalner neeting opecial for requiremente and may be further placed in enother $[. r$ Specification 22 contniner for handling purposes. 


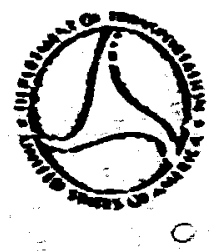

\section{DEPARTMENT OF TRANSPQRTATION HAZAREOUS MATERARLS REGULATIONS EOARD

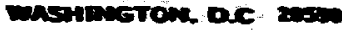

SPECIAL PSPRIT :0. 5451

This speclat parit is issucd girstent to the aithority of 49 CFa 173.22(a)(1), Depertmant of Trenzportztian (DCT) Lazardous Ezterials Reziletscns, 23 aroncied.

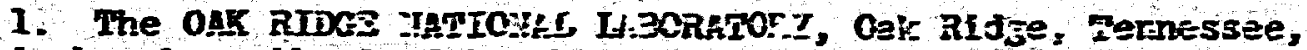

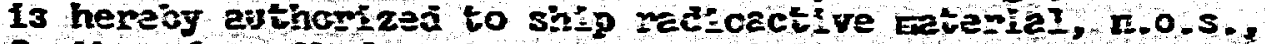
further jesepijed es transtren um fsotcpes, unjer the pro visions of 49 ca $173.393(f)(S)$, and $17.393(\mathrm{~m})$ of the

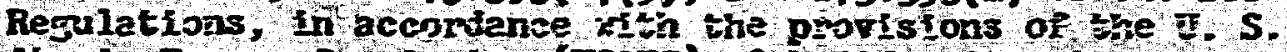

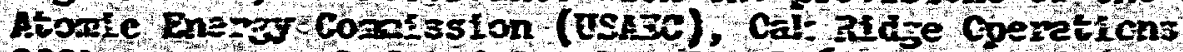

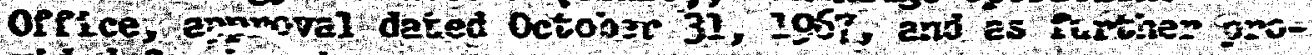
rides ecr hovin.

2. The authori:ed packegtng shell ccneses of 2 leat ent

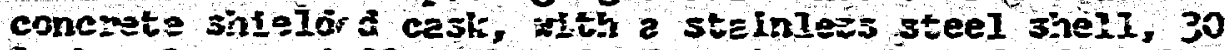
Enches lone ani 20 snches In ctereter, fdentifled as tis=

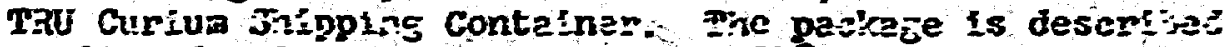

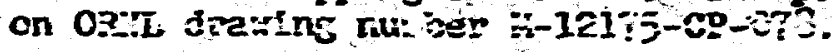

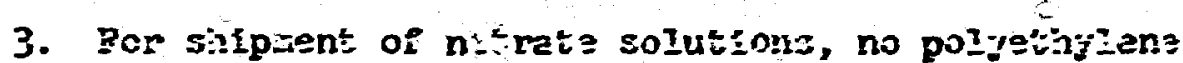

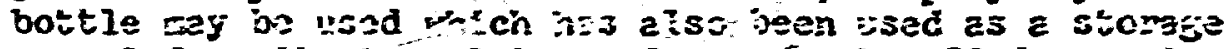

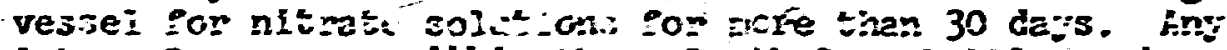

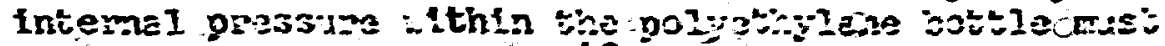

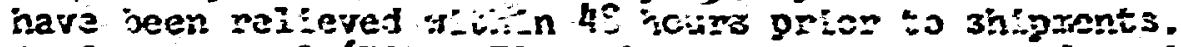

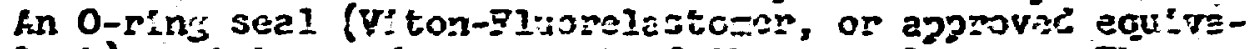

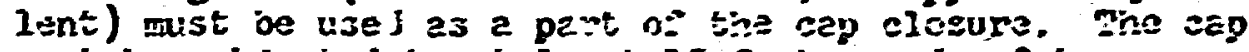

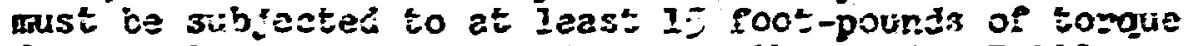

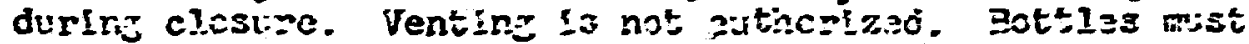

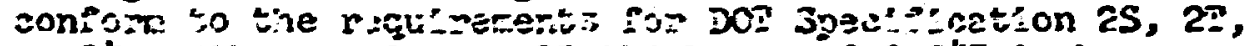

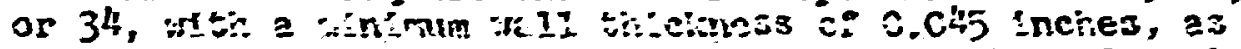

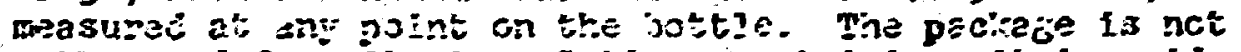

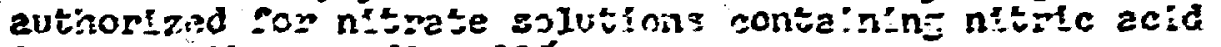
In stongat: excseding $20 \%$

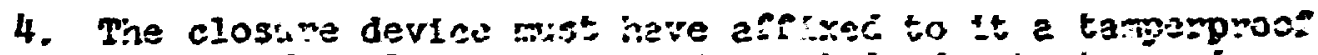

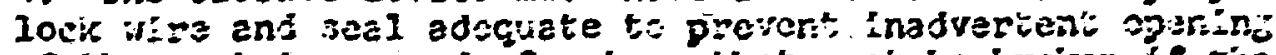

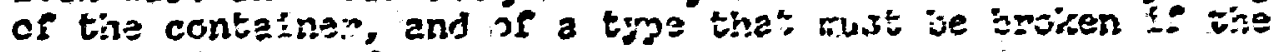
pacliaze is cpanzd. 
Pursuant to the authority of 49 CrR 173.22(a)(1), Department of Transportation (DOT) Bazardous Materials Regulations, as amended:

Special Permit to. 5461, authorizing the shipment of not more than 10 grams of certain transuranium isotopes in the TRU Curiun Shipping Container, is hereby anended by adding the U. S. MTOMIC DIERGY COMISSION as an anthorized shipper under the terms of the permit, and by changing paragraph (3) to read as follows:

"3. For shipment of nitrate solutions, no polyethylene bottle may be used which has 21 so been used as a storage vessel for nitrate solutions for more than 30 days. Any internal pressure within the polyethylene bottle must have been relieved within 48 hours prior to shipwents. In J-ring seal (Viton-Fluorelastomer, or approved equivalent) must be used as a part of the cap closure. The cap must be subjected to at least 15 foot-pounds of torque during closure. Venting is authorized. Bottles must conform to the requirements for DOT Specification 34. The package is not authorized for nitrate solutions containing free nitric acid in strength exceeding 6 molar. The package is exerpted from the provisions of Para. 173.268 of the DOT regulations.

All other terms of the permit remain unchanged.

Issued at Washington, D.C., this 7th day of June 1968.

W. R. Fiste

For the ddrinistrator

Federal Highway Administration
Kac E. Rogers

For the Administratcr

Federal Railroad Administration

Address all inquiries to: Secretary, Hazardous Materials Regulations Board, U.S. Department of Transportation, Washington, D.C. 20590. Attention: Special Permits. 


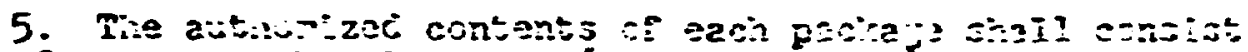

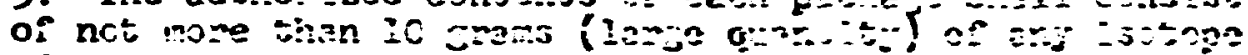

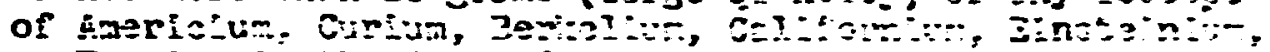

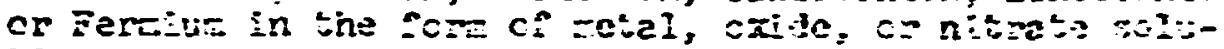
tion.

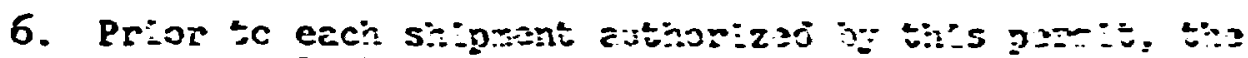

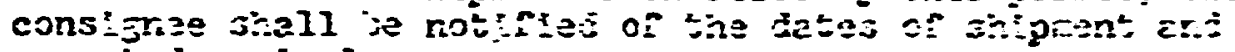
expected arsive?.

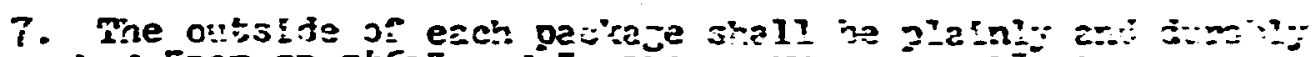

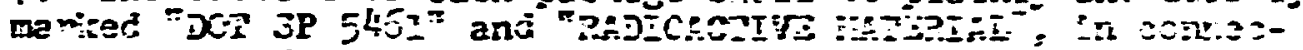
tion $: i t=$ and In ajo

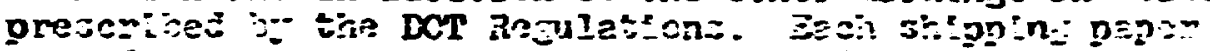

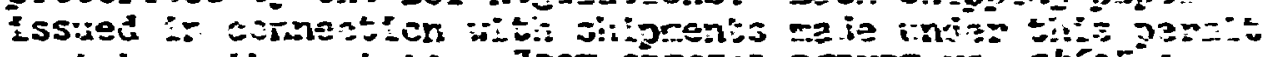

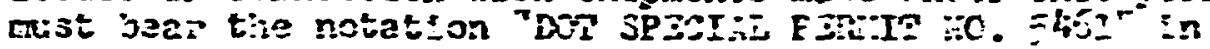

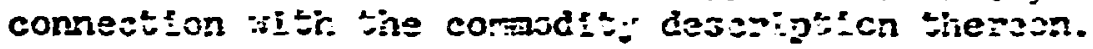

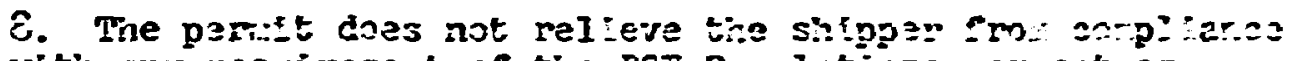

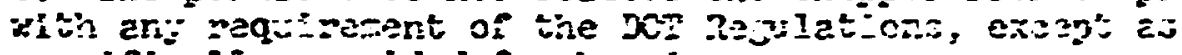

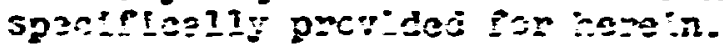

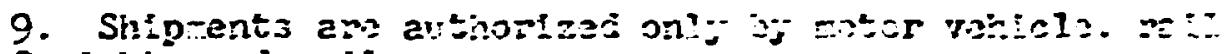
fre-git, and rexl cazrojis.

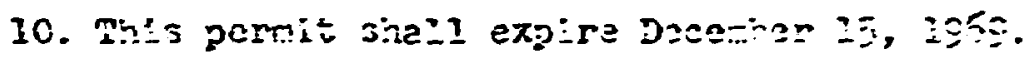

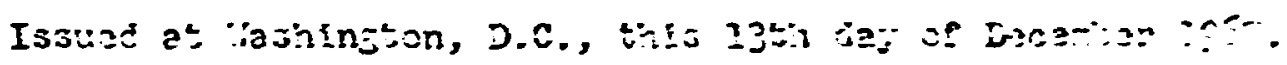

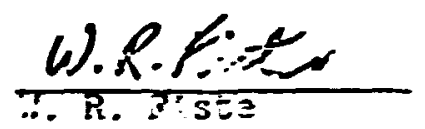

Bor the sulnistrator

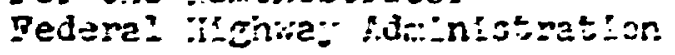

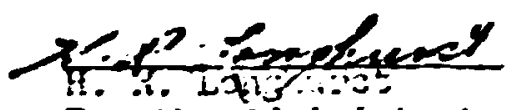

Bor the ecintistrator

Bederal Se'ircad sinin:stuaticr:

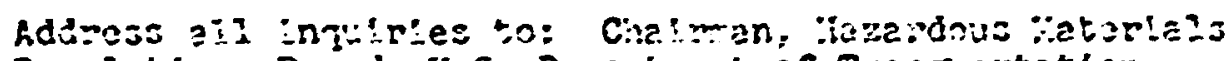

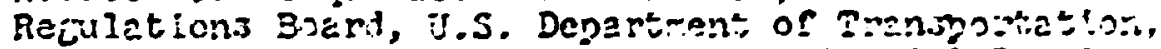

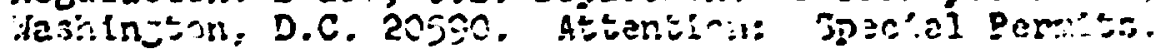




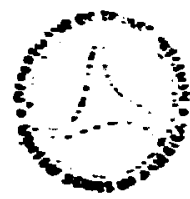

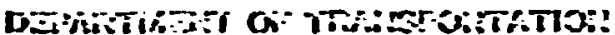

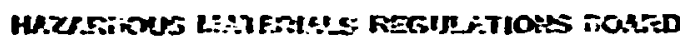 \\ censtatictors ac $x=5$
}

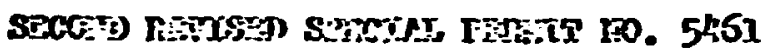

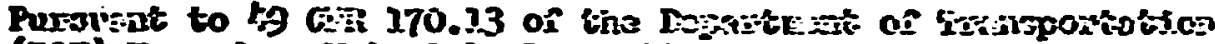

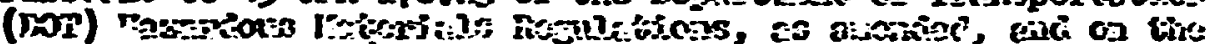

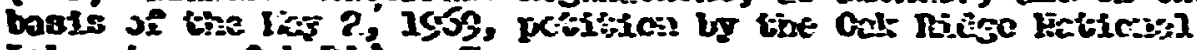

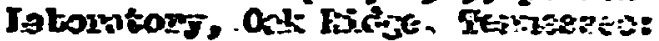

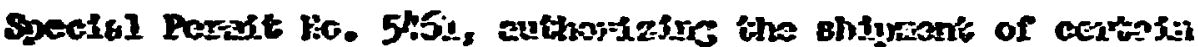

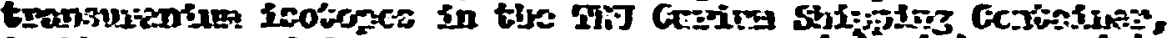

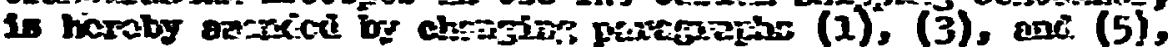

to rori an follosis:

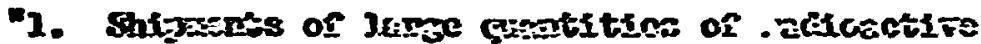

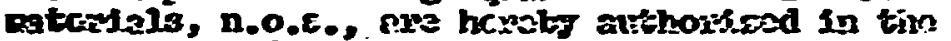

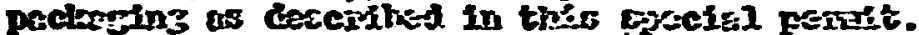

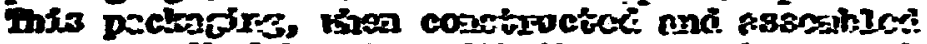
as prescribad hersin, wish the costeints as exthos

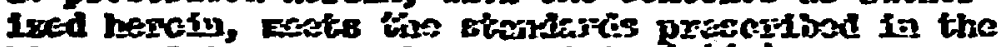
Dot restiations, sectiors $173.395(\mathrm{c})(\mathrm{z})$ end 273.

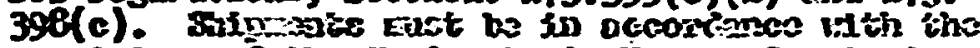
provisions of the U. S. ffoste Basieg Coritistoa

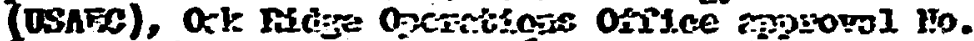
69-010, dater boil 15, 1959, and es furcher rorovieed IOF toretn.

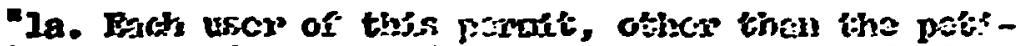

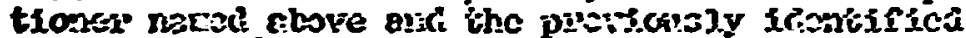
petitic

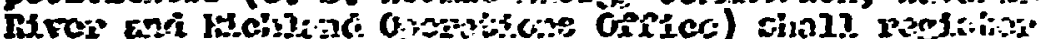

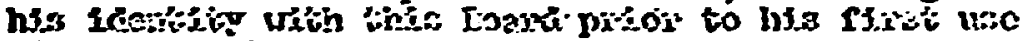
of the peritit.

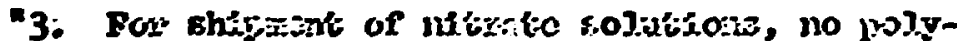

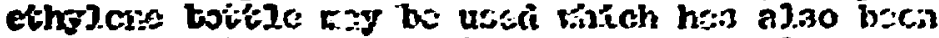

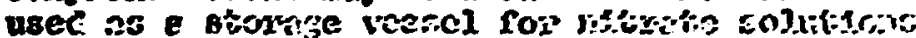

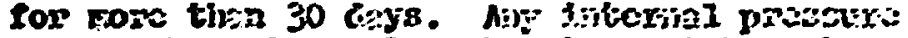
whin the polyothgleno toit?e lust havo bis

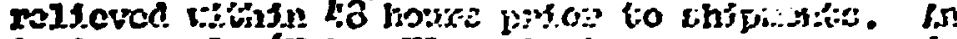

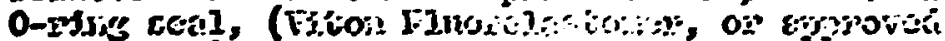

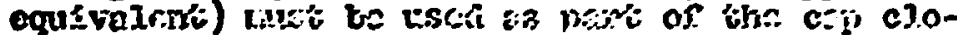

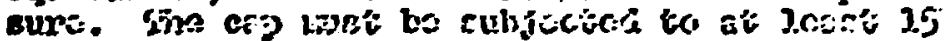

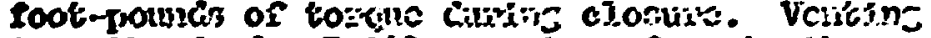

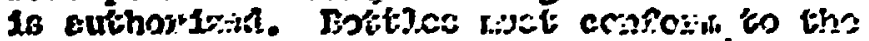

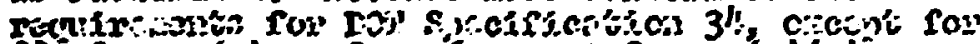

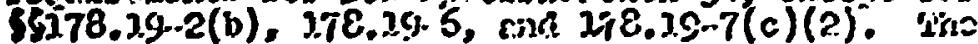

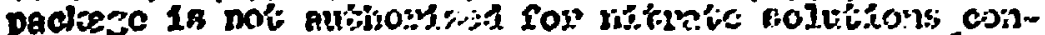

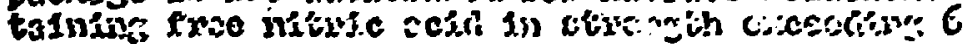

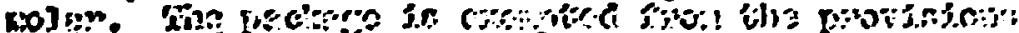

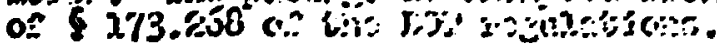




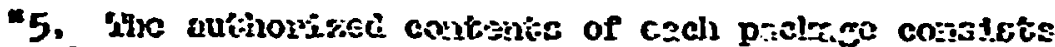

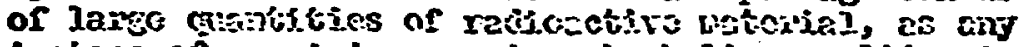

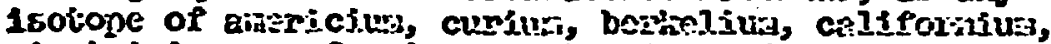

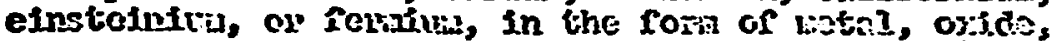

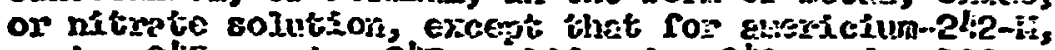

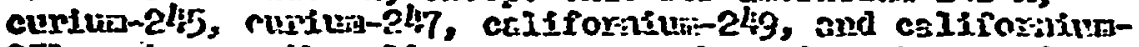

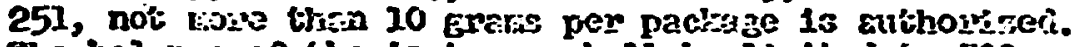
The belance of the j.gotepes shall be limited to 500 BIJ/hx hitit coixtent."

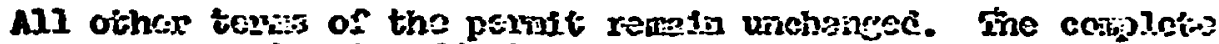

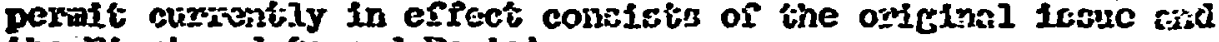
the pluet ard second Rerisions.

Issued at Hashirigton, D.C.:

(1) 152 Merion

For thrs Atiulutistrator

Federti Highiay Acininlstratios

Hacto

Por the fictinfetirictor

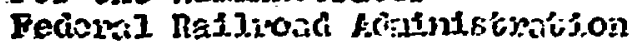

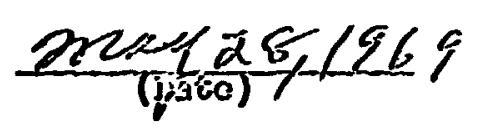

Firiv 27109

(ives)

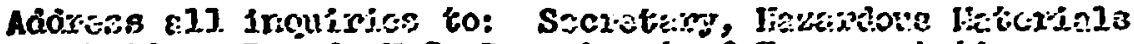

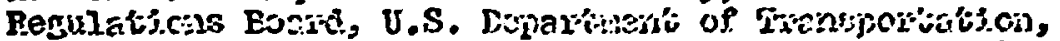

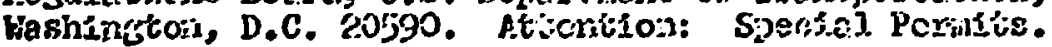

Dist: $2, d, e, h, 1$

U. S. Atonic lowgy Comancion, rijchjand, Henh.

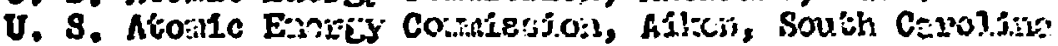



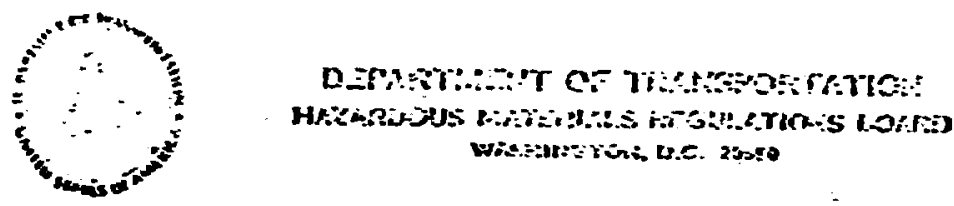

THIRD REVISED SRECIAL PERAIT NO. 5461

Pursuant to 49 CFR 170.15 of the Department of Transportation (DOP) Hazardous Materials Regulations, as amerded, and on the basis of the Octobex 20, 1969, petition by the oak Riage Bationai Iaboratory, Oak Ridge, rennessec:

Special Permit No. 5461 is hereby amended by revising paragraph (10) as follows:

10. This permit expires on Decenter 15, 1971, and may be revoked for cause at any time."

All other terns and conditions of this permit as revised remain unchanged. The complete permit currentiy in effect consists of the original issuc and the second and Third Revisions.

Issued at hashington, D.C.:

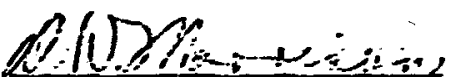

R. R. Piste

Por the Administrator

Pederal Highway Administration

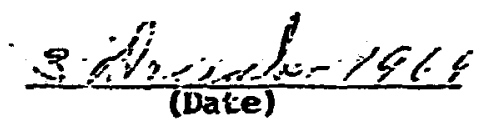

(Dale)

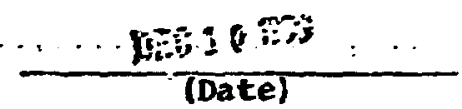

Address a]1 inquiries to: Secretary, liazaráovs Hatcrials Regulations Board, U. S. Department of Iransportation, Vashington, D.C. 20590. Attention: Special Permits.

Dist: a, d, e, h, i

v. S. Atomic Energy comision, Aiken, S.C.

D. 8. Atomic Enes:gy Comission, Richland, Mash.

oak Ridge Assocleted Universities, Inc., Oak Ridge, Tenn. 


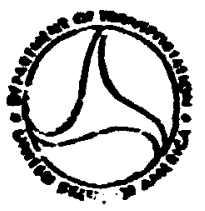

\author{
DEPARTMENT OF TRANSPORTATION \\ HAZARDOUS MATERIALS PEGULATIONS BOARD \\ wachingtron, oc. zaseo
}

FOURTH REVISED SPECIAY RERUIT NC. 5461

Pursuant to 46 CFR 146.02-25 of the U. S. Coast Guard (USCG) Dangerous Cargs Regulations and $49 \mathrm{CrR} 170.15$ of the Department of Transportation (DOT) Hazardcus Materials Regulations, as amended, and on the basis of the February 10, 1970, petition by the Oak Ridge National Laboratory, Oak Ridge, Tenn.:

Special Permit No. 5461 is hereby anended by revising paragraphs (9) and (10), and by adding new paragraphs (11) and (12) as follows;

9. This permit authorizes shipments only by ocean vessel, motor vehicle, and rail.

10. For shipments by water:

a. A copy of this permit must be carried aboard any vessel tranisporting radioactive materfal under these terms.

b. The shipper or agent shall notify the v8CG Captain of the Port in the port area through which the shipment is to be made, of the name of the vessel on which the shipwent is to be made, and of the time, date, and place $n$ loading or unloading. Then the initial notification is given in a port axea, it must be accompanied by a copy of this pemit, addressed to the attention of that Captain of the Port.

c. Packages shall not be overstowed with any other cargo. If stowed below lecks, the hold or compartment. In which stowed must be ventilated.

11. The authorized package described herein is bereby certified as meeting the specific requirements of the International Atomic Energy Agency's (IAE) "Regulations for the Bafe Transport of Radioactive Material", safety series 10. 6, 1967 aftion, as follows: 
a. Marginal C-6.2.3 - The package design neets the requiremients for Type B packaging for large quantity (source) radioactive materials. Specifically, the packagIng design meets the requirements of Marginal C-6.2.3.1 (a) for unilateral approval.

b. Marginal C-2.4.3 - The packaging ciesign is based on the anbient conditions.

c. Marginal C-6.5 - to special transport controls are necessary during carriage and no special arrangenents have been prefcribed, except as specified herein.

-12. This pernit expires on Febrhary 28, 1972, and may be revoked for cause at any time."

N11 other tens of this pernit as revised rewain unchanged. The complete perinit currently in effect consists of the original issue and the Second and Fourth Revisions.

Iasued at Washington, D.C.

$$
4
$$

E. G. Grundy, Capt. For the Commandant

0. S. Coast Guard

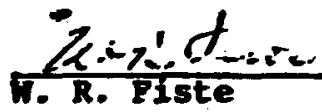

For the Administrator

Pederal uighwey Mdministration

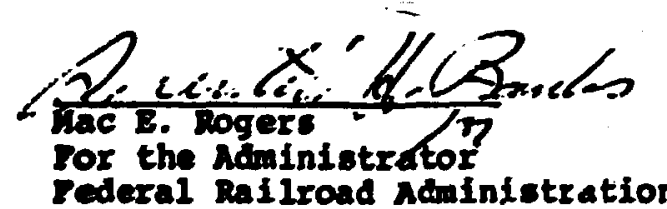

Pederal Railroad hduinietration

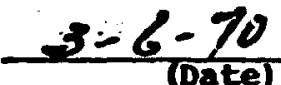

$2+15>3$ (Date)

FES 26 ETO 
Address ali inquiries to: Sicretary, Hazardous thaterials Reguiations Board, 0.S. Departhent of Transportation, Mashington, D.C. 20590. Attention: Special Permits.

Dist: $a, b, d, e, h, i$

0.- S. Atomic Energy Comission, Richland, Wash.

0. S. Atomic Energy Comission, Aiken, South Laiz? ina rawrence Radiation Iaboratory, tivermore, California. Oak Ridge Associated Dniversities, Inc., Oak Ridge, Tenn. 


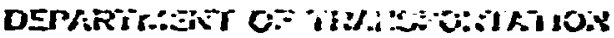

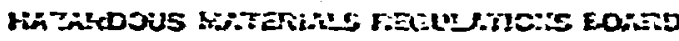

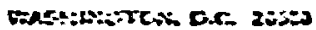

SPECIEI FEIET: YO. 5661

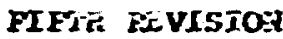

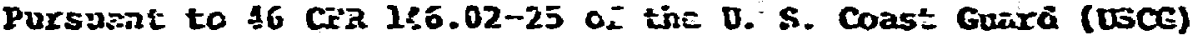
Dancervas Carde Regulations end $\$ 9$ Crat 170.15 of tise Deprertwent of Frensportefion (IDOR) Kazirdous ifelerials Regulations, as azirited, and on tiac besis of the noverber 5, -1970, perition by the trion Carbide Corporation, Iuclear Division, Oak Ridige, Tennessen:

Sp scial Persit do. 5461 is herebj inenicd as folions:

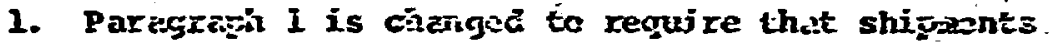
involving the coi tents as cescriteó in paranzangh (5a) mist be in accordance with the provisices of the USAEC, Oak Ridge Oyerations Osfice anproval NG. 70-006, dated Octooer 19, 1970, of other equivalent USPEC agproval.

2. A nes paregräph. 5a is aldeà to reac as follows:

-52. As an elecried:, tine contrats of caci package authorized by this permit azy consist of large guartities of ary non-jissile radiouctive Exiferizl, n.o.s., Iurther linitad to a maximud thermal $c$ izy encrey of not more than 500 Btu/hr. Conceries sill be cither singly or doubly encejsulated, or containca within DOr spccification 2R inicr containers."

Al: other teriss of this perait, as revised reinir linciicaged. The coripletc peruit currently in effect comists of the original issue and tine Second, Fourth, and Pifth Ravisions. 
Jssuced at tre:-ingtor, D.C.:

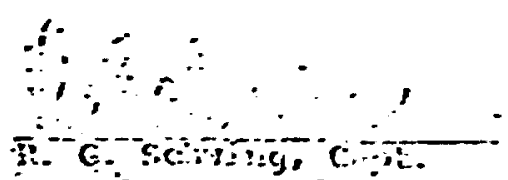

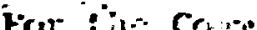

y. : Coric Go.ri

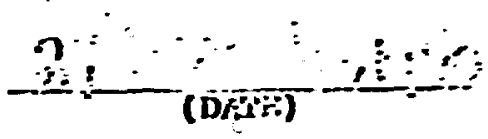

A.

For tine fizinistrator

"Feceral ig ghtar hatinistration

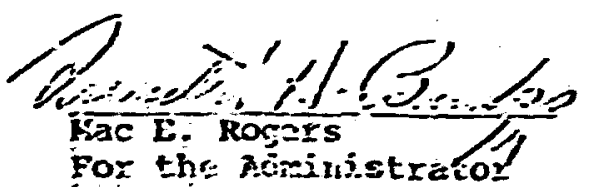

rot: : E

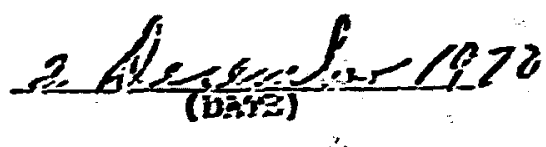

Fecera! Rei Iroad Mrainistratios

(DAF?)

hadrese all inguizics to: Secretary, Hazarcoos Haterials

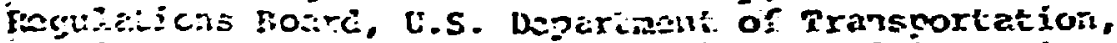

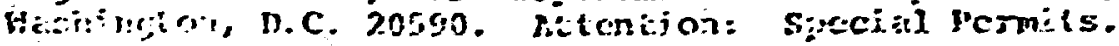

List: $a, b, d, e, h, i$

University of Gorgia, Athens, $C a$.

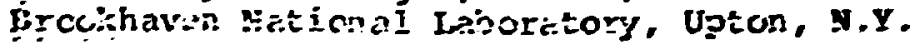

I,afre,ces Rediation Lajoratory, I,iveraore, Calif.

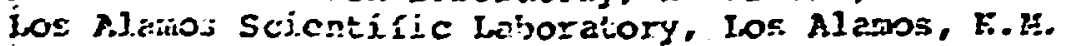

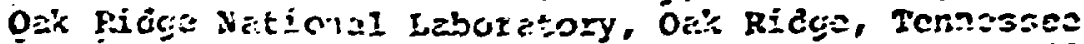

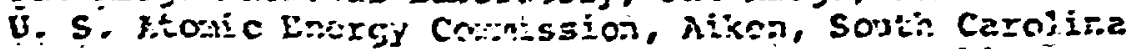

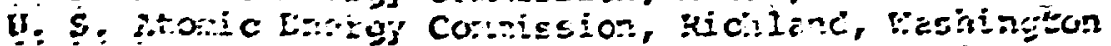

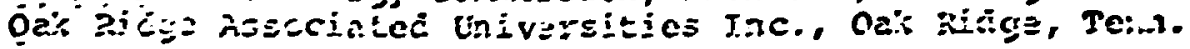




\section{INTRA-LABORATORY CORRESPONDENCE}

onc adoce matroual LADORATORT

Anget 7, 1974

IC 74-3

$=\stackrel{5}{9}$

To: B. B. Aln, b. B. Sheppert

Irow: Tramportacton Condtee

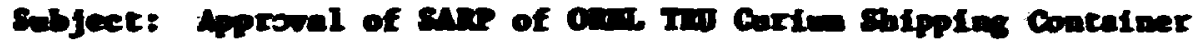

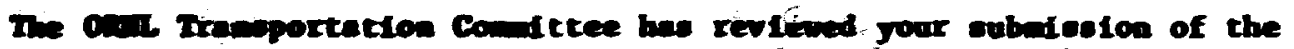
object san to fulfill the requiremente (Interinal review) of paragraph $B$

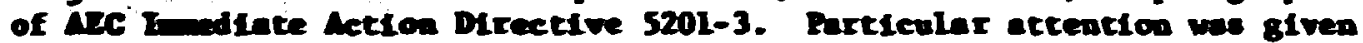
the five areap of exructural integrity, thermal reoletence, redietion

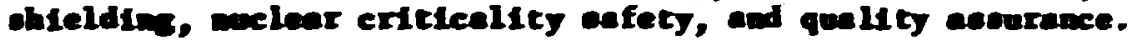

I. revalite of the evaluntion ohow thet the container weets the require-

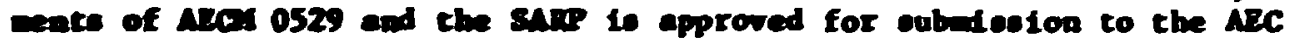
for requent of a Coretficete of Complinnee for approval of the cask for

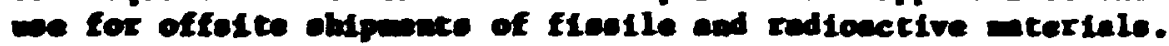

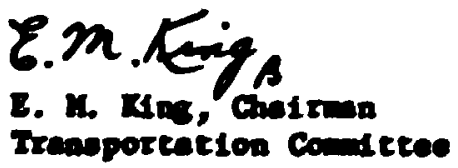

Eass

ce: Iranopercetion condeter 


\subsection{Computer Program to Calculate Corner Drop Dece'tration Forces}

The computer program shown in the following pages was developed by John $H$. Evans, Engineering Division, ORNL, to calculate the deformation of a cask undergoing a 30-ft corner drop. It utilizes an assumed specifix energy absorption for the concrete-steel body of the cask. A high specific energy of $28,000 \mathrm{lb}$-in./in.' was used to calculate the maximum stress in the bolts holding the plug. This value is ansidered to give conservative deceleration rates on which the stress calculations were based.

The lowest specific energy assumed was $\mathbf{4 0 0 0} \mathrm{lb}$-in./ in. ${ }^{3}$, which is conservative for this cask construction. This value produces a deformation of 4.15 in. Higher specific energies will produce less deformation and higher deceleration rites.

$L=$ distance from corner of cask to inner coishiner, 16.1 in.,

$D=$ deformation resulting from 30 -ft cornet drop, 4.15 in.,

L - D = minimum thickness,

$16.1-4.15=11.95>11.5$

The minitnum shielding thickness necessary to shield the cask safely is II.S in.; thus, the above calculations indicate that the cask will be sha lded adequately. 


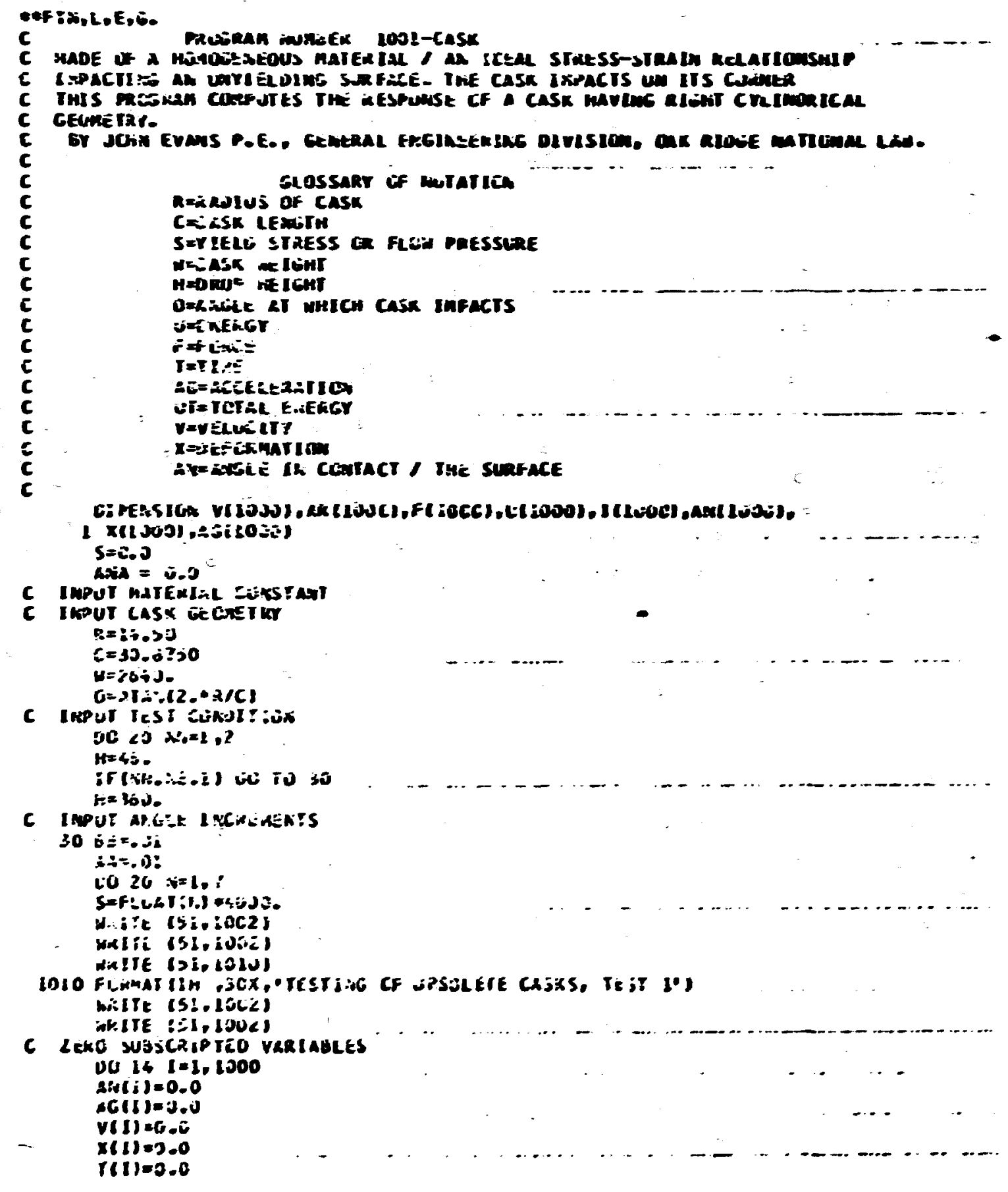


$F(1)=0.0$

Ui II $=0.0$

$A R(1)=0.0$

14 Ccait brite

C LERO masusscripted variatles

$T A=0.0$

$\triangle E=0 . G$

$\Delta=0.0$

$x=0.0$

$\mathrm{T} x=\mathbf{6 . 0}$

$1=0.0$

$x x=6.0$

$x A=0.0$

UT $=$ h thi

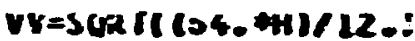

DO $I I=1.1000$

$\triangle R=\mathbf{J} .3$

6 IULẼ̄KENT MLTLE A

$9 \quad h=n+a n$

CA=cesish

$\theta=0.0$

$\triangle E=0.0$

Sur $1=0.0$

$10002 J=1,1000$

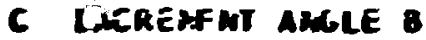

$B=d+68$

$C B=\cos (b)$

c calculaje julbe displaceo

Li $C C=(C B-C A)$

$s Y=T$ ASE $[]\} * R * C$.

$B X=R=C:$

$12: 2=\AA * C E=B S$

Din-\$ $Y=3 x 40 z+S$

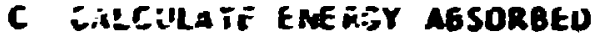

Sir.v= SCHVt ou

C CaLCULATE AREA

$130 A=2 * 6 x+32 / \cos (0)$

$A C=A F+U A$

IF (B.GE.A) GE TO 3

2 CLNTIRLE

3 Lillasin:

If(UII).GF.LI) SO TO 4 R.SI I) = AंE

C Calculate FONCE $f(I)=\operatorname{Aa}(I)$ )

C calculate velceity

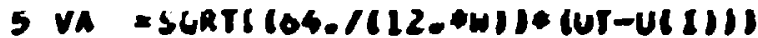

C CalCulate accelerstion $2 C 11)=F(1) / W$

C CALCULATE DEFJAMATION $x A=(T A N(0)+\cos (0) * 2 *(1,-C A))$ $x(1)=x A$

c calculate tIme $T x=(x A-x x) /(1) y+y A)=6$.

7 TAETALTX TIII) TA41000. $x \times=X A$ 


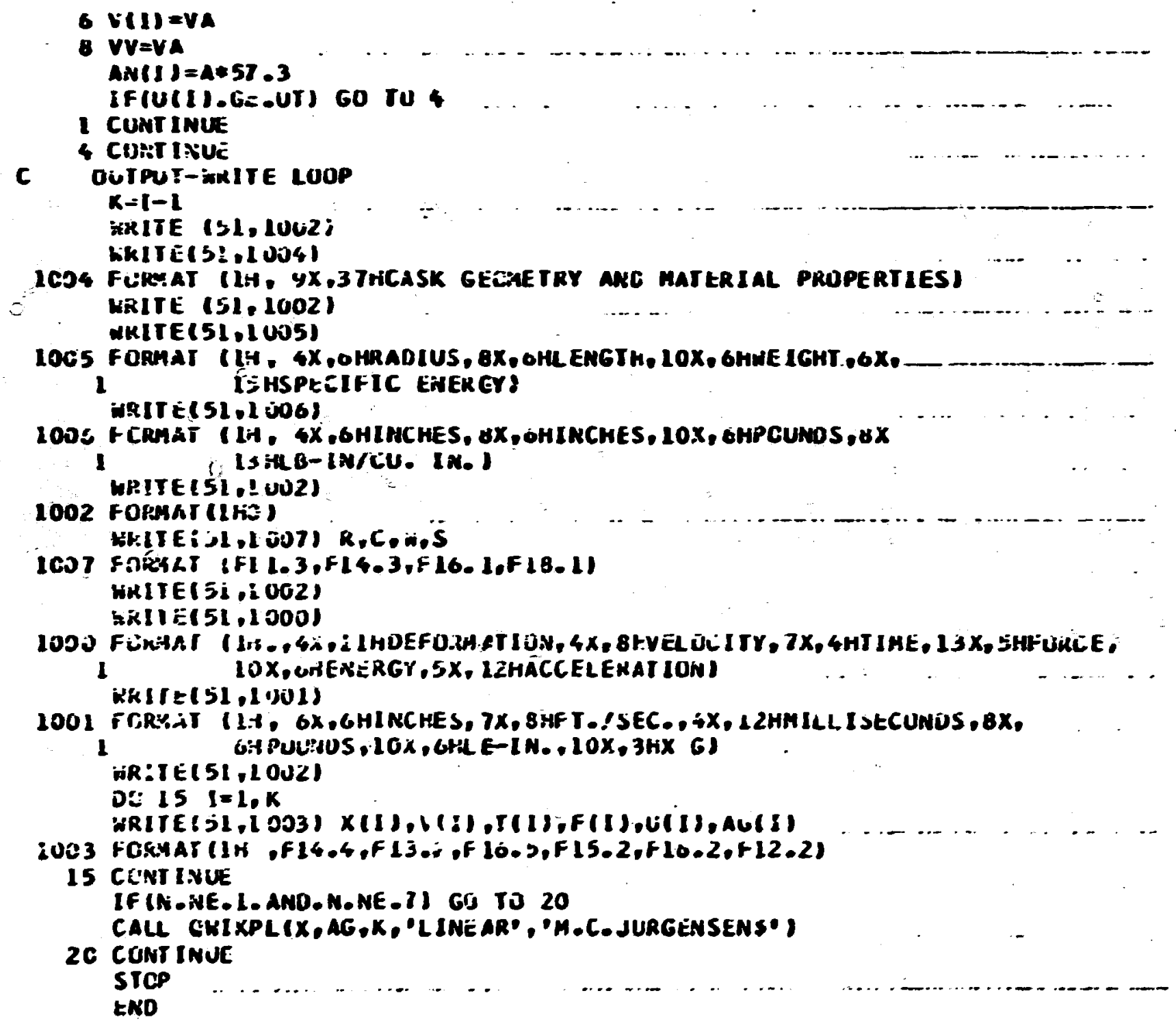




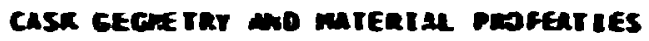

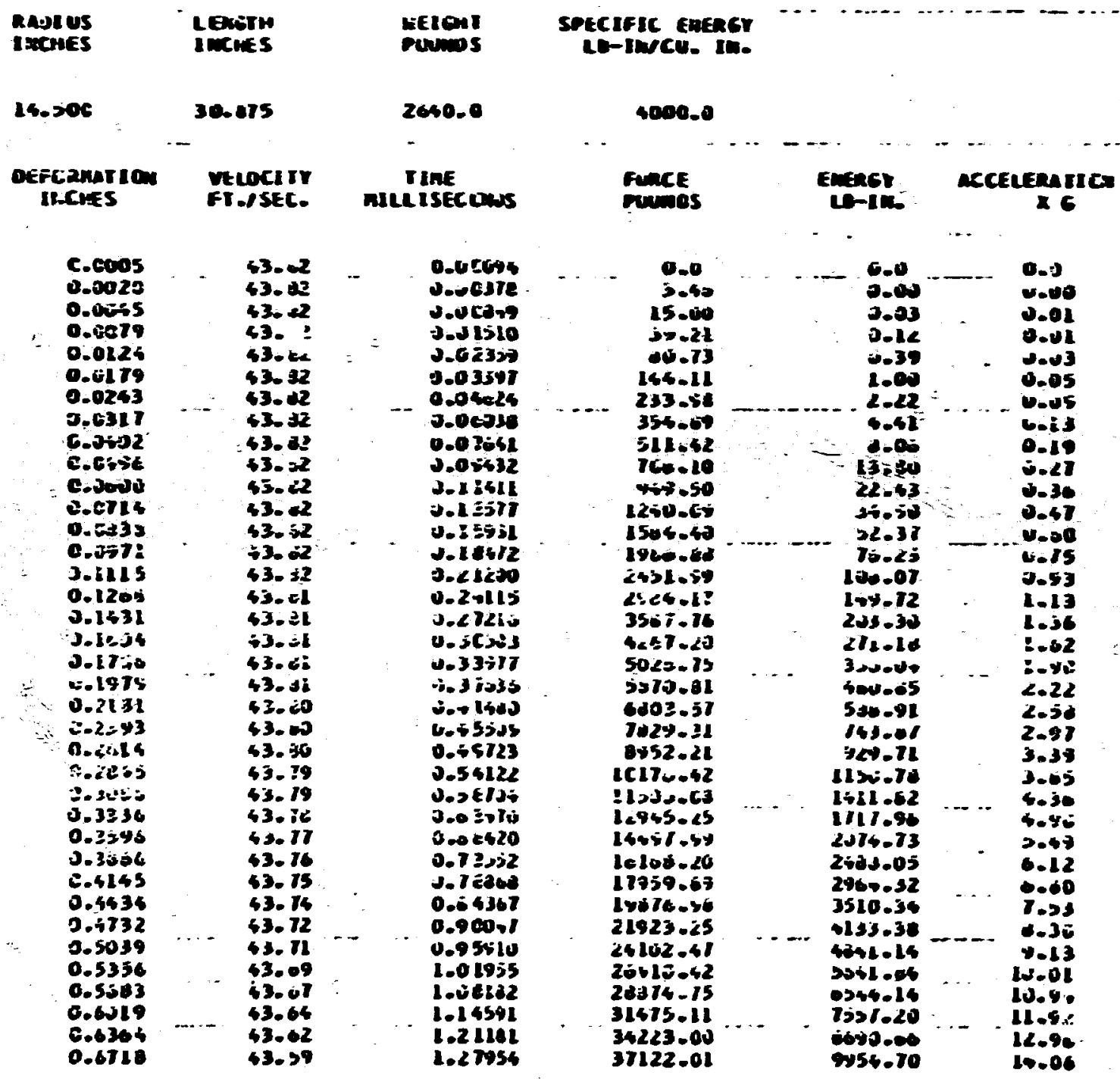




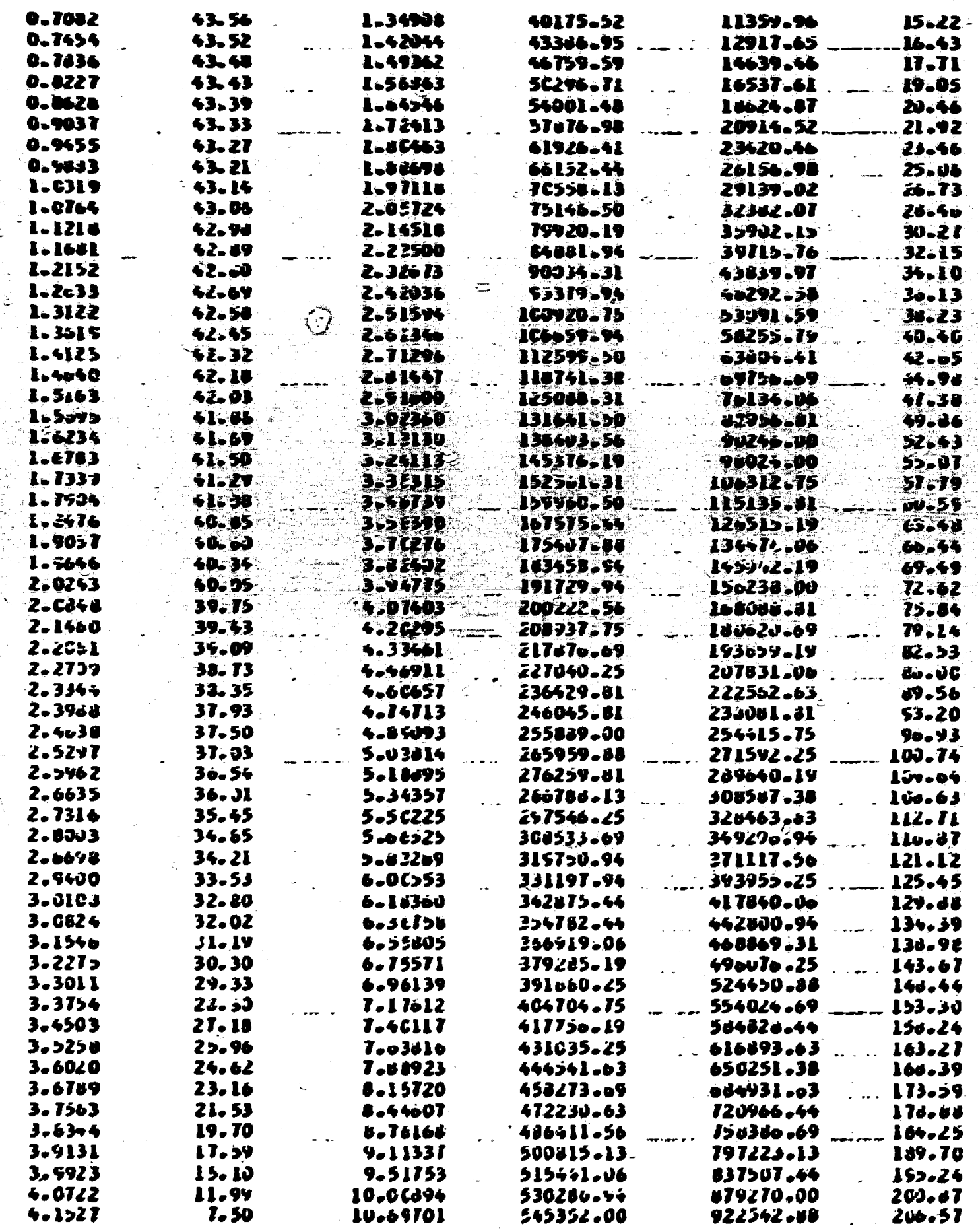


ว j:

\section{$\frac{1}{10}$}

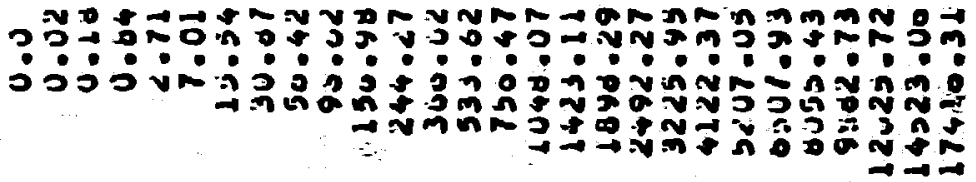

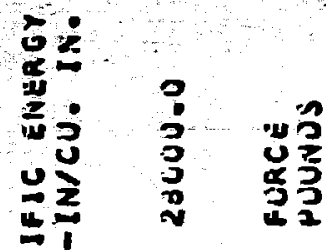

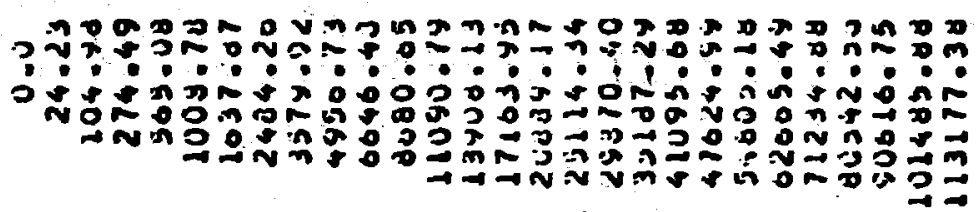

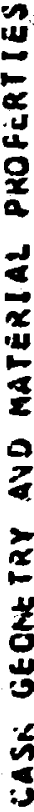
10

$\dot{n}$

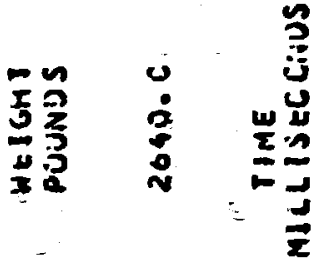

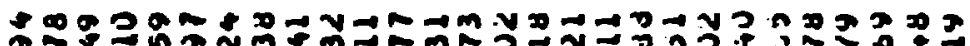

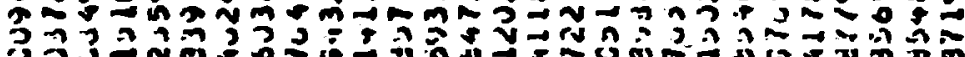

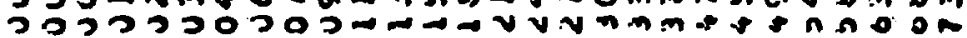
j:

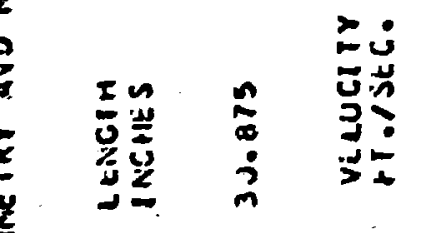

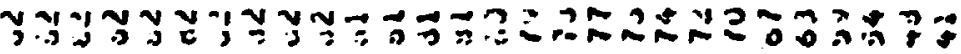

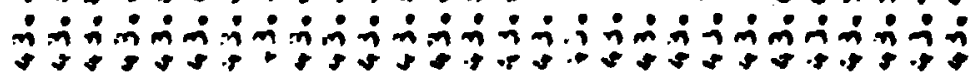

7

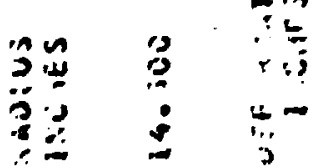

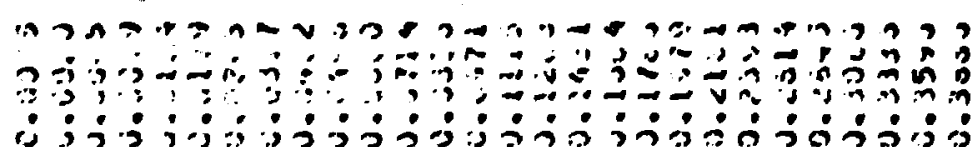

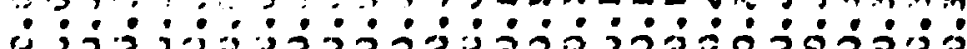




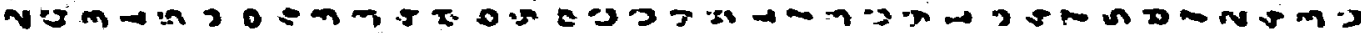

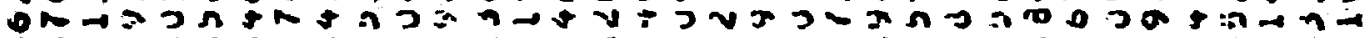

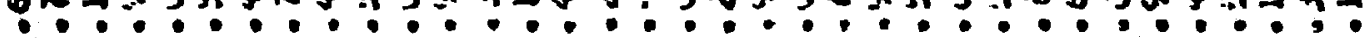

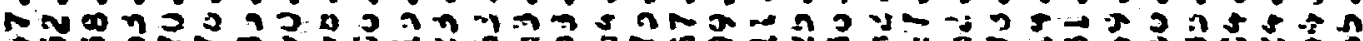
S n

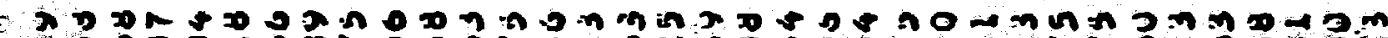

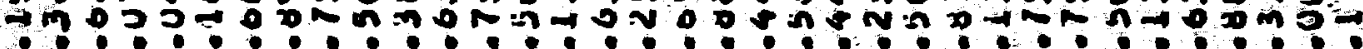

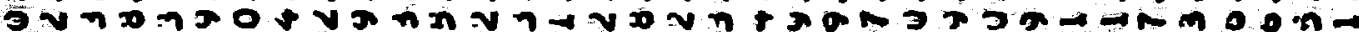

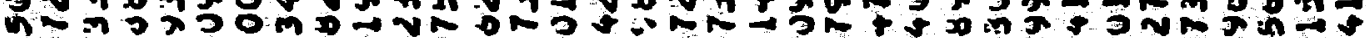
15;

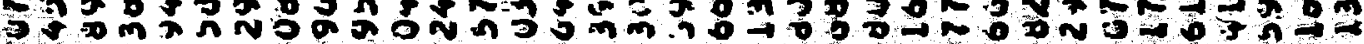

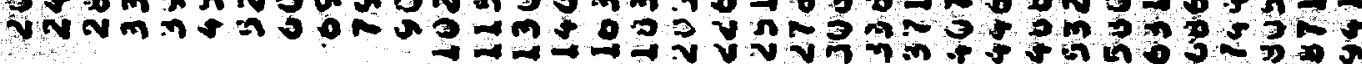

$$
-
$$

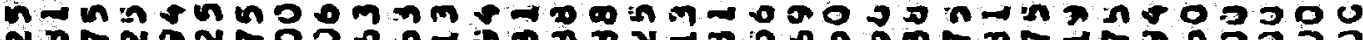
Nom

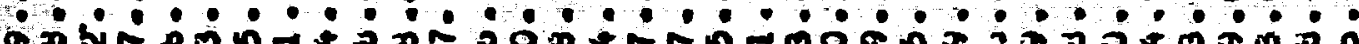

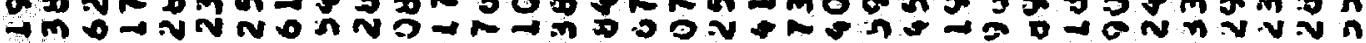

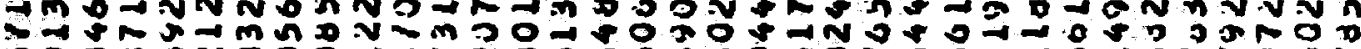

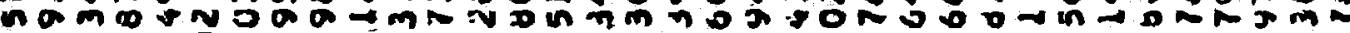

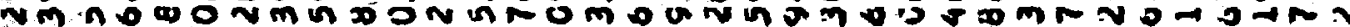

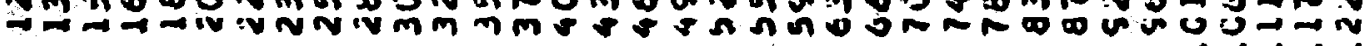

a - o t n N

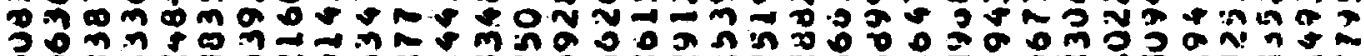

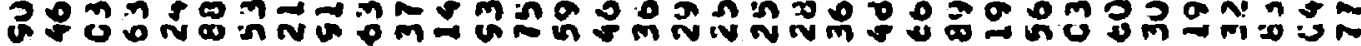

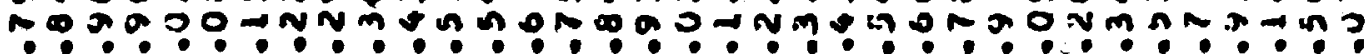
பீ:

- in $n$ in

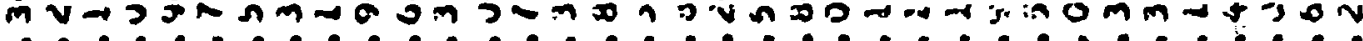

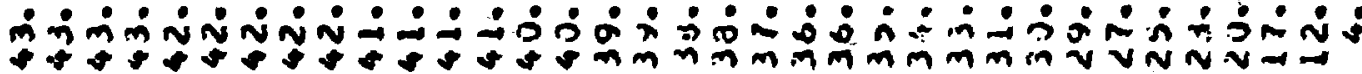

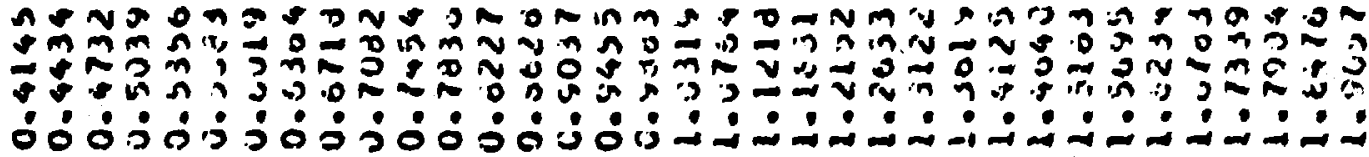



Transuraniua Processing Plant

ORNL NOS. 4S2-209, 210 and 213

DOT APPROVED 5461

ORNL DING. NO. 12175-CP-073E

PROCEDURE FOQ USE OF:- TRU CURIIM SHIPPING CONTAINER

Shipping Container No.
Date : Tine By
1.
.
.
12
2.
3
4.
5.
6.
7.
8.
$8 a$.
9.
10.
11.
12.
Materials to be shipped
quantity ; to
Quantity Certified by
Move carrier to loading area following clothing procedures of that area.
With health physics personiel present, rewove hex nuts from plug cover and remove cover.
Remove hex nuts from plug.
While surveying with cutie pie carefully remove plug Rdg. mrem.
Have cavity smeared for alpha and gama contamination: $\mathrm{c} / \mathrm{m} / \mathrm{cm}^{2}$ alphe $\mathrm{c} / \mathrm{m} / \mathrm{cm}^{2}$ gamina
Clean if above smears exceed $30 \mathrm{c} / \mathrm{m} / \mathrm{cm}^{2}$ alpha and $300 \mathrm{c} / \mathrm{m} / \mathrm{cm}^{2}$ gamma.
Plug gasket seating surfaces clean and do not need repair.
Plug gasket present and in good condition.
Using appropriate procedures to limit personnel expcsure to < 20 mrem, load material into cavity. Exposure uren.
Replace plug into carrier.
Carrier ioaded shall not have over the following readings.
$200 \mathrm{mr}$ at surface. $10 \mathrm{mr}$ at $3 \mathrm{ft}$.
Replace hex nuts on plug studs and tighten. 


\section{$8:$}

Shipping Container No.

Date Time By

13.

Cover gasket seating surfzces clean and do not need sepair.

13a:

Cover gasiret present and in good condition.

14.

Replace cover and tigkien hex nuts.

15.

Container tied to skid in approved manner.

16.

Approved for shipwent.

(This procedure wiv not be used for shipments of liquids until a letter or procedure has been executed indicating compliance with paragraph 3 of DOT Special Permit 5461.) 
85

ORAL NOS. 4S2-209, $21 \mathrm{U}$ and 213

DM T APPROVED 546i

ORNL DUG. NO. 12175-CP-078E

RU CURIUM SHIPPING CONTAINER

Shipping; Container

Number
Inspection Check List
Routine

Annual

Dace Time By

1.

2.

3.

4.

5.

6.

7.
General condition of carrier checked.

Remarks:

Cover gasket present condition:

good poor replaced

- Plug gasket present condition:

good

poor

replaced

Sealing surface condition:

good needs

reworking or cleaning

Nuts condition:

$\operatorname{good}$

replaced

Studs condition:

$\operatorname{good}$

replaced

Welds inspected (visually)

good need repair repaired

8. All needed repairs and final inspections completed. Cask is in good condition to use.

Approved

Date 


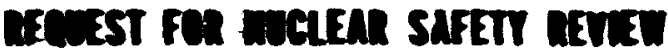

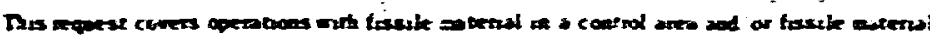

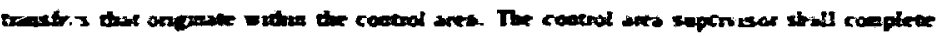

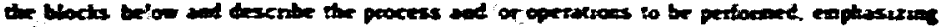

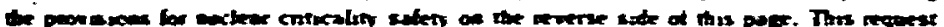

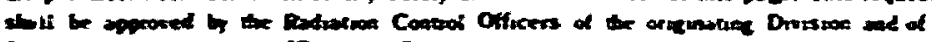

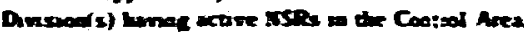

and

concurr comminte

$\infty$

969

Ju15, 1904

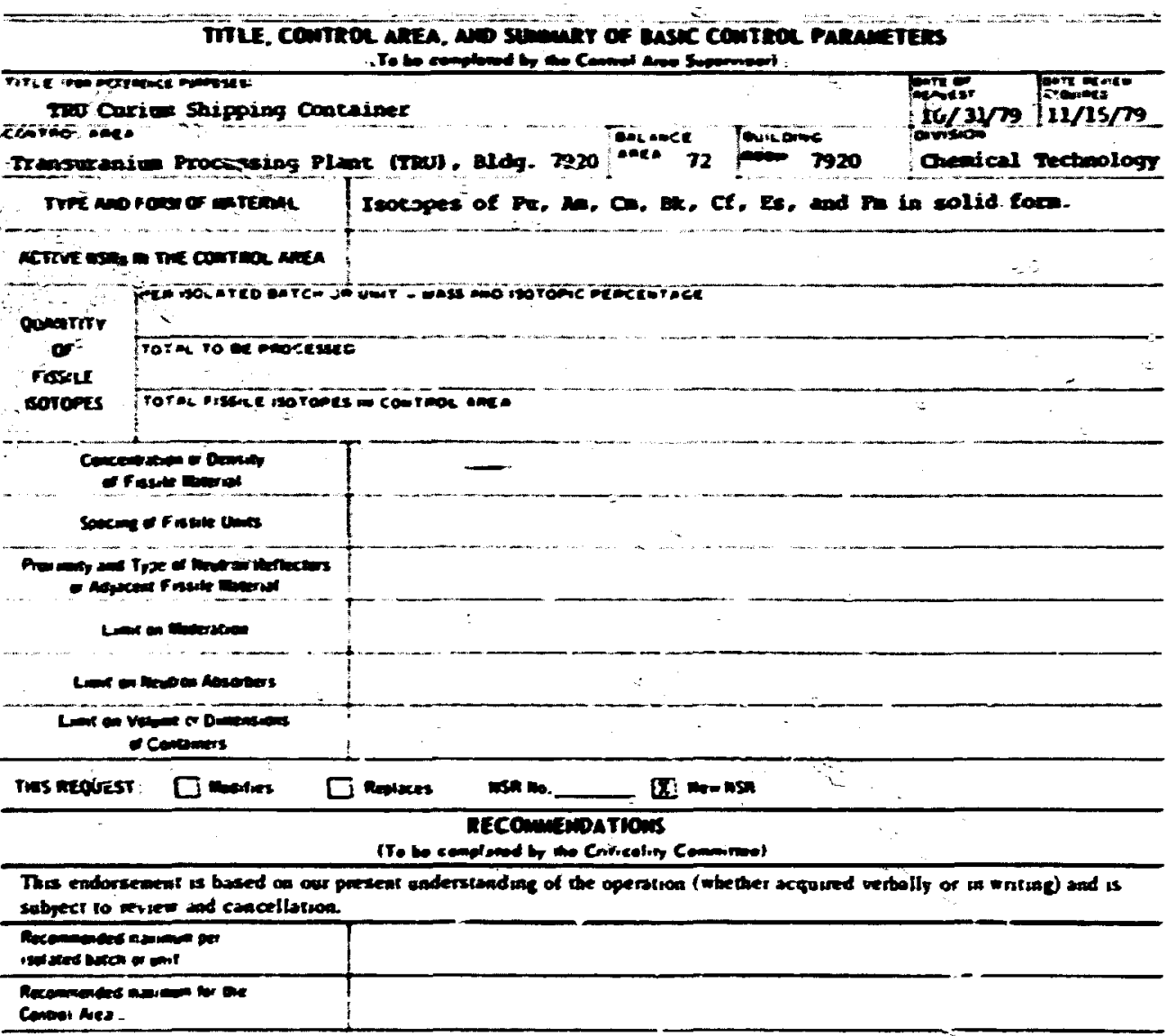

This reques: is approved.

uratir

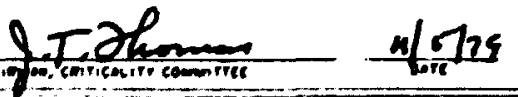





\section{REFERENCES}

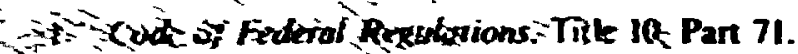

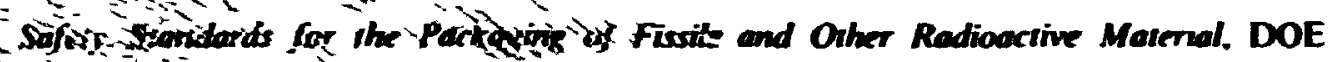

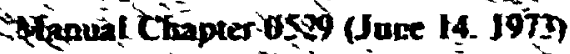

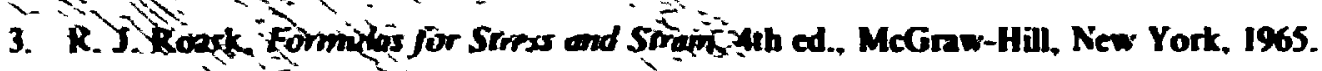

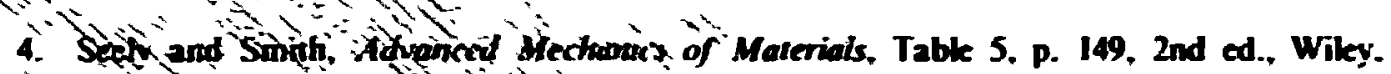
rewation:

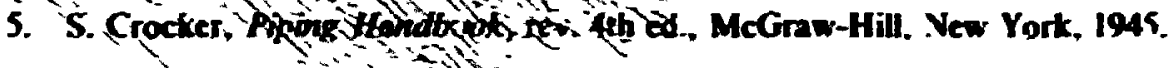

6. S G. Pearsall, S. Majestî, and L. Gemmel. -Design and Testing of a Shipping Container for Large Quantities of Radionctive Waste." in Proceedings of the Secoud International Symposiuon on Packaging and Transporiasion of Radioacrive Materials. CONF-68:001 (1968). pp. 624-36.

7. J. H. Faupel, Engineering Design, Eq. 8.253. p. 54'. Wiky, New York. 1964.

8. D. S. Clark, "The Influence of Impact Velocity on the Tensile Characteristics of Aircraft Materials and Alloys,- Tech. Note 868, National Advisory Committee for Aeronautics, Wáshington, D. C. (Octobyr 1942).

9. L. B. Shappen and J. H. Exans. Analysis of the SARP 2S-Ion Target Tube Cask. ORNL TM-3531 (Jangery 1972), Appendix V. pp. 89-91.

10. M. F. Spotts, Design of pachine Elements, 2nd ed., p. 459. Prentice-Hall, I.ondon. 1954.

11. H. A. Nelms (thesisy, Siructural Analysis of Shipping Casks Effects of Jacker Physical Properties and Cunvature ofr Bioniture Resistance, ORNL/TM-1312. vol. I (June 1969).

12. W. D. I urner. D. C. Elrod, and I. I. Simon-Tov, HEATINGS, An IBM 360 Hear Conduction Program. ORNL/CSD/TM-I5 (March 1977).

13. Seal Compound Manual, Catalog C5702, Parker Seal Company, Cleveland. Ohio (April 1971).

14. T. N. W. A kroyd, Concrele, Properries and Man-facture, p. 265. Pergamon. New York, 1962. 
15. Agent R. M. Grazianos Tariff Xo. 29. Hazardous Malerivls Regulations of the Deju. tment of Transportation Including Sprecifications for Shij.ping Containers rissued Dec. 15. 1974: effective Jan. 14. 1975). paragraph 178.34.

16. Code of Federal Requiations. Titk 10. Pan 71. Appendix D.

17. E. D. Clayton. "Ihe Sature of Fission and the Criticality Process (from Protactinium to Californium and Beyond).- Proceedings of Short Course on Nuclear Criticalit!: Sofety, Taos. NM. May 7-11, 1973. USAEC TID-26286 (1974). p.I.

18. Cude of Federal Regulations. Titk 49, part 173.393 (j).

19. W. D. Box, K. D. Seagren, and C. D. Watson. The ORNL Chemical Technolog: Division Quality Assurance Program for Radiodcive Material Packaging. ORNI.: TM-647I (September 1979). 